\title{
Basic Education for Poverty Alleviation: Community Perspectives from South Sulawesi, Indonesia
}

\author{
Detty M. Saluling
}

School of Geography, Environment and Earth Science Victoria University of Wellington Wellington, New Zealand

Thesis submitted in partial fulfilment of the requirements of the degree of Masters of Development Studies

February 2009 


\begin{abstract}
In efforts to combat worldwide poverty, education is considered a vital device. It is believed that basic education has a significant impact in stimulating a range of positive forces for change and to fight poverty. However, global efforts to ensure every child has access to quality basic education are still far from being achieved, especially in areas that are physically remote and isolated. Such issues are continually faced by Indonesia, which has many widespread regions and diverse communities and various traditional and customary beliefs, which can affect peoples' attitudes to the education of their children. In addition to an examination of several issues regarding the Government of Indonesia's quest to provide basic education to all Indonesian children, this thesis will also focus on a case study from two villages in the South Sulawesi Province. The study aims to explore the rural community perspectives on the value of basic education in people's lives, and whether it is important to improve their conditions and their children's future.
\end{abstract}




\section{Acknowledgements}

First, I would like to thank my supervisor Prof. John Overton, who many times read, commented on and helped shaping this thesis. I am grateful for his assistance, guidance and encouragements, particularly during critical periods of the thesis writing and completion. I also thank Gillian Ruthven and Suzanne Weaver for their kind assistances. I have to thank two very good friends at the Highbury Mansion (Alexa and Ronan) whose friendships are precious and unforgettable. They made life away from family a lot easier and their supports were very helpful in the completion of this thesis.

I would like to acknowledge the supports of those who have participated and offered their assistance in this research. My appreciation to people in Batu Lapisi and Kampung Baru who have risked their suspiciousness to subscribe to my research needs. Terimakasih banyak ki gang nah.. Special thanks to Ati for her assistance and friendship, especially during field research.

Above all I thank my extended family (all my brothers and their partners) who has been very accepting and accommodating. My deepest gratitude is to my parents: my late father, the root of my perspectives and passion in learning, and my mother, for her blind faith and unwavering support in my persistence for institutional learning. They are truly a blessing. Finally to two people who are as much involved and influential in this learning pursuit: my son Jamie PDI, who has been in this journey before he could talk. He adjusted amazingly well to all the travels and family relocations that this study required (from scorching hot Bangkok to cold and windy Wellington to humid seaside Makassar), whether in cities or rural villages, and to all the compromises this study had to undertake. I truly hope that his memory of these few years can contribute positively to his future understanding of different global environments. And to my husband Phi Khaek: his absolute commitment and support and constant reassurances to my goal are without doubt the backbone of my efforts, especially during family relocations, complicated times and the few months when he cared for my son alone while I was away concentrating on the thesis writing in Wellington. Kop jai maak maak na ja...

Without all your supports and assistances, this thesis would not have been completed easier and better. Thank you. 


\section{Table of Contents}

$\begin{array}{lr}\text { ABSTRACT } & \text { ii } \\ \text { ACKNOWLEDGMENT } & \text { iii } \\ \text { TABLE OF CONTENT } & \text { iv } \\ \text { LIST OF TABLES AND FIGURES } & \text { vi } \\ & \\ \text { CHAPTER ONE: INTRODUCTION } & \mathbf{1} \\ \text { Background of the Research } & \mathbf{3} \\ \text { Content of the Thesis } & 4 \\ \text { Conclusion } & 4\end{array}$

CHAPTER TWO: BASIC EDUCATION FOR DEVELOPMENT 6

History of Development as World Development 6

Education is Influential in Development 9

The Enlightenment as the Pioneer for Freedom and Knowledge 9

Basic Education for Freedom from Poverty 10

Basic Education for Development 13

Does the Basic Education Campaign only Focus on Boosting Statistics? 14

$\begin{array}{ll}\text { Conclusion } & 17\end{array}$

CHAPTER THREE: SITUATIONAL REVIEW OF PRIMARY

EDUCATION IN INDONESIA $\quad 19$

Global Efforts for Universal Primary Education 19

Eradicating Illiteracy Campaign 19

EWLP and Freire's Conscientization 21

$U P E$ and Global Movements $\quad \mathbf{2 1}$

Overview of Primary Education in Indonesia 23

Decentralisation of (Primary) Education at the Regional Level 26

Primary Schools in Rural Areas of Indonesia $\quad 30$

Conclusion $\quad 32$

CHAPTER FOUR: METHODOLOGY

Background and Settings of the Case Study $\quad 34$

Methodology of the Case Study $\quad 36$

Challenges of the Case Study $\quad 40$

Conclusion $\quad 42$

CHAPTER FIVE: RURAL COMMUNITIES AND THEIR VIEWS
ON THE IMPORTANCE OF PRIMARY EDUCATION

Overview of Batu Lapisi and Kampung Baru 43

Source of Living $\quad 44$

Customs and Family $\quad \mathbf{4 5}$

Education background and Its Influence on the Community Life and Attitude $\mathbf{4 8}$

Community's Perception on the Value of Education 52

Barriers to Children Education $\quad 60$

Sustaining Primary Education for the Community 64

$\begin{array}{lr}\text { Conclusion } & 65\end{array}$ 
CHAPTER SIX: RURAL PRIMARY EDUCATION IN INDONESIA: PRACTITIONERS' VIEWS

Profiles of the Practitioners

Challenges of Primary Education in Rural Areas 67

Cases from Batu Lapisi and Kampung Baru $\quad 67$

Poverty, Customs and Lack of Commitment $\quad 68$

Remoteness $\quad \mathbf{7 1}$

School's regulation and "hidden" cost of education 72

Welfare of and Supports for Rural Teachers $\quad \mathbf{7 3}$

Discussion on the Education Decentralisation System 76

The Importance of Primary Education $\quad 79$

Interventions and Strategies to Improve Rural Primary Education 80

$\begin{array}{lr}\text { Conclusion } & 85\end{array}$

CHAPTER SEVEN: CONCLUSIONS AND RECOMMENDATIONS 87

Influence of Urbanisation on Rural Poverty and Development $\quad 87$

Rate of Return of Basic Education to Rural People $\quad 90$

Decentralisation and Community Participation $\quad 93$

$\begin{array}{ll}\text { The Road to Achieving the MDGs } & 93\end{array}$

$\begin{array}{ll}\text { Concluding Remarks } & 94\end{array}$

$\begin{array}{lr}\text { REFERENCE LIST } & 98\end{array}$

$\begin{array}{ll}\text { APPENDIX 1: Indonesia's Key Indicator } & 100\end{array}$

APPENDIX 2: Status of MDGs on Education by Provinces (1993-2006) 101

APPENDIX 3: Distribution of Primary and Junior High School Net

Enrolment Ratio by Province (2006) 102

APPENDIX 4: Drop out causes for population aged 7-15 years (2006) 103

APPENDIX 5: General Data of Case Studies Participants from

Batu Lapisi and Kampung Baru Communities 104

APPENDIX 6: Specific Data of Case Studies on Batu Lapisi

and Kampung Baru Communities' Perspectives 


\section{Tables and Figures}

\section{List of Tables}

Table 1: Proportion of the basic education budget against gross domestic Product (GDP) from 2004-2006 (in billions of rupiah)

\section{List of Figures}

Figure 1: Country map of Indonesia

Figure 2: Chart of Parents' Education and Children's Education

Figure 3: Pie chart of Parents' Aspirations

Figure 4: Pie chart of Children's Aspirations 


\section{CHAPTER 1 \\ INTRODUCTION}

"The basic purpose of development is to enlarge people's choices. In principle, these choices can be infinite and can change over time. People often value achievements that do not show up at all, or not immediately, in income or growth figures: greater access to knowledge, better nutrition and health services, more secure livelihoods, security against crime and physical violence, satisfying leisure hours, political and cultural freedoms and sense of participation in community activities. The objective of development is to create an enabling environment for people to enjoy long, healthy and creative lives." (ul Haq, 2008)

A lack of education, even basic education, does not always translate into poverty. Nor does education automatically provide a means to escape poverty. There are many high school and college graduates who struggle to find employment and who live in poverty. The circumstances of poverty are multifaceted and entangled, so complex that any effort to address the issue of deprivation will most likely incorporate many pertinent elements. There is an increasing number of views that designing strategic measures based on a single subject solution is misguided and can even cause more damage to other components of poverty mitigation attempts. Yet education is often viewed as the single most important factor in poverty alleviation.

The main focus of this research is to observe rural communities' views on the importance of basic education in reducing poverty in developing countries. A case study that supports this research objective was carried out in two sub-villages in Indonesia. The choice of rural areas is based on the consideration that almost half of Indonesia's population live in rural and remote areas, most of which are poor and neglected. This study also takes on one specific goal of the world's leading development campaign, the Millennium Development Goals (MDGs), namely to 'achieve universal primary education'. Since the launch of the MDGs in 2000, governments and development organisations worldwide have been vigorously designing and implementing new strategies. This research looks into the suitability and benefits this global focuses have brought into the venture of fighting poverty. 
The sections that follow introduce the thesis and the subsequent chapters that develop this research. As mentioned, the major component of this thesis is the case study chapters which provide more comprehensive discussions on rural communities, their lives and customs, their perspectives on basic education and economic priorities, and how key sources in this field correlate to the community's views. The last section will lay out conclusive ideas on the values of basic education in today's quest to reduce poverty, especially in rural areas.

\section{Background of the research}

For the researcher, going to school and pursuing education are natural courses of life; they are neither privileges nor choices. They are merely unavoidable stages in life. Thus, there was a sense of exasperation when learning (from previous visits) that there are still many parents in villages she was long familiar with in Indonesia who married off their young daughters before the girls could resolve the confusion of puberty. In one of the trips, the researcher encountered a 27 year old mother of four named Imus ${ }^{1}$. Her oldest daughter had just completed primary school and was sent off to work as a housemaid in the nearby main city of Makassar. A week into her work, her parents requested the girl to take a few weeks leave from the work to assist with the harvesting season in the village, oblivious to the fact that city employment is not sensitive and sympathetic to such an arbitrary demand. Consequently, the daughter lost her job and for the same reasons she often missed school before. Despite living in a very poor living condition, Imus' family is increasing in size, an inevitable likelihood since she and her husband did not comprehend the need, or importance, to use birth control nor can they spare resources for it.

Imus' story is prevalent among many communities. The researcher then could not comprehend the community's lack of determination to have a better future and reluctance to let go of (disadvantaging) customary practices while they admit being poor and lacking hope for better future. It was this frustration that influenced the decision to undertake upon this research topic in this specific rural area. This research has offered some insights into the reality of the challenges these rural communities constantly face, and how those lead to (and influence) their current lives. People in Malino villages live in poverty and their main livelihood of farming is declining due to long-term effects of over fertilising and decreases in land ownership (meaning fewer plots to work on to

\footnotetext{
${ }^{1}$ Throughout this thesis, people's names have been changed to protect their identity
} 
generate income or food resources). When households struggle securing food and income, it is less likely that other needs, like education or health, will become priorities. As the locals always said, "When the stomach is empty, one will not be able to learn. Thus, making sure that there is a pot of rice cooking in the kitchen will precede any other matter."

\section{Content of the Thesis}

The concept of development has long been part of the human consciousness though it has only become a global 'project' in the past 60 years. Chapter 2 will briefly discuss development as a notion and its connection to education, its importance and influence. It is argued that education is not only a tool for intellectual development, it is quintessentially the root of the development idea. This chapter aims to confirm that knowledge-exploration and education will allow people the ability to comprehend various issues around them, a notion of freedom that reinforces human's desire for growth and change.

Chapter 3 focuses on the place of basic education in the development arena. In 2000 during the Millennium Summit, hundreds of world leaders committed to a global partnership in order to reduce extreme poverty by 2015 (UN Millennium Project, 2008). The agreement, the Millennium Development Goals (MDGs), produced eight targets which are perceived as crucial elements in fighting poverty and delivering proper development to global poor. The second goal, universal primary education, aims to have all children in the world be given access to, and complete, basic education. The campaign of this goal has caused some debate within the education sector itself. This chapter further discusses rising criticisms on the isolation of focus of basic education.

Chapter 3 will also delve further situational and institutional states of basic education in Indonesia. It seeks to assess current issues regarding basic education in rural areas of the country. A critical issue that cannot be ignored when touching on rural education is the newly implemented structural mechanism of decentralisation. Decentralisation was recently adopted in an effort to transform the government system and shift responsibilities of the central government to regional administrations.

The following several chapters will be inclusively discussing and revealing findings from the case studies that support this thesis. Chapter 4 discusses the 
methodology of the study and general introduction of the case studies. The basis and application of qualitative methods, the main means to conduct the research, will be explained, including justification and motives. General introductions on the case studies' locations and settings will follow in this chapter.

Following the Methodology chapter, chapter 5 will reveal the findings of the research exclusively from the researched communities. In this chapter, sections will explore issues pertaining to histories, situations and perceived importance of basic education in the areas from the perspectives of the local rural people. Existing traditions and customary practices are without doubt key factors in understanding the issue. The rural settings, conditions, limitations (lack of vital infrastructure and supporting facilities), and backgrounds will also be discussed here to elucidate how they influence views of local people and play roles in the way the communities decide on the education plans of their children. It includes the communities' (particularly the parents) opinions on the learning institution' systems and mechanisms, their demands and the (supposed) burdens they imposed on the parents. In other words, this chapter will stand as a section that represents the community's perspectives and attitudes on the worth of basic education.

Chapter 6, on the other hand, will represent views of experienced practitioners in the sector, locally or nationally, directly or theoretically. This subsequent chapter is intended to offer a counterbalance to the preceding chapter. Views and analysis of practitioners (from local primary school teachers to professionals from international organisations) will offer more comprehensive explanations on the issues at the rural level, especially as they relate to the inevitable matters of traditions or recent structural changes in the administrations (from national to district levels). These practitioners, who work closely with the issues, discuss various factors leading to the inefficiency and ineffectiveness of the basic education campaign. Finally, they also point to some systems and strategies, several are in progress, which can be utilised to manoeuvre the issues to benefit the local schoolchildren, their families and local schools.

\section{Conclusion}

Poverty and development may be on each end of a life progression spectrum and the global community is spread across this spectrum. Poverty violates the quintessential purpose of human existence as no individual should have to experience this grimmer 
reality of life. At present the world is in bold pursuit of campaigns to alleviate poverty and one of the key methods to achieve this is by means of providing basic education to all children. Children who are without basic education cannot further their education and enhance their capacities and assets that have been deemed crucial in exposing chances for better prospects.

Like other countries, Indonesia has also been proactive in its basic education campaigns. The country has achieved significant results in improving access to basic education. The 2007 report on the Achievement of MDGs in Indonesia (2007) shows evidence that the net enrolment ratio $^{2}$ of primary school has increased from 88.79 per cent in 1992 to 94.7 per cent in 2006. More encouraging are the report's figures of the gross enrolment ratio $^{3}$ of primary school, which was 102 per cent in 1992 and reached 109.9 per cent in 2006 (UN \& National Development Planning Agency, 2007). It is then fair to say that there have been significant improvements in basic education in the country.

These figures, however, do not reflect the reality in all areas of the country. There are still about two million school-age children who are not in school (UNICEF Indonesia, 2007). The government may deserve credit for current successes based on the statistics, but it still needs to fulfil its obligation of providing access and quality basic education to all its children. With joint global efforts and growing transformation of good governance, Indonesia should reach the goal and, most of all look after the upcoming generation. Prioritising quality basic education, hence promising higher education, in the foundation of next generation can be the simplest and most fundamental investment the government has to do to ensure better future. This research aims to provide insight into the realities of this quest at rural village level. Here we will see that global and national goals and strategies may not be easily converted into good development outcomes.

\footnotetext{
${ }^{2}$ Net (primary school) Enrolment Ratio is the number of children enrolled in primary school who belong to the age group that officially corresponds to primary schooling, divided by the total population of the same age group (UNICEF Indonesia, 2008).

${ }^{3}$ Gross (primary or secondary school) Enrolment Ratio is the number of children enrolled in a level (primary or secondary), regardless of age, divided by the population of the age group that officially corresponds to the same level (UNICEF Indonesia, 2008).
} 


\section{CHAPTER 2 \\ BASIC EDUCATION FOR DEVELOPMENT}

Since 2000, the world's development community has been occupied in pursuing development agendas and projects guided by the United Nation's Millennium Development Goals. Within these, the education sector has aimed optimistically to provide basic education to all children in the world. Policymakers and experts in the sector believe that by providing basic education to children, it can significantly contribute to the overall goal of combating poverty. This review will explore the historical connection of education and development and how it has mainly been prescribed as a cure for poverty. At the end, the discussion relates arguments and theories on the importance of education to the grim reality of the economic struggle of rural people.

\section{Development History as World Development}

Although the notion of "development" was explicitly formulated after World War II (Rist, 1997), its roots can be traced back to the eighteenth century. The "Enlightenment" era (Power, 2002), followed by revolutions and reforms of the traditional order of society, pioneered the concept. The enlightenment period was marked by a movement to seek out new paradigms of social order of humankind and nature to challenge the dominant control of Christianity in Europe and major parts of the world (Power, 2002). It was an attempt to demystify "superstition in 'traditional' society" (p. 66) and allow intellectual freedom to form hypotheses of progress using rational thinking. Power (2002) further writes that communities of intellectuals and philosophical disciplines yearned for greater knowledge and views different to what the Church espoused. They asserted convictions of using reason, empirical entities, and sciences for new approaches. On these views it was believed that society could and should progress to seek justice and improve both human welfare and social order. This Enlightenment period was significant to the concept of development as a means of social progress that was concrete and finally outside of the Church's influence.

It can be said that the effects of the Enlightenment movement and subsequent revolutions were formalised and universalised after WW II. It commenced when President Truman of the United States of America gave a speech on the importance of solidarity and peace building in the post-war world in 1947. Although some theorists 
claimed that "development" is culturally conceptualised by the West, and that it is not a "transcultural concept that can claim universal validity" (Rist as cited in Tucker, 1999, p. 2), the world has since been convinced that the development project was a global project (McMichael, 2000).

Development, as the name suggests, implies no more than to offer betterment and positive changes. The notion of changes from existing structures is not without appealing benefits, especially to post-war societies with economic and political tribulations. Modernisation theory suggests social and political reforms by altering the order of the society from a traditional (and uncontrolled) to a modern (organised and controlled) one. Structuralism (heavily influenced by Keynesianism) was an economicbased development scheme with relative control from the government which became a key element of modernisation.

These views were conceptualised to offer mostly economic and political progress for the lasting security of a country's society. Such progress includes efforts to build infrastructure (roads to connect remote areas with more central areas or the management of river water for irrigation and drinking water), population control through policies and medical interventions, and government support for small-scale enterprises. These were among the many development interventions that aimed to bring improvements and security to society as a whole throughout the second half of the twentieth century.

In present circumstances when there are about one billion people who live in absolute poverty and millions suffering from lack of basic human rights (Thirwall, 2002), development for betterment of socio-economic conditions is more than necessary. In conditions like this, human development interventions are essential in order to impede rising numbers and to provide assistance for poor people to escape from poverty. Providing education for poor people will assist them to gain basic skills, and it opens opportunity for them to compete in the workforce and secures economic gains (with regular wages) for their families.

In this process of developing the "underdeveloped" countries, the philosophy of Western superiority was without doubt the principal theory behind the proposed modernisation programmes. According to Hettne (2002) the concept “... implied the 
bridging of the gap by means of an imitative process, in which the less developed countries gradually assumed the qualities of the developed" (p. 7). The model advised was to imitate the Western development course by investing in industrialisation, infrastructure, and skill specialisations. In other words, this development focused on economic growth. Such as approach was continued and refined with neo-liberalism and a more explicitly market-oriented approach in the 1990s. In this case the market replaced the state as provider of industrialisation and infrastructure but the aim to imitate the West remained. However, Buarque et al. (2006) pointed out that poor countries' lack a "skilled and educated workforce" (p. 223) which disadvantaged them by not being able to fully utilise the financial assistance and, in consequence, they were trapped in debt. As Jeffrey Sachs (2005) writes, development economics is "like eighteenth-century medicines, when doctors used leeches to draw blood from their patients, often killing them in the process" (p. 74). It was clear that this development concept could not work everywhere, especially if it had a hand in debt accumulation of so-called developing countries and their collapse during the development process. Wolfgang Sachs (in Kothari \& Minogue, 2002) emphasises this: "The idea of development stands like a ruin in the intellectual landscape. Delusion and disappointment, failures and crimes have been the steady companions of development and they tell a common story: it did not work" (p. 2). The constant critics on these failures and symptoms of environment degradation from not only human rights groups but also within the development practitioner circles then prompted alternatives ideas on development agendas.

The decade of the 1980s was later identified with titles like the "reversal" of development (Elliott, 2002, p. 46) and the "lost decade of development" (Bonal, 2004; Carmen, 2002, p. 409) due to the failures and catastrophes which happened in the period. Although several theorists have previously challenged the classic theories and produced their own development theories, it was not until 1990s that the world saw redirection in development society from changing ideas and goals to measurement instruments (Elliott, 2002). More attention and measurement methods were focused on poverty in aspects of level of mortality and illiteracy rates, health, water and malnourished children. This transformation pointed out the inclination towards human rights issues and "of the interconnectedness and multidimensional nature of these component issues" (p. 47). Furthermore, the work of Amartya Sen (1999) opened up global perspectives that development is more than just an economic advancement. It is 
in essence a matter of human freedom. It is a freedom to expand necessities based on the values each human embraces, and which will contribute not only to the advancement of individual's qualities and capabilities, but to the overall enhancement of society, economic and culture.

It is now increasingly acknowledged that development is not only economic in nature, it also a process of social improvements. This includes basic human needs, such as food and clean water, education, health, etc., that are essential to long term survival of human beings, particularly to those who are deprived. Ensuring that one has these basic needs fulfilled is to ensure that her or his basic human rights are met. In September 2000 during the Millennium Summit, world leaders committed to the MDGs to fight global poverty by 2015 (UN Millennium Project, 2008). The eight goals in the MDGs are not much different than other previous missions; they were simply frameworks to reinforce and expand the initial goals set up by the World Bank. This move by the UN, and by commissioning special team called the Millennium Project, proved that the world's development agencies and members were willing to acknowledge and shifted their priorities into more rights and social service based priorities. Since then, most organisations and government agencies have practically rearranged their agendas to adhere to the MDGs.

\section{Education is Influential in Development}

\section{The Enlightenment as the Pioneer for Freedom and Knowledge}

Hundreds of years ago, education was merely a choice among other leisure activities and, to other societies, a form of social interaction. One needed no diploma and could be wealthy by tending to their cattle or farms. However, just as society was intensely influenced by norms and traditions, religion was the core of learning in civilised society. In major religions (Buddhism, Judaism, Christianity, Islam, etc.) learning was characterised as a practice to enhance oneself by intensely studying and mastering aspects that were essential for the surrounding community. Learning was also a tool for social categorisation, directly proposed those who studied as selected and best among others.

The role of the Enlightenment period was inevitably crucial to use knowledge in exploring the progress of life and the freedom to examine other means of understanding humankind and the world (Power, 2002). During and after the previous era of past 
colonisation, Christian missionaries were famous for travelling across the oceans to different continents to spread Christianity. Although it was a common perception that the missionaries would generally enter new areas as virtual aid workers, numerous accounts noted the missionaries' covert goals to convert the selected communities into Christians. It was similar with Arab traders who would often introduce Islamic teachings to trade partners and communities they encountered during their travels. The practices used included building infrastructure (road, water system, bridges, etc.) and introducing Western medicines to the communities by the Christian messengers or marrying into and offer modern materials to the communities by the Muslim traders. Many of these religious envoys also believed their presence were called for to civilise and modernise the backward communities or counsel them from possible evil influences of other tribes or societies.

In time the role of religion in education has further expanded. A prevalent practice involved offering poor children assistance (scholarships or materials) when studying in religious-based schools. In Indonesia, it is common for Muslim parents to put their young children in Islamic schools, Pesantren, to both reside and study. It is perceived that the children will be better guided and have better knowledge under dominant religious influences.

\section{Basic Education for Freedom from Poverty}

In today's new era where traditional customs are rapidly diminishing and hightechnology and globalisation influence the lives of the world's population, education is, first and foremost, one vital asset an individual's need to survive. Education has become one of the basic necessities and human rights. The UN Universal Declaration of Human Rights authenticated this importance, "Everyone has the right to education. ....Education shall be directed to the full development of the human personality and to the strengthening of respect for human rights and fundamental freedoms" (UNESCO, 2000, p. 16). More important is to underline the point 'full development of human personality', a message emphasising that education is not merely an activity of going to an institution, but is a knowledge-enrichment process so as to develop individuals with critical judgement, ideas, and attitudes that hold human rights freedom in high esteem.

In this world where there are approximately six billion people, one billion are still living in poverty. People still die every day from preventable diseases and babies 
are born with HIV/AIDS. The role of education in reducing this number and improve this condition is critical. Poor people who are not educated have a high probability of staying in their current conditions. Sachs (2005) explains this poverty trap as demographic:

...When impoverished families have large numbers of children, the families cannot afford to invest in the nutrition, health, and education of each child. ...High fertility rates in one generation, therefore, tend to lead to impoverishment of the children and to high fertility rates in the following generation as well. Rapid population growth also puts enormous stresses on farm sizes and environmental resources, thereby exacerbating the poverty ( $\mathrm{p}$. $65)$.

Although the link to education is not mentioned here, the role of education, and schooling, is crucial in this illustration. A teenage girl from a poor family, which is usually uneducated and illiterate, will probably get married early. Because of her illiteracy and lack of knowledge, she will most likely oblivious to the importance of healthy pregnancy, let alone have the authority to make fertility choices. She will then have several children. Because of the demand to sustain a large family in the households, the likelihood her family has extra money to invest in her children's education is low. This condition will recycle itself within her children's families and their next generations, and they will contribute to a population that is often illiterate, disease-prone, and poverty-stricken.

Being educated, or involved in an educational institution, has some beneficial stimulus. Poor people who are deprived in many aspects of life often found the status of being literate or having some sort of schooling can provide them with a boost to their self-esteem. "Literacy is universally valued as a means to survive, to avoid exploitation, and to maintain mobility" (Narayan, Patel, Schaaft, Rademacher, \& Koch-Schulte, 2000 , p. 268). The mere pride of having experienced school and being literate can reduce the chance of people being exploited and discredited by others, especially for poor people who live in a small community.

A classroom is also supposed to offer a medium of equality to its students, a place where they are all in the same intellectual level, despite the numerous cases of discrimination. Particularly for girls, the continuous campaigns for girls' education have 
brought so much advancement to girls' lives and futures, and indirectly to their families. Girls who attend schools often have choices of employment later in life. They also tend to delay marriage and opt to migrate to bigger cities for better employment prospects and the possibility to choose their own partners. "Investment in girls' education yields some of the highest development returns. ... translated into lower fertility, later marriage and better health" (Burnett, 2008, p. 182). Overall, what education offers to girls is knowledge and empowerment to have choices and chances over their lives. Empowering women with education and knowledge leads to more and long lasting benefits for her life, her families, and society as a whole. These cumulative factors "add up to a virtuous cycle of social development" (Mehrotra \& Delamonica, 2002, p. 1106).

Securing rights for education means providing opportunities for human development. Education offers young people chances to cultivate knowledge and groom awareness, so they can develop to be mature and competent adults. These assets are necessary factors in fostering human resources and are helpful in preparing young people with skills and proficiencies needed to participate in the economic growth of a society. "Education is indeed one of the principal means available to foster a deeper and more harmonious form of human development and thereby reduce poverty, exclusion, ignorance, oppression and war" (Burnett, 2008, p. 181). Burnett goes on to point out the impact of education on economic and social development. Education, he writes, is "a major determinant of individual income, with each extra year of schooling resulting in a ten per cent increase in earnings" (p. 182). Today, career gateways often depend on the education qualifications one has. The world has formed its economic growth based on human capital supplied by educational institutions. Countries who invest enough in education have able to build sustainable economic growth and social development. Countries with more educated citizens tend to control their population better, thus allowing the governments to provide more social welfare to the population. A healthier and secure society can lead to more productive and happier human capital, and contributing to sustainable economic growth.

Emphasis on social services was not a novelty, especially priority on education. Many governments have been offering free education to their citizens with the aim to train their human capital for necessary work industries needed by their countries. Many experts have supported the argument that education is a vital element for combating poverty (Buarque et al., 2006; Mehrotra \& Delamonica, 2002; Narayan \& Petesch, 
2002; Sachs, 2005). This faith could be seen from decades of world meetings producing declarations which were meant to achieve universal education.

There have been increasing numbers of primary school enrolments and several positive statistical results, UNESCO (2008b) reports that in 2004 there were about forty-six million children who are out of school, a decline from seventy-two million in 2000 (Burnett, 2008, p. 183). The numbers have indeed dropped, but the target is far from being reached. And, considering the predicted population growth by 2015, there needs to be a more strategic and effective manner to deal with it and the overall poverty issue.

\section{Basic Education for Development}

The commitment to provide basic education to all, or notably referred to Universal Primary Education (UPE), can actually be dated back to 1960s "when Ministers of Education at conferences held on all three continents predicted UPE 'by 1980"' (Carmen, 2002, p. 410). Yet, this target has proven tough to meet as the education community still witnessed widespread unschooled children as years passed, be it from shortages of schools or teachers. The sector clearly required more extension to the time threshold and stronger commitment. In 1990, the Jomtien Declaration set a new target to reach UPE by 2000 (Carmen, 2002). Ten years later, in 2000, the agreement was renewed and the deadline extended to 2015 (UNESCO, 2008a).

According to report by UNICEF (as cited in Bowden, 2002), in 2000, there were about 130 million children who were not in school, 56 per cent of whom were girls. This discouraging fact confirms that governments and international community still has a great deal to do. As a key element in combating poverty, without a significant lift and improvement to education attainment, specifically in poor and underdeveloped nations, poverty will only inhibit the progress of other interrelated sectors. The significance of investing in basic education is too critical to ignore as its long-term benefits carry expanding effects to the wellbeing and future of people's lives. Further on the UNICEF report points out that there will a "decrease in infant mortality levels of 4.1 deaths per 1000 if girls' primary school enrolment were to increase 10 per cent, and a further reduction of 5.6 deaths per 1000 for similar increase in secondary enrolment" (p. 405). It can be taken for granted that perhaps by staying longer in school girls will avoid early marriage, and thus, reducing the number of young girls risking their lives during 
childbirth. The significant of this data is the clear evidence that by only investing more in early years of female education, immediate benefits can directly impact the women's lives and futures. In this report UNICEF (1999) further highlights that education has the greatest impact on health indicators based on the findings from a study of several interventions on health in nine countries. It points out that there were significant improvements in rates of infant and under-five mortality, life expectancy at birth and total fertility (p. 53). Data from Kerala State in India, the Republic of Korea and Costa Rica also show the positive associations of a rise in primary school enrolment rate and a decline in infant mortality rate (p. 53). This encouraging data simply displays the multiple benefits for society only by utilising the power of knowledge and education to influence sensitive decision of households in developing countries.

There is no doubt that the international community is agreeing to universalise education, especially since the launch of MDGs' renowned targets. However, enormous efforts and huge budget allocations to this target do not seem to be enough. Moreover, recent years have seen increasing criticisms on this specific target (primary education) by MDGs and education international community.

\section{Does the Basic Education Campaign only Focus on Boosting Statistics?}

A reasonable way of measuring the application of providing basic education is by measuring the numbers of enrolment. This indicator met no problem as countries reported astoundingly good increase in primary enrolment. An immediate criticism of this method is that statistics only measure enrolment numbers and is insensitive to numbers of dropping out or primary completion rates. At the beginning of the campaign, schools in numerous countries were facing trouble allocating students due to sudden increase in new students but with the same limited classrooms, books, and teachers. As a result, many classrooms in developing countries were overcrowded and learning processes became compromised. This might cause more harm to the previous states of the schools. Burnett (2008) pointed out that many countries were strained for having to hire more teachers in order to achieve the target. To fulfil this requirement, governments hired teachers who were not fully trained and qualified to teach. Students then learned less effectively due to less concentration and learning materials; teachers taught less effectively and became more stress because of additional responsibility and pressures; and schools' resources were immediately strained due more enrolments without significant budgetary increase. The impact to this is children were dropping out 
of schools halfway the curriculum or unable to pass the grade. Most often they will not re-enrol again.

There is no contestation that basic education is necessary and can be an effective antidote for fighting poverty. It is not, however, a magic potion. Global society and governments should look beyond the statistical outcome of it and attempt to fathom the principal of acquiring basic education in the first place. Bowden (2002) stresses the growing criticism that frowns upon applauses for soaring statistics figures instead of prioritising the quality of education that children attain. He further warns that "High levels of enrolment can mask erratic attendance, irrelevant curricula, poorly trained teachers, gender insensitivity and a lack of facilities that often combine to result in low completion levels" (Bowden, 2002, p. 406). In other words, high rate of enrolment does not guarantee pupils' quality of education, continuation of attendance and full completion of primary schooling.

Although the focus on education for children is not at all wrong, critics have pointed the flaws in this specification. By focusing the efforts only to primary school, it is excluding the other levels and types of education: preschool, junior high, senior high, vocational and higher education ${ }^{4}$. The policy changes by governments and international organisations to reallocate their budget and concentrate on primary education were viewed as poor strategies by critics (Bonal, 2004; Bowden, 2002; Krueger \& Lindahl, 2001; Palmer, 2006). Schools and students who are not in primary education receive less attention and assistance, leading to gaps and inequality in education development as a whole. Ironically, students who finally graduate from primary education are seemed to be out of list in educational priorities since the focus is only on primary level. This phenomenon definitely does not in any way helpful for human capital development and poverty alleviation efforts.

In terms of education's role in human capital investment, some argue that the rate of return of primary education to economic and social development is not significant and offers little advantage for combating poverty. Palmer (2006) discusses the issue in depth about the rate of return of education in each level. He further stresses

\footnotetext{
${ }^{4}$ The terms junior high (the level of education between primary and senior high) and senior high (the level after junior high) will be used interchangeably with the terms junior secondary and senior secondary.
} 
that "investments at the primary level have to be complimented by suitable investments at the post-primary level" (p. 7) for the education to contribute positive outcomes. Moreover, according to World Bank findings (as cited in Palmer, 2006), "significant positive returns are only found for senior secondary and tertiary graduates" (p. 7). These arguments support the rising debates regarding funding deficiencies or diversion to other levels of education, criticising the overemphasis on primary education without considering its return and benefit to the whole picture. Bonal (2004) further stresses in his paper that the overemphasis on primary education means that aid organisations and policy makers have overlooked the very objective of education for poverty alleviation. Education, in forms of formal or informal schoolings, trainings, vocational, etc, are aimed to equip students and school attendants with skills that are supposed to be worthy when they enter workforce. The World Bank use of rates of return to measure the value of education for poverty alleviation efforts has pointed that the investment on primary school is not as valuable as the investment on secondary and higher education, in terms of economic output.

With the destabilising of today's workforce, particularly in underdeveloped or developing countries, parents are increasingly unsure of the value of education. Primary education, on the other hand, has been seen as a normal path of a child's life, with no particular expectation of the outcomes and benefits. The concept of educating a child is by sending him or her to schools to produce a smarter child. Education has long been forgotten, or avoided, to be perceived as a process of knowledge gaining, critical mental preparation, and life-skill development of an individual. In rural areas, primary school is mainly successful when able to produce a student who is able to read, write, and do a simple arithmetic. When these skills are achieved, parents think that their children has gained a fair quality of primary education but then, simultaneously, they are perplexed at how almost nothing can be gained from this qualification to assist the family's household economically at once. It is surely not fair to demand an instant economic benefit from a child who has just finished a primary education qualification. However, when government policies widely campaign for children's education and the prosperous few naturally embrace the concept of education, it is easy to understand the reason behind the poor parents' expectation of child education's economic output. When poverty is not a condition of living but an unavoidable circle of fate and when dreading the thought of having to let the family go without meal for the next several days are 
constant agonies poor parents' face, it is more than reasonable to acknowledge their despair in showing outcomes of "worthless" primary school.

\section{CONCLUSION}

Poverty and development are generally perceived within the same spectrum: development on the upper end while poverty on the other end. In between there are numbers of key influential constituents that, if are not employed appropriately or distributed correctly, would tilt the balance of the spectrum. The past has confirmed that this imbalance has disadvantaged people who lack these essential constituents and as a result they become victims of their own state's unfair distribution system. Education for development is one of the main elements emphasised in the development process in order to enhance one's knowledge horizon and equip him or her with skills for workforce in real life. This concept is strongly believed through the deeper layer of society, through religion and surrounding communities.

The importance of educational attainment in fact has gained universal support decades ago with the establishment of various international organisations and agreements. Recently, with the launching of MDGs and an emphasis on primary education for all children, the international communities have been very vigorous in promoting projects and funding for primary education. Despite many positive outcomes from the target pursuits, criticisms and demands for program readjustments are not lacking either. As discussed above, the arguments that focus solely on primary school without supporting the next advanced levels may indeed pose a further impediment for the very purpose of education's mission as a basic for fighting poverty are not without grounds. Global organisations and governments truly need to reflect and revisit the target's focus and implementation's orientations to avoid further deviation from the overall goal.

As Sabine Etzold (as cited in Sindhunata, 2000) ponders, the appropriate question to ask now is not anymore of what is the best and most effective school for the future, but will there be a future for the school itself? The critical issue that needs to be deliberated according to Sindhunata (2000) is what if the school that used to be the outlet to prepare future no longer has prospects itself? How can school have no future? This straightforward yet profound scepticism perhaps has become the recurring question 
many rural people have asked over the years as their economic security fails and conditions became worse. This is where the global efforts should probably begin to focus on to revive the growing millions' faith in education and to cultivate belief of better prospects. 


\section{CHAPTER 3 \\ SITUATIONAL REVIEW OF PRIMARY EDUCATION IN INDONESIA}

The adoption of the Millennium Development Goals was signified when 189 countries signed the Millennium Declaration (World Bank, 2008b) in 2000. The eight goals of the MDGs today serve as the world's focus and measurement tools in combating poverty. With enormous budgets and attention throughout all levels of governments and organisations, this project to alleviate poverty globally aims to reach its goals by 2015 .

The second goal of the MDGs is to "Achieve Universal Primary Education," a goal that has indeed been planned, targeted, and worked on decades before by education sectors. Similarly, the Government of Indonesia has a long history of child education campaigns, efforts that have influenced the nation's attitude towards education. In 1999 the Indonesian government issued a decentralisation law which finally enabled individual provinces to manage their own administrations, including the management of education and its curriculum. This chapter will discuss the transformation of education systems at the global, national and regional levels in Indonesia. It will examine how each level influences and contributes to education adjustments within the country and region, as well as highlighting contributing and interrelated factors that are hindrances to the progress of education in rural areas.

\section{Global Efforts for Universal Primary Education}

The global mission of offering education for all has been discussed at many international conferences, seminars and meetings. It has been a global belief that education is more than another choice or skill; it is now a human right. Education has become a necessary phase any human being should receive along with other significant aspects of life.

\section{Eradicating Illiteracy Campaign}

The international campaign on education initially started in 1950s following the Universal Declaration of Human Rights proclamation: UNESCO was urged, by the United Nations General Assembly, to deal with the illiteracy problems found mostly in colonial territories, those that were newly independent and were developing (UNESCO, 2000). This resulted in UNESCO carrying task of literacy campaigns all over the world, 
summoning studies on literacy statistics and perceptions. A UNESCO (2000) comparative study of national censuses of literacy in several countries from 1950 to 1990 showed that the meaning of 'literate' or 'illiterate' has different connotations in different places, from the ability to just read to the ability to both read and write. Data from the study shows high illiteracy rates in many developing countries. The conclusion from this data, as emphasised the in UNESCO World Education Report (2000), is that despite international efforts in fighting illiteracy, the number of people with "no meaningful experience of the right to education was actually to increase" (p. 32) due to the rapid expansion of the world's population.

This World Education Report (UNESCO, 2000) reviews some major ideas and policies that influenced education strategies. The report points that during the $1960 \mathrm{~s}$ many countries began progress on and expanded their literacy campaigns. This movement led to international community formulating suitable strategies, which resulted in two different policies. One of the ideas was to emphasise "national campaigns', in which positive outcomes could be seen from the former USSRs' literacy campaign in early 1920s. The then Soviet government took serious measures to fight illiteracy (then 76 per cent of its population), from compulsory schooling in the military to wage subsidies for working students to enlistment of every literate people as 'literacy fighters' to teach the illiterates (p. 32) ${ }^{5}$. Although many believe that this approach could be the right strategy to immediately realise universal education, some identified the potential challenges of its implementation. It is particularly because the differences in each countries' internal formations and the weak foundation of this strategy's "superficial level of literacy that could contribute little to the society's overall development" (p. 32). In the mid-1960s, another view surfaced to offer an alternative tactic to the literacy campaign. The "selective approach" (UNESCO, 2000, p. 33) suggests this alternative which put emphasis on people's own motivation and willingness to educate themselves for the benefit of their own lives instead of generally making people literate. This approach attests that people "learn when literacy meets their 'learning needs"' (p. 33). What this refers to is that education (literacy) campaigns need to be aligned with "socio-economic development" (p. 34) for a broader progress of society. It is perceived that literacy effort should be responsive to specific socioeconomic needs and that it provides economic provisions for those who invest in it.

\footnotetext{
${ }^{5}$ Refer to Box 2.3 in the World Education Report 2000 (UNESCO, 2000)
} 


\section{EWLP and Freire's Conscientization}

Following the discussions and decisions by the education sector on which better strategies to provide education to all people were marked by several world conferences and their agreements and launched programmes. The Experimental World Literacy Programme (EWLP) launched by UNESCO and UNDP in 1966 was to eradicate adult illiteracy (UNESCO, 2000). Universal Primary Education (UPE) made its debut in the same period with the deadline of year 1980. According to the World Education Report (UNESCO, 2000), many countries joined in adopting the EWLP's "experimental" pilot projects to experiment with "'selective approach' focused on 'functional' (especially 'work-oriented') literacy, and in particular to test and demonstrate literacy's economic and social 'returns"” (p. 34).

Upon this widespread enthusiasm for the EWLP, Paulo Freire's alternative view on literacy emerged. According to the distinguished Brazilian educator Freire, literacy programmes carry both "technical-pedagogic" and "political" features (UNESCO, 2000, p. 35). The report (UNESCO, 2000) indicates that Freire considers "the process of acquiring literacy (i.e. learning to read and write) was necessarily accompanied by the learner's increasing consciousness of his/her existential situation and of the possibility of acting independently to change it, a process which he termed 'conscientization', and which today would more likely be called "empowerment" (p. 35). This concept advocates the expanding and advanced function of literacy strategies in other sectors and contexts. It broadens perspectives to see beyond the mere ability of reading and writing to employ similar enthusiasm and motivation to enhance one's capacities, knowledge and aptitudes through "self-instruction or spiritual enlightenment" (UNESCO, 2000, p. 35). In other words, without the literacy skills ultimately one will be unable to attain a higher phase of learning, a vital element in self-development, and can hamper his or her opportunities for advancement, socially and economically.

\section{UPE and Global Movements}

The concept of basic education (for children or adults) has since been generally taken to include 'elementary and fundamental' education (UNESCO, 2000, p. 46). Subsequent major international agreements, either regionally or universally focused, include the Addis Ababa Plan for the African region, the Karachi Plan for Asia, and the Jomtien Declaration with the deadline of 2000 (Carmen, 2002). However, these seemingly vigorous activities and decisions have not translated to well functioning and 
effective strategies. Deadlines were often extended and targets readjusted along with formations of new resolutions and their goals and, automatically, decisions on new deadlines. Jomtien Declaration's UPE was modified as the Dakar Framework for Action was born with the new deadline of 2015 to reaffirm and achieve the Education for All (EFA) target (World Education Forum, 2000). During the Millennium Summit in September 2000, the Millennium Development Goals were declared; the second goal is concentrated on basic education. "Ensure that, by 2015, children everywhere, boys and girls alike, will be able to complete a full course of primary schooling" is the goal's only target (United Nations Millennium Development Goals, 2008). It validates the community's belief and extensive efforts towards basic education.

The incorporation of basic education in the MDGs - to achieve universal basic education - as a priority leads to the sector receiving more attention from global communities (including government and organisations), streams of international funding and larger shares of government budgets. Organisations and governments at different levels - international, national and local - were prompted to reallocate and revise their priorities and funding, ensuring that by 2015 the target is realised. Despite this long-due reinforcement, the MDG's definition and target of basic education has created more complexity within the sector, resentment among practitioners and policy makers, and weakened the fundamental aim of basic education.

The international community's continuous priority on basic education has at all times referred to fundamental education for all individuals, be it children, youths, or adults. It is not intended to aim merely for the first six years of formal schooling (also referred to as primary) or to exclude the levels previously and afterwards. The UNESCO World Education Report (2000) discusses the terminology of basic education and how the Universal Declaration of Human Rights stresses the concept of basic education as one whole and interconnected learning process instead of separate parts. In this report the various concepts of lifelong education and lifelong learning are emphasised, referring to learning knowing no age boundaries and promoting learning as a constant part of life. In doing so, states promote knowledgeable and prepared citizens who willingly and constantly keep up with the demands of socio-economic progress.

The shift of emphasis of the education sector programmes to align to the globalised MDGs has heavily influenced priorities and budget allocations. Primary 
schools suddenly are given much bigger budgets and assistance, resources that are claimed to be taken away from those of other educational levels (Bonal, 2004)._Many children who have graduated primary levels suddenly are not in priority groups anymore, causing significant percentage of children who are lost in education ladders. They have achieved rudimentary skills of reading, writing and arithmetic, but do not understand the functionality of these skills in their or their families' lives. In other words, primary schooling does not offer anything substantial for the improvement of their lives in return of the time and cost invested in it for six years. As a result, higher education and schooling is not seen as potential help and, often, the experiences of older children will determine the education fates of the younger children in the family.

Moreover, mostly in accordance with aid agreements, because governments and education departments were pressured to achieve the percentage targets, many projects and policy reforms were implemented merely to attain the target instead of achieving the fundamental objective of providing basic education to all children everywhere in the world. The concern of many critics and practitioners is this isolated focus group can create bigger gaps in education access to children and youths, particularly those from poor families who perceived education merely as a bonus when there is spare money. A more destructive result is to have a large number of poor and uneducated populations who do not believe in the importance of education and build up a helpless and disheartened society.

\section{Overview of Primary Education in Indonesia}

According to the UNESCO Institute for Statistics (UIS) (2008) Indonesia's population in 2006 was approximately 228 million, of which 26 per cent were children aged under 14. As of 2007, the Online Atlas of the MDGs (World Bank, 2008a) displays an astounding 99 per cent of the country's primary education completion rate. Yet data from the Agency for Research and Development of the Indonesian National Education Department (Balitbang Depdiknas) showed that in 2005 more than 50 per cent of primary school aged children in Indonesia's eastern region were not in school (Ibrahim, 2007).

Indonesia's population is widespread across over 17,000 islands, many of which are remote and difficult to access. Although Indonesia is made of hundreds of various ethnic groups (and language dialects), under the former President Soeharto's dictatorial 
style, the nation was very much centralised in every sector, including education. The curriculum always came down from the centralised government in Jakarta and the nationalised examination contents and schedules were based on the standard issued by the central government.

Under Soeharto's centralised administration, Indonesia's campaign for education made rapid progress. Along with many other countries involved in the worldwide illiteracy eradication campaign of EWLP (UNESCO, 2000) throughout the 1970s, the Indonesian government was very pro-active in pushing for primary school enrolments of school-age children and the expansion of public primary schools. Along with his success in advocating family planning (only two children per family), the campaigns for primary education were everywhere, including in the state TV station TVRI, and in posters in streets and newspapers. One renowned programme was the Presidential Instruction (Inpres) Block Grant that was used for country-wide school construction. This resulted in the country's success in raising literacy rates and the numbers of schooled children. Statistics from Kristiansen and Pratikno (2006) showed that from 1973 to 1984 primary schools increased in number from 65,000 to 130,000 and within the same duration the numbers of enrolled students doubled and reached 26 million (p. 515). An education law (Law 2/1989) was passed in 1989 to extend basic schooling from six to nine years, and in 1994 the nine-year compulsory education scheme was launched officially and it aimed to reach 95 per cent of students by 2004 (Kristiansen \& Pratikno, 2006).

Yet, the encouraging statistics disguised a fundamental problem. The education curriculum in Indonesia until recently was restricted to rote learning where students memorized lessons and repeated their teachers without properly and fully understanding the subject contents. "The unstimulating teaching-learning experience of 'talk and chalk' instruction method" is unfortunately still common in schools, especially with unqualified and untrained teachers, most of who work in rural and neglected areas (UNICEF Indonesia, 2007). The lack of students' participation in class and interactions between teachers or among students are one of the underlying causes of low quality education and attendance rate in the country, particularly among economically deprived students whose families struggle to finding motivation in keeping their children in school. 
There was also a culture of punishment in Indonesian schools that has been in practice for a long time. Many teachers believed that punishing students, physically or psychologically, could be effective for disciplining and ensuring teachers gain respect and obedience from students. Particularly in the rural areas where teachers were perceived as educated and of higher status than most common rural people, children were easily and constantly abused by teachers without being questioned by parents. There were paradigms that teachers knew best and that education affairs and disciplining children were solely the responsibility of teachers and schools. Hence, disciplining was considered one of the routines in attaining education. The lack of sympathy from families, especially parents, caused serious distress for students who were subject to punishments and embarrassments at school. Over time they tended to withdraw and lost interest in learning, putting them behind academically. These cumulative effects could result in the students' failures in passing grades or final examinations. It would lead to long-term effects in which they would maintain negative sentiments toward the school system and were less enthusiastic in sending their own children to school. In addition, this practice of punishment contributed to a nation with a culture of violence. It accepted and perpetuated violence as a as a way to resolve problems (SCUK Indonesia, 2006).

Toward the end of his 32 years presidency, Soeharto was faced with political and financial turmoil. The central government had huge debts with the IMF and was on the verge of collapse. When the Asian economic crisis hit in 1997 the country's economy turned upside down. Suryahadi et al (2000) estimated that the poverty rate increased by 164 per cent from the time when the crisis hit to its peak 18 months later (as cited in Suryahadi \& Sumarto, 2003, p. 46). This circumstance especially impacted those of the lower middle class and below which eventually led parents to pull their children out of school. In many cases, children ended up labouring to help sustain their families.

The repercussions of the economic crisis affected educational progress in Indonesia. Kristiansen and Pratikno (2006) pointed out that the gross enrolment rates before the economic crisis were above 100 per cent at the primary level, 72 per cent in junior secondary, and 46 per cent in senior secondary. However, a report in Jakarta Post indicates that in regard to the government target of reaching 95 per cent of students by 2004 as it announced the implementation of the nine-year compulsory education law, by 
the time it reached the deadline year only 90 out of 440 districts were able to reach the targets, meaning that 3.2 million children aged 13 to 15 years old were excluded from the nine-year compulsory education programme (as cited in Kristiansen \& Pratikno, 2006, p. 515).

To restore the nation's economic and socio-political situation, a financial-based remedy was suggested. The neo-liberal strategy focused on trimming central government spending, namely slashing subsidies on daily commodities as well as spending on health, education, etc. As part of the reform and the central government's expenditure restrictions, the Indonesian government finally announced the implementation of decentralisation: a transfer of authority and responsibility from the central to the regional government. It came into effect in 2001, and although this was considered a long-due reform, the autonomy did not come as a full gift basket to the region. Autonomous authority also means independence in managing and developing the area's resources, which includes management of local administrations and (supposedly) liability to provide social services to local residents.

\section{Decentralisation of (Primary) Education at the Regional Level}

The decentralisation of education was aimed to empower regional administration and, specifically, local schools. This meant that the district and local schools were to create their own curriculums and budgetary plans to finance the learning programmes. It included deciding on appropriate learning materials for each school areas and management of the school and its funding. This system was to allow regions to be empowering, independent, and self-sufficient.

In 2003, the Ministry of Education initiated an education reform agenda that aimed at enhancing democratisation and community participation, increasing financial support for education and building professionalism. According to SCUK Indonesia (2006) in its Education Report, the implementation of one core element in the reform called competency-based-curriculum (Kompetensi Berbasis Kurikulum or KBK) were found very challenging by local school officials. This is because most local teachers are "under-qualified and under-prepared" for the new curriculum's implementation, especially with limited support and attention given from the higher levels of administration, the Education Department and Ministry. 
In addition, despite the constitutional mandate to provide at least 20 per cent of the annual national budget to education, in reality the implementation is far from close. At the national level, the allocated budget so far only reached 9 per cent, while below at the district level, the number is only around 5 per cent (Ibrahim, 2007). A table derived from the Indonesia MDGs Achievement Report (UN \& National Development Planning Agency, 2007, p. 32) below shows the distribution of basic education budget throughout all government institutional levels. It can be seen that, against the country's GDP, the basic education spending in 2004 and 2005 were very little and minimal. This clearly indicates that government at many levels is still finding it hard to be pro-education, especially for children of rural and poor areas.

Table 1. Proportion of the basic education budget against gross domestic product (GDP) from 2004-2006 (in billions of rupiah)

\begin{tabular}{|c|c|c|c|c|c|c|c|}
\hline COMPONEIT & Year & $\begin{array}{l}\text { Education } \\
\text { Dogts }\end{array}$ & $\begin{array}{l}\text { Deptiof } \\
\text { Roligion }\end{array}$ & $\begin{array}{l}\text { Proincial } \\
\text { Budgat }\end{array}$ & $\begin{array}{l}\text { Regrency } \\
\text { Budght }\end{array}$ & $\begin{array}{l}\text { City } \\
\text { Budget }\end{array}$ & Total \\
\hline \multirow{3}{*}{ Total GDP (1) } & 2004 & & & & & & $2,299,000$ \\
\hline & 2005 & & & & & & $2,651,000$ \\
\hline & 2006 & & & & & & $3,041,000$ \\
\hline \multirow{3}{*}{ Education Spending (2) } & 2004 & 20,000 & 5,500 & 3,401 & 28,133 & 6,932 & 63,966 \\
\hline & 2005 & 26,115 & 6,762 & 3,452 & 30,287 & 7,596 & 74,212 \\
\hline & 2006 & 36,437 & 8,312 & 4,420 & 43,754 & 10,683 & 103,606 \\
\hline \multirow{3}{*}{$\begin{array}{l}\text { Education Spending } \\
\text { Against GDP }(2 / 1)\end{array}$} & 2004 & $0.87 \%$ & $0.24 \%$ & $0.15 \%$ & $1.22 \%$ & $0.30 \%$ & $2.78 \%$ \\
\hline & 2005 & $0.99 \%$ & $0.26 \%$ & $0.13 \%$ & $1.14 \%$ & $0.29 \%$ & $2.80 \%$ \\
\hline & 2006 & $1.20 \%$ & $0.27 \%$ & $0.15 \%$ & $1.44 \%$ & $0.35 \%$ & $3.41 \%$ \\
\hline \multirow{3}{*}{$\begin{array}{l}\text { Basic Education } \\
\text { Spending Estimate (3) }\end{array}$} & 2004 & 11,488 & 2,200 & 3,401 & 30,384 & 7,140 & 54,613 \\
\hline & 2005 & 15,663 & 2,467 & 3,452 & 32,104 & 7,748 & 61,434 \\
\hline & 2006 & 20,060 & 2,666 & 4,420 & 45,505 & 10,790 & 83,440 \\
\hline \multirow{3}{*}{$\begin{array}{l}\text { Basic Education } \\
\text { Spending Estimate } \\
\text { Against GDP }(3 / 1)\end{array}$} & 2004 & $0.50 \%$ & $0.10 \%$ & $0.15 \%$ & $1.32 \%$ & $0.31 \%$ & $2.38 \%$ \\
\hline & 2005 & $0.59 \%$ & $0.09 \%$ & $0.13 \%$ & $1.21 \%$ & $0.29 \%$ & $2.32 \%$ \\
\hline & & $0.66 \%$ & $0.09 \%$ & $0.15 \%$ & $1.50 \%$ & $0.35 \%$ & $2.74 \%$ \\
\hline
\end{tabular}

Source: Bappenas, Department of Finance, National Education Department, Department of Religious Affair and USAID (Including revised state budget supplementary funds)

Somehow the autonomous management of the education system was perceived as a relief and work at the same time. This was because for decades the regional 
government was "passive"; submissive and dependent upon the central government's complete control of the curriculum and assessment methods. The strict control of the curriculum and programs by the central government was not only dampening the creativity and intellectual mobility of teachers in regions, over time it also created ignorance and irresponsible attitudes of the teachers towards their professions and their students' education (Sindhunata, 2000; Sujanto, 2007). Sindhunata (2000) further confirms that if societies (ordinary and education community) at local and regional levels are still to have such a paradigm in education, decentralisation will only add deterioration to education in that region. A society which lacks interest and is not willing to take responsibility for the education and knowledge attainment of its children should not throw the blame to the government either. As Sindhunata (2000) stresses, if the local society avoids responsibility, they are merely "suicidal" in the autonomy of education (p. 13).

Aside from the need to cultivate society's sense of responsibility and ownership for their own education, the country's education community has to resolve several fundamental problems that have been in existence since the era of centralisation. Mulyasa (2008) indicates these factors as grounds for the lack of professionalism among teachers in Indonesia: (i) teachers who were not fully committed to their professions due to diversion from side-jobs for additional income; (ii) the sector has not had standardised qualifications for teachers; (iii) (probably) many private institutions produced unqualified or "half-made" teachers without considering their employment outputs; and (iv) teachers' lack of motivations for self-improvement due to lack of demand for them to perform research (like teachers abroad) (p. 10). Mulyasa (2008) considers these to contribute to the depletion of the country's national education.

The harm this process causes is not only serious but also long-term. During the transition process regional schools and institutions would experiment with designing curriculum and lesson programmes, and in the process compromising the quality of education students needed to have. Even if the school finally settled on a proper curriculum, the time used to arrive at the decision disadvantaged the present students and their preparations to further their education.

As mentioned above, these problems and concerns stemmed from years of improper and ineffective practices within the education system. Capacity building and 
welfare of teachers in Indonesia were not a priority of the Ministry of Education in the past. There were numerous educators in the country, especially in rural areas where resources were limited, who were under or not qualified to teach. Some held teaching diplomas, but it was not rare to find teachers who were only high school graduates. Moreover, teachers barely received regular training and updates on curriculum, which hampered their teaching skills and knowledge. Because of poor salaries, many teachers took on alternative work to supplement their income. Teachers in urban areas switched hats to be tutors or salespersons while those in rural areas went about tending their vegetable gardens. This lack of capacity and welfare support results in teachers' lack of focus and interest in their main occupation as educators. Ultimately, it was the children's learning opportunities that were being compromised and risked.

However, in spite of some setbacks, Indonesia indeed has made considerable progress in promoting child education. There is an increase in net of primary education enrolment from 88.7 to 93 per cent from 1992 to 2004, and similar increases in net of junior secondary education enrolment from 41 percent in 1992 to 65 per cent in 2004 (UNICEF Indonesia [a], 2007). These encouraging numbers can reflect the recovering stability of Indonesia's economy and political status, and they go concurrently with increasingly good results and improvements in overall literacy rate, health, infant and child immunisation intakes, infant mortality reduction, etc. (UNICEF [a], 2007). Working to accomplish the decree of President Instruction no. 5, 2006 on Illiteracy Elimination and Nine Years Compulsory Basic Education, the Indonesian government is hoping to increase elementary and junior secondary school participation rates and is confident of reaching 95 per cent by the end of 2008 (Ibrahim, 2007).

As part of the decentralisation and sector-wide approach, efforts to improve education access to children around the nation have been more programme-concentrated and area-targeted. National and international organisations working on the sector, specifically on primary education, have been advocating involvements and empowerment of local resources. Various joint efforts and programmes by different organisations are now providing regular technical trainings and support systems for teachers since they are now responsible for their schools' curriculum and lesson plans. Several international-based organisations have established regional offices in different parts of Indonesia in order to better execute, facilitate and monitor their programmes. 
Such an approach can ensure consistency of the overall goals achievement, especially the global endeavour of MDGs.

Presently the education sector in Indonesia is under two departments: the Ministry of Education (MoNE), which is responsible for overall education matters, and the Ministry of Religious Affairs (MoRA), which is in charge of the Islamic schools, Madrasah and Pesantren. The curriculum within the Islamic schools includes the national curriculum on top of the religious curriculum. Since Indonesia is the world's largest Muslim country, huge numbers of children enrols in Islamic schools. In addition to feeling confident with the moral guidance and religious orientation of the schools, many Islamic schools in rural areas are less expensive than state-run public schools, and provide a better alternative for parents of poor rural communities (SCUK Indonesia, 2006).

\section{Primary Schools in Rural Areas of Indonesia}

The discussion of primary schools in rural Indonesia is necessary due to a large population percentage residing in rural areas. Unlike the urban population, many rural people in Indonesia live in impoverished conditions and around inadequate basic facilities. Consequently, education becomes less of a priority, leading to the issue being increasingly ignored by the people and community at large.

The Eastern region is the part of Indonesia that is less developed and receives less attention from the central government. The region's economic development generally lags behind the other regions and the issue of basic education does not become a priority in the people's daily lives or the regional government. The country's high rate of primary school enrolment does not translate equally to all regions across the country. The numbers in more remote areas are lower, such as Papua with rate at 78.1 per cent as recent as 2006 (UN \& National Development Planning Agency, 2007). A figure derived from Indonesia MDGs Report (appendix 3) shows the provincial distribution of primary and junior high school new enrolment ratio (p. 27). The four provinces (Papua, West Papua, North Sulawesi, and Gorontalo) that have the lowest primary and junior secondary net enrolment ratios in 2006 are from the Eastern region (UN \& National Development Planning Agency, 2007). A paper by Ibrahim (2007) offers several explanations behind this trend: households' inability to spare resources to school children, children having to skip schools to help parents obtaining food, and the 
remoteness of villages and far distance to schools that become too arduous a challenge for children.

A distressing issue with such statistics is the fact that the majority of Indonesian children who are not in school are in district levels or below, and are even in remote and isolated areas. The Eastern region's ratio of primary school students to classrooms is 1:40, much higher than the national ratio of 1:29 (Ibrahim, 2007). Not only does this suggest overcrowding that can lead to poor quality education attainment by the students, it also indicates requirements for more classrooms or school facilities in order to maintain the high demand of students in the area. Failures to facilitate these needs may results in early drop out due to lack of quality results attained from schools.

Economic factors are often cited as the main reason for families failing to send their children to school since not all district government are able to offer free education. In fact, there are often other extra costs requested by schools aside from the school fees, making it extremely difficult for poor parents to keep up with the payments. Delay in school fee payments also leads to students feeling embarrassed by their households' poor financial conditions, a dilemma that often contributes to the children dropping out of school and deciding not to exhaust families' meagre resources.

Other contributing causes include the remoteness and geographical barriers of some areas that can make it difficult to establish schools and post teachers there. Children who live far away have to walk hours to reach the nearest schools. This is physically demanding for young children and they often end up exhausted and hungry from the travel and, thus, are unable to pay full attention and participate in the learning. In more remote islands and villages, there is simply no school presence in the area while transportation facilities like boats or accessible roads are very limited, posing a huge hurdle for children to access nearest schools on other islands or villages. Moreover, transportation connection between remote places depend very much on the season and weather (Ibrahim, 2007).

Parents may also feel unsure of letting their young children, especially girls, travel alone or in small groups passing through unsafe routes for fearing kidnapping of or harassment on their children. Considering the risks and sympathizing with their children physically-gruelling school trips, many parents only allow their children to attend 
schools on some days in a week, or even will not be reluctant to pull the children out of school at all. In addition to all these factors, however, it is undeniable that the teaching methods and system as well as the capacity training of teachers in Indonesia's education are crucial aspects that produce low quality of education, hence, attract less interest and commitment from poor and economically struggling households.

Isolation is also regarded as a major reason many teachers leave and teach in places closer to cities. In isolated areas like West Seram, Maluku or Loloda, some schools only have one teacher (Ibrahim, 2007). Rural areas and underprivileged districts offer less attractive economic prospects, mostly comprised of families and students of lower income and deprived groups. For teachers, getting placement in rural and remote areas is hardly a dream assignment. It is not as convenient as in urban areas and they will not have the chances of earning more money by city standards. And because fewer numbers of qualified teachers are willing to be assigned in rural areas, the ones who agree to teach in rural districts will mostly have poorer qualifications, training and capabilities. Furthermore, teachers who are reluctant and unhappy with their placements often do not care about their work and do not teach effectively. The children are the one who suffer the most from the process and system, unable to absorb quality learning and catch up with the curriculum. At the end, school and education come across as insignificant and worthless for poor students and families in rural areas.

Finally, there is a convincing connection linking unschooled poor children to unschooled urban street children. In cities where various sorts jobs available, legally and illegally, rural poor children can be seen working and wandering on streets at all hours of a day. Known as street children, they are vulnerable to physical, mental, and sexual harassment faced on streets, including risks of traffic hazards and health implications. Unschooled and uneducated street children have a tendency to continue to be poor and unskilled adults, contributing to the already huge poverty problems of cities around the country.

\section{Conclusion}

The quest for universal primary education has been extensive and occupied with transformations and adjustments. At present, the MDGs-led goal is making progress and influencing Indonesian's national and regional policy measures on education. The approach is necessary considering there are about two million children who are still 
without access to education. In 2007, the country's net enrolment rate of primary education is at a convincing rate of 94 per cent (UN \& National Development Planning Agency, 2007).

This encouraging figure, unfortunately, is not without weaknesses and concerns. The recent decentralisation policy that transforms education structure mechanism within the country has created some instability and dilemmas down at the regional level and below. A passive education system has suddenly been wakened up to run and manage on its own without proper preparation and resources. This autonomy transfer has almost jeopardised the education prospect of Indonesian children, in particular children of poor and in rural areas.

The discussion in this chapter should offer an introduction of the essence of this thesis, the case study. The issues and concerns examined here will be the stepping stones in analysing the core issue of the case study. What is the rural community think about the value of primary education in improving their situation? Is primary education necessary for the children? How has decentralisation, which encourages active community participation, impacts education profile for the community? 


\section{CHAPTER 4 METHODOLOGY}

The case studies for this research are derived from two villages in Indonesia's South Sulawesi province. This research commenced with the aim to explore the perspectives of the communities on the value of basic education in improving their current living conditions. Because of the small scale of the intended study qualitative methods of research were selected as the main way to acquire data. In addition to this approach, specific data and statistics from the selected schools have been obtained to complement the study. This chapter will introduce and further explain the case study, its locations and participants, and the methodology used to make-up this study. At the end, the research will also discuss outcomes of the research process as adjustments and compromises to challenges faced during research.

\section{Background and Settings of the Case Study}

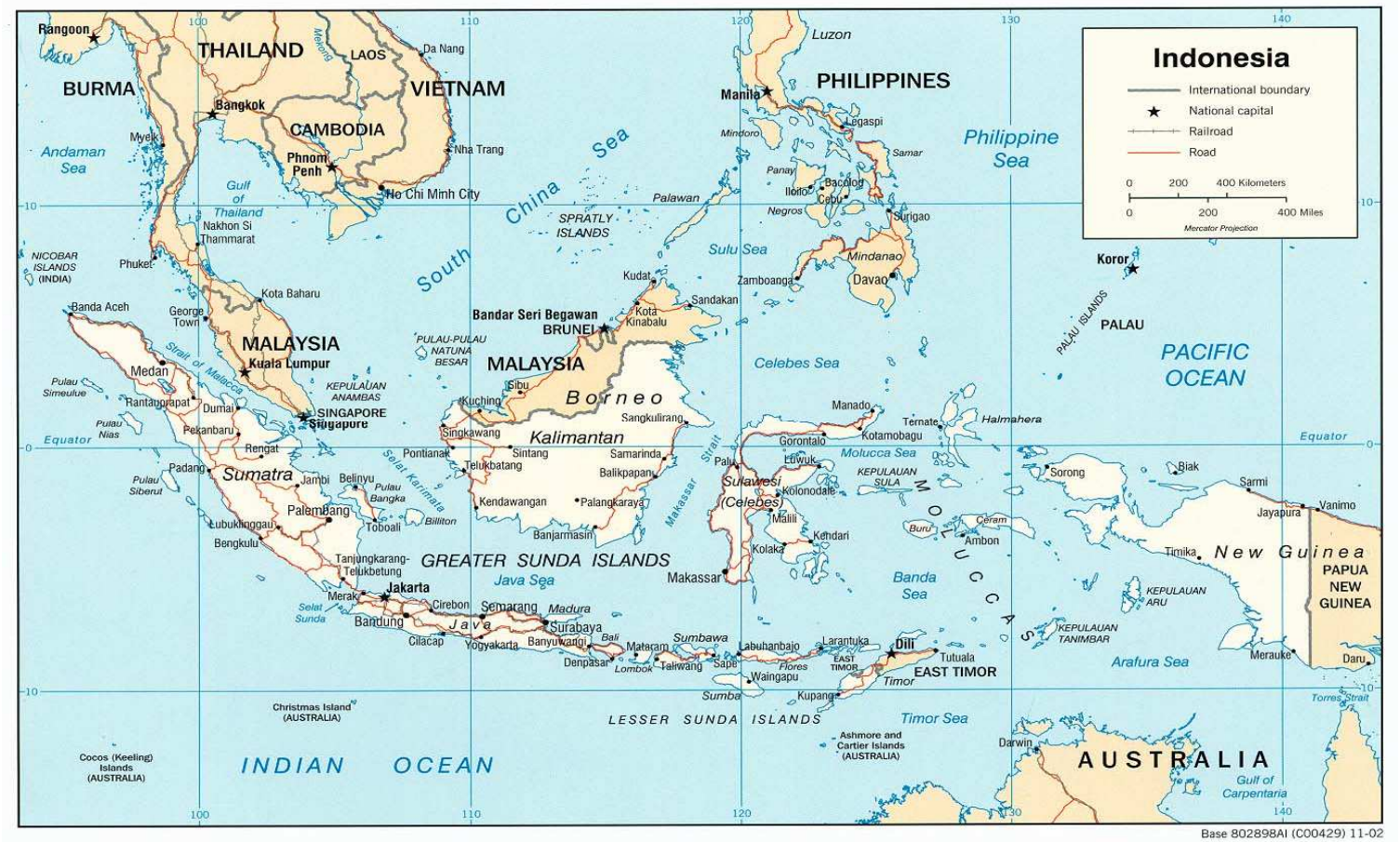

Figure 1: Map of Indonesia

Derived from Perry-Castañeda Library Map Collection at http://www.lib.utexas.edu/maps/middle_east_and_asia/indonesia_pol_2002.jpg

This research attempts to observe and analyse the rural community's perspectives on primary education. The research was carried out in two small villages at one of the five main islands of Indonesia, Sulawesi. 
The island of Sulawesi, historically called Celebes, is at the centre of the Indonesian archipelago and has a distinctive $\mathrm{K}$ shape. At present, the island is divided into six provinces, and a province is comprised of regencies, districts, villages, and subvillages. The province of South Sulawesi has several main native ethnic groups, namely Bugis, Makassar, Toraja, etc., all of which have their own customs and dialects. The majority of the people are devout Muslims although some Torajans and people in the surrounding areas are Christians. This province has 20 regencies and three special municipalities. Makassar is the province's capital, a city located at the southwestern coast of Sulawesi Island. Due to this strategic position, Makassar is historically renowned as a trading area and a transit port. One native ethnic group, the Bugis, has long been known as great seafarers and traders and for their expertise in traditional boat building. With total population of 1.25 million the city is the most populated and biggest city in the island. Recently, due to the city's expansion and fairly rapid infrastructure developments in addition to its favourable location, Makassar has been referred as the gateway to and the centre of Indonesia's eastern region.

The case study took place on two small sub-villages in Malino village, 80 kilometres east of Makassar. Malino is in the district of Tinggimoncong of Gowa regency, one of the major regencies in South Sulawesi's province. Malino is one of the main and more developed villages within the Tinggimoncong District. A two-hour drive from Makassar, Malino is mountainous and, thus, offers the comfort of fresh air, a much better climate than Makassar's warm and humid seaside environment. Both aspects of the location's historical background and tranquillity have brought Malino to be a comfortable getaway place for Makassar residents. At the centre of Malino modern houses have started to mushroom with surrounding roads paved and well maintained. This is because over the years many wealthy Makassar residents have shown interest in the area by purchasing lands and building better houses for holiday villas or to be rented out to vacationers.

Despite this influx of wealth, however, Malino overall is not well-developed or prosperous. Poverty is still widespread, local people are struggling to secure incomes, and education has not yet become a priority in the area. Ironically for the place which has been a renowned tourist site locally, vital infrastructures are only available at certain areas while at others they are still unreliable. 
The two sub-villages (or locally called $R W$ ) where the case study was concentrated are the rural community of Batu Lapisi Dalam (Inner Batu Lapisi) ${ }^{6}$ and Kampung Baru Tassa' ${ }^{\prime}{ }^{7}$. These two villages are indeed neighbours and many people in both areas are interrelated. The village's road is still rocky and it takes about one hour by foot to reach Malino's centre. The other village, Kampung Baru, is located across the mountain and most of its residents live along the hilly mountain. It is also a relatively smaller community. Because of its less strategic location, basic infrastructures and facilities are very scarce and the main road to reach Malino is through Batu Lapisi. It normally takes about one-and-a-half to two hours from Kampung Baru to Malino's centre. Most people travel by walking as motor transportation is rare. There is only one old and rusty car transporting both communities to and from Malino. Some used their motorcycles as taxis for extra income. The main occupation of people in both areas is farming (owners and contract workers). When the harvest period is over many engage in wage labouring in Makassar or other areas, as construction or seaport labourers, which are temporary jobs and can be low-paying.

\section{Methodology of the Case Study}

Knowing that time and budget were limited, the researcher tried to keep the study focused on two village case studies so that it could be well-managed and performed effectively.

Qualitative study, hence, is the most appropriate choice in this research because it was feasible and was expected to present more in depth results rather than attempt a large-scale representative quantitative survey. In addition, based on information from the local contact, most people in the communities were illiterate and not fluent in bahasa Indonesia. Using quantitative method of sending surveys to all households could fail because there would be a poor response obtained. And because the communities did not have regular wage-paying occupations and most income generated after harvests, it would be difficult to seek response on set income.

In accordance with the requirement from the Victoria University of Wellington's Human Ethics Committee, ethics approval needed to be obtained for any research

\footnotetext{
${ }^{6}$ Batu Lapisi Village has two sub-villages: Outer Batu Lapisi and Inner Batu Lapisi. However, the name Batu Lapisi will be used in this case as a reference to Inner Batu Lapisi.

${ }^{7}$ Hereafter referred to as Kampung Baru only
} 
including human participations before the research could commence. Because the very nature of this research is community's perspectives, people's participation was vital and could not be done without. In addition to this requirement, because this research also focused on children and students as underage individuals, a different form of ethics approval needed to be fulfilled for the research to commence.

Initially the researcher only planned to do the case study only on one village, Batu Lapisi. During several conversations with Tiya, a family friend who took upon the role of a local contact, research assistant and interpreter, she continuously talked about a more problematic and poverty stricken neighbouring village, Kampung Baru. It was then decided to include both villages in the study. The consideration was that by having the nearby villages in the study the data could show some trend of community's perspectives on education. Although the scale of the study is small, it perhaps could lead to overall perspectives of surrounding districts and areas.

Utilising qualitative method of research, from the beginning it was decided to categorise the participants into three groups: (1) community members (parents and local people); (2) children and students; and (3) authorities or practitioners in the education sector (teachers from the community, government officials or NGOs working in the field). Semi-structured interview questionnaires were applied when collecting data and all groups have different sets of questionnaires.

The semi-structured questionnaires were designed to ask specific questions on community perspectives on schools and their benefits for a family's financial security. To understand fully the background of their views, a few general questions were asked on parent's educational background, size of the family and age ranges of its members, and estimated income. The interview questions for children were designed to be more flexible depending on the ability of the individual child to understand and respond to the questions. The questionnaires would cover their interest on the education so far and what were their views about future employment and status of their villages. Lastly, the questionnaires for the authorities and education practitioners would be more comprehensive and technical about the issue, focusing more on policy and mission of the government's (and global) educational campaign. 
This case study's aim to analyse the perspectives of community on the importance of basic education was to purposely approach the communities first hand and document their thoughts. Therefore, research subject's participation is vital in collecting data and information. It was decided that the numbers of participants from both communities should be equal, and selections of the participants needed to be done in order to acquire balance and valuable data. Considering the time allowance and size of the research, 15 families from each community (total of 30 families) were interviewed, and for each family, a parent and a child participated. In total, there were 60 people interviewed from both communities.

Anticipating that some of the communities' members might not speak fluent bahasa Indonesia, the researcher prepared herself to improve her skills in speaking the region's dialect, Bugis. However, upon confirmation with the local contact, it was learned that the communities converse in their own dialect, Konjo, a sub-dialect of Bugis, which the researcher cannot speak nor understand. The researcher therefore solicited assistance from the local contact, Tiya, to accompany her and became an interpreter when conducting interviews with the communities so as not to miss any vital information. This was not an ideal situation as confidentiality could be breached and the researcher had to further brief the interpreter on the questionnaires and the issue of confidentiality of the interviewees.

Furthermore, Tiya took the role as a host and "guarantor" when the researcher entered the communities. The researcher is from South Sulawesi, but coming into another community and not speaking the local dialect could be equally be seen as a foreigner. The researcher had anticipated that without any local contact, it would be very difficult to establish connection with the people in the communities, let alone be able to interview and collect data. Also, a more traditional community might have had more acceptance toward a foreigner of completely an opposite race and appearance than someone coming from a nearby area who was unable to speak their language.

Early during the planning stage, the researcher did not plan to do a strict selection of the participants. However, because there was only limited number of participants that would be interviewed, selection was inevitable and necessary. The researcher sought to ensure that a wide range of the communities' household economic and educational backgrounds were represented in the spectrum. The criteria looked for 
was households who were considered poor and with children in primary school. Furthermore, anticipating that young children could be reluctant to talk to strangers and would not be able to respond to difficult questions, the researcher insisted on including only children who are in grades four to six (usually aged ten to thirteen). Due to the tendency of this research's nature to relate to out of school or uneducated children, the researcher also allowed several spaces for poor households whose children were not in school for any reason. This was intended to cover aspect of poor families' conditions and struggle in sending their children to schools.

In doing the selection, the researcher consulted with the research assistant to identify in a preliminary way households with primary school children and who were considered poor. Afterwards, the researcher went to consult with the headmasters of schools in both communities about the list. This provided a better list considering the headmasters should have much more comprehensive understanding on background of the students' families and offer inputs on who would make better participants.

Researching perspectives of the community on basic education cannot be effective if the surrounding education institutes are excluded. Thus, the researcher sought to interview representatives from each school, a headmaster and a teacher (total of two headmasters and two teachers). Including school authorities was expected to provide information and data that could explain further about the communities' value on education. An interesting aspect that could be drawn from this group was that schools and teachers are always perceived as the "authority" who regularly compel parents to send their children to school. On the other hand, most of these "authorities" are not only locals of the communities but also parents of students in the local schools. In fact, they are also parts of the community but sometimes have to take on the uncomfortable role. School authorities as locals are also good sources as they are the middlemen or a bridge between the community and higher level bureaucrats who regularly criticise the smaller areas' lack of motivation in supporting education. Because of their positions, and having higher education and knowledge, local school authorities can give more detailed explanations and descriptions of the situations and barriers faced by local parents; similarly, they can also provide more inclusive understandings of government's (education institution) objectives and missions in general and what challenges they face in realising these tasks. However, it is also important to note that because of their status 
as government employees, there might be a tendency for them to defend or conceal the weaknesses of the government.

In addition to interviewing local communities, the researcher aimed to obtain viewpoints and information from sources who are considered knowledgeable and working in the field. This included government officials or staff of NGOs or organisations (local or international) engaged in education. Getting more ample and comprehensive information from practitioners can definitely enhance and offer more critical viewpoints to the research. It is also valuable to obtain response of the research's question from individuals who regularly deal with the issue.

\section{Challenges of the Case Studies}

Several challenges occurred during data gathering and interviews with the communities. For example, the problem with this research's focus on poverty posed a challenge when trying to define a paradigm for poverty and those who qualified as poor. However, without an intention to demean and patronise the communities, the researcher and her local contact came to the conclusion that the majority of the community members lived in poverty or lacked economic security. It was arbitrary and subjective, but it would need larger-scale research, resources and higher degree of skills to be able to objectively and statistically determine the yardstick measurement for poverty and who falls into the criteria.

Setting benchmarks and criteria for data building arose as an issue in trying to obtain general data of the community's background and situation. For example, when trying to gauge the economic condition of households by enquiring about monthly income proved particularly problematic and such attempts did not really work. This is especially because most parents in the community have little or no education, meaning they lack skills to accurately calculate incomes and expenses. Also, the irregular nature of their cash incomes, usually spent immediately on necessities, made 'monthly income' a rather meaningless concept for many.

Of all the households interviewed, only one parent was able to confidently supply their monthly income. She was a teacher at the village primary school and received a monthly salary. Nevertheless, when providing the figures, she did not include the earnings from her family's paddy and crop production, which her husband managed. 
As a result, despite having provided correct income on her part, she left out the substantial amount of income the family had as a whole. Another woman from Batu Lapisi cited family's paddy harvest and crops as the source of family's income; however, she also ran a small convenience shop next to the family's living room. Her husband was regularly called in to operate his motorcycle as taxi for the community to get to places. He also got commissions for collecting electricity bills within the community and paying them at electricity office in Malino. Because these extra incomes came irregularly and at small rates, they were not highly regarded as reliable earnings, which as a result, are left out from the women's calculation when supplied her household's income.

This trend occurred often throughout the general households' data gathering. Some men from both communities worked as keepers for villas owned by rich Makassar residents, while women would take upon the tasks of cleaning the villas and the gardens for a monthly extra income. After the harvest period, some men travel to cities to work as manual labours or in construction, which roughly pay about Rp. 25,000 to Rp. 50,000 (US\$ 2.5 to 5) a day. All of these are indeed earnings, however, as with the other household, lack of mathematical skills and income regularity result in inaccurate estimations. Nearly all interviewed parents provided answers with rough estimations of yearly earnings (it was almost impossible to acquire a monthly-base income estimation), and of which they often calculated mistakenly. It was either too large by their standard or worryingly low. However, there was no intention to distrust or demean their statements, but it reflected parents' lack of rudimentary arithmetic skill or the irregular nature of meagre cash incomes.

Aside from the households' economic status that needed to be selected and considered, the issue of schoolchildren sometimes posed confusion. Many families did send their children to primary schools; the question was how long did they stay in school and what constitutes "sufficient" education in the eye of the parents and communities. Some children only stayed for the first few levels, while others did not continue to junior high school after graduating from elementary schools. Thus, it was necessary for the parent to clarify children who went to schools, those who did not and their current status of schooling. 
Classification of parents' educational status also required more time and several reviews before completion. Many parents claimed they had primary schooling when they were younger. However, they were still illiterate or struggled with literacy skills. Some said they were literate but they actually had acquired the skills recently through the literacy adult program (Paket A), not from their past educational background. Other parents stated that they completed primary schooling but did not regard themselves as drop outs when they did not continue to junior high school.

Similar confusion had to be clarified when the researcher tried to gather data on the number of children a family had. Multiple marriages were not uncommon, meaning people (men and women) tended to have a number of children with different partners. However, because some of these children did not live with the interviewed parents, occasionally they were excluded them from the counting.

\section{Conclusion}

The case study was conducted at two neighbouring sub-villages in the district of Malino. Like the majority of Indonesia's rural population, their main source of income was from paddy and vegetable crop production. Education background of the community had not developed much for the last several decades. And because the communities were small and the goal of the research concentrated on their perspectives, qualitative methods, were chosen in obtaining data and necessary information.

As always occurs in field research, challenges and modifications were two unavoidable issues faced during data collection. Fortunately, such adjustments can prove to be essential elements in the research and in next steps when conducting analysis of the community's perspective and the influence of their cultures on the subject. Ultimately, this was a research about the community, their views, their lives, and their futures. 


\section{CHAPTER 5 \\ RURAL COMMUNITIES AND THEIR VIEWS ON THE IMPORTANCE OF PRIMARY EDUCATION}

The district of Malino is fertile and has favourable soils and climate for agriculture. It is blessed with picturesque scenery and has long been a historical tourism site for the region. Unfortunately, these great assets do not translate to prosperity for Malino locals. Essential infrastructure and facilities are lacking in many areas, essentials that are a prerequisite to enhance local capacity and productivity. Stable incomes are rare and numbers of children leaving schools to help their families survive are high.

School facilities in Malino do exist. The question is whether they serve the purpose of providing education to the children and benefiting them and their families. Obviously schooling is not a priority when a family constantly struggles to secure even basic provisions, especially since primary education is not free in Indonesia. Rural residents see their future as survivors of bad harvests or low-class migrants who try their luck in the modern urban world.

This chapter aims to provide background pictures and situations of the two villages selected for the case study. It will continue with analysis on the communities' perspectives on the value of primary education, by parents and children, and how customs and conditions influence their views.

\section{Overview of Batu Lapisi and Kampung Baru}

Inner Batu Lapisi and Kampung Baru are two neighbouring sub-villages in the district of Malino. They are located on the outskirts of Malino's centre but the roads to access the villages are not paved. The rocky pathways are between ravines and steep dells, which when raining often sends down loose rocks and small trees. From the main road it takes half an hour by foot to reach Inner Batu Lapisi, and the main access to Kampung Baru is through the centre of Inner Batu Lapisi or through the nearby tea plantation.

Batu Lapisi is better off in terms of economic and land development. A water supply runs from a reliable spring water source and periodic electricity from Malino's centre provides enough power at night. Many households are able to enjoy 
entertainment from TV programmes and radio, introducing the urban lifestyle and visions and taunting them with new-age gadgets, such as mobile phones or gas stoves.

Kampung Baru literally means "New Village" and directly implies the later establishment of the village. However "new" does not always mean better. Compared to Batu Lapisi next door, Kampung Baru lacks necessary infrastructure, is more rugged, and the landscape is tougher to explore and access. The people and their living conditions are indeed more destitute.

\section{Source of Living}

The main sources of livelihood and income of both villages are rice production, harvested once or twice a year, and vegetable crops in smaller plots in between the paddy cultivation. Each household owns different sized land plot, depending on the share of inheritance and household economic status. The custom of rice and crops productions was a classic business concept: land owners (those who are fairly better off economically) contract workers (poorer farmers) as labours to help at the field from the planting through the harvesting. A system of yield shares has been customarily established and maintained by their predecessors. Land owners compensate the works of buruh tani (farm labourers) with an agreed percentage of the overall yield production after harvest.

One of the most important elements of the research is the data on households' income to indicate their economic status. Because rice production is the main livelihood of both villages, it is necessary to understand the calculation of its production and selling price in order to identify the income figures. The customary yardstick used to estimate households' income is by counting the total numbers of shared basse or bundles they obtained from a harvest. One bundle produces about 10 litres of paddy (uncooked rice). The common practice is to subtract three bundles in return for milling and transportation costs. The remaining seven bundles or 70 litres of paddy is valued at around Rp. 245,000 or about US\$ 25 (1 litre sells about Rp. 3,500 = US 0.37 cents). ${ }^{8}$

For a very poor family in the communities, the common paddy earnings can be as little as 100 litres per year or about US\$ 37. A majority of families in the

\footnotetext{
${ }^{8} 1 \mathrm{US} \$=$ Rp. 9,500 (as of May 2008)
} 
communities produced about 500 litres of paddy or more a year or about US\$185. These figures excluded other crop production and extra incomes attained by several families.

Normally households keep a certain amount of the rice shares for their own consumption and sell some for cash. When not working on the rice fields, farmers (and their families) tend their plots of vegetable crops. The people's working days are not routine. The communities rely on "good (or lucky) days" to go out and work either on rice fields or crop gardens. Three times a week on "market days", particularly on Sunday where Makassar residents flocked Malino, farmers bring in their week's yield of vegetable crop to sell at the market in central Malino. Any cash obtained are used to buy daily necessities, like soap, sugar, coffee, etc., or alternative foods (fishes, tofu, beans, etc). In other words, cash gained from the crops sales are frequently used up and there is barely any excess to be saved up for emergency or put aside for savings.

However it was considerably difficult and complicated to obtain a proper, or even an accurate, measurement of household's income. There are several factors to this matter. Households do not cash in their paddy after harvest share allocations; the paddy is kept in a lumbung (stock house) and is sold at times when cash is needed, at which times the selling prices frequently fluctuated. When investing in new paddy or crop seedlings, farmers often have little knowledge whether they gained profits, or losses, for that matter. As mentioned earlier, cash gained from crop sales was more than often exhausted for buying other items at the market. With little education and knowledge of cash handling, most people in both villages were unable to accurately respond when asked correctly about their households' incomes or their estimation.

\section{Customs and Family}

Similar to other regions, the size of a household was always relative within the communities. Normally a family would have about three to five children, and only a few couples had up to ten children. The number of children per couple had definitely decreased over the years due to either the increasingly popular use of birth control or, sadly, incidences of child mortality in the area.

Some families would have in-laws living with them. However, because the community in each village was small and people were living practically next door to their extensive families, it was not rare to find older people living on their own or 
accompanied by a young grandchild. One grandmother lived next door to her daughter and she was practically at her daughter's house all day and only went back when it was time to sleep. She ate her meals with her daughter's family, worked together in their nearby vegetable gardens, watched TV with them, and so on.

Because of this interrelatedness within the communities, the family bond and support were strong. When a family has a member who has fallen ill, their relatives and neighbours would regularly accompany them and help sort out the family's daily errands, such as providing food, tending to small children, or helping with the washing. In addition, relatives and neighbours regularly shared with each other their produce and had meals together. When families ran out of food supplies, they simply asked for a bunch of spinach and potatoes at their neighbours' backyard. Thus, despite their meagre incomes and sometimes difficult living conditions, people in the community were very confidence about their livelihood sustainability and worry less about future resources.

Multiple marriages, by both men and women, young or old, were not rare within the communities. This was complemented by the high rate of divorces, the undeniable aspect of multiple marriages. Several marriages and divorces could happen throughout someone's life span, from the age of 14 to 60 . The root of this custom could be associated to the sensitive issues of the customary practice of polygamy to show prosperity and the law in Islam allowing multiple marriages. Uniquely, because the community was small and people were already interrelated, multiple marriages would often reinforce closer familial ties among the community members. There were cases of a woman who is married to her third step-mother's younger brother or a girl who went to school with her cousin, which is also her grandfather's youngest child from his fourth wife.

This mention of multiple marriages is important because of the means used and the consequences. When providing dowry (in form of money, cattle, and rice) to a bride's family, too often the groom's family have to sacrifice their inherited lands and cattle or, worse, put themselves in debt to uphold their pride. There is a fixed amount of dowry that has become a norm within the community; and the amount has grown over the years, especially with the rising prices of basic food and cattle, two of the most vital substances required in any community wedding. At present, the dowry for a young teenager (and supposedly a virgin) is about Rp. 15 millions or US\$1500. This amount 
is supposedly substitute for "milk money", a symbolic referring to all the cost incurred to raise a baby girl to the time she is married off. A lesser amount will be very reluctantly accepted and can be considered a humiliation. A family whose daughter has higher education, such as a diploma or undergraduate degree, can request a higher amount. It goes even higher if she is to have a higher degree or is a civil servant.

The dowry money is to be used for days of lavish wedding parties. The bride's family is expected to make full use of the money to cater the celebrations. The custom requires for hundreds of litres of rice, a few cows, dozens of chickens, and an orchestra band to intensify the pride of both families. The standard yearly income of a family in Batu Lapisi was roughly Rp. 2 millions or US\$210. Salvaging family pride with a US\$ 1500 party often resulted in families not only losing their capital resources, but also investing in life-long debt. It is a rather disturbing fact that newly weds are frequently faced with a grave financial predicament as soon as their wedding celebrations end.

As in other cultures child marriages are normal and could be a source of family revenue. Without the intention of humiliating this custom, this practice however was one of the main barriers for children, especially girls, to attain sufficient education and have opportunities to expand their skills. A thirteen or fourteen-year old girl who was starting to adjust to a new phase of adulthood suddenly has to accept the role of a wife and mother. Uneducated teenage mothers generally have less knowledge of how to provide sufficient health care to their children, which can result in family's overall poor health.

Moreover, remarrying means having more children or family members to support. When households continue to struggle to meet basic necessities of their members due to lack of resources and income, chances that education and health became priorities were unlikely. Children inevitably had to join their parents in the labour force to sustain their families instead of going to school. They would grow up unskilled, uneducated, and stay in the vicious cycle of poverty. They are shutting the door of opportunity for better conditions. Customary practices such these undeniably contribute to the persistent poverty continuously faced by the community. 


\section{Education background and Its Influence on the Community Life and Attitude}

Generally, education has a positive influence within the communities. An essential aspect observed from the interviews, conversations and meals together with the community confirmed the earlier supposition of the influence education has on the community. In addition to strong customary social hierarchy and wealth, having an education bolstered people's self-confidence and their pride within the community. This could obviously be seen during research interviews and travel observations around the community. After knowing that the research activity had been granted permission, people in the villages were proud to take part in it, especially as they understood that only several families with school children would be selected.

During the many visits to the families in the community, considerable distinctions could be seen between families with educated and uneducated parents. Several uneducated parents, who occasionally referred to themselves as stupid, were more apprehensive and unwilling to participate in the research. A lot more time was required to explain the research, the interview process, and their rights (and total privilege to withdraw from the research without any consequences). The "ad hoc instruction" letter from the head of education regional office did not seem to give them any assurance, let alone research permission letter from the university Ethics Committee, consent form, and participant's information sheet. Even an "unwritten" assurance, that their participations would not harm them, from both the interpreter (a community member) and the researcher could not easily relieve them of their fear.

However, acceptance came more after an interviewed conducted with the school teacher, Haysia, at her house. Knowing that the "educated and successful" person had acknowledged and participated in the research made the interviewee recruitment easier. In Batu Lapisi village, some of the parents' interviews were conducted at Haysia's house. This was a valuable facilitation of the teacher because the trust and assurance she committed to this research. Instead of visiting the families' houses and interview them there, she called them to her house, briefed them about the research in the local dialect Konjo. During interviews, she often sat across the room, and although this would breach the confidentiality issue, interviewed parents seemed more assured and willing to participate. 
As mentioned above, parents who had junior high education or higher understood the research and interview process faster and were less nervous when interviewed. They also signed the consent form without concerns. Signing paper was a considerable commitment it was often associated with very legal and formal matters and might cause significant anxiety for the rural people who were used to the norm of unwritten trust.

Parents with less education background were normally more anxious about the interviews. Only a number of them signed the consent form, while the rest were very apprehensive about the consequences and chose to skip it. Interviews in Kampung Baru village, similar recruiting and conducting process as in Batu Lapisi were used. Instead of going around recruiting them, several parents came to one family's house and gathered there and waited for their turn. It was somehow comforting for them, especially as majority of the parents in the village had no education and were very poor, to see the process beforehand and make their decision. Despite having been warned about the confidentiality issue, a number of participants chose to be interviewed with their families and neighbours around. Their suspicious were obvious and they needed constant assurance that their participation would not backfire on or harm them.

Data from the interviews provided a spectrum of education attainment by the parents. Several parents never entered school at all and are illiterate; several were in school for a few years and dropped out; a few finished primary education and even continued to junior high school; and only one had a teaching diploma. Uniquely, no parents from the interview groups had a high school education.

Research data and observations showed that parents who had a few years of or completed primary education could also be illiterate or still struggled with the rudimentary skills of reading and writing. A few parents who were bold enough to claim that they had forgotten them or simply never acquired the skills from school until they left. Some parents who never got any schooling professed that they had taken upon the weekly Literacy Program for adults (Sekolah Sanggar or Paket A), a free government program operated jointly by school teachers and district officers. The program has so far helped them with the literacy skills and, for these parents, joining the program was like to redeem their lost opportunities and being literate enhanced their knowledge and skills and, most importantly, their self-esteem that had long been pushed down. 
Thus, the grouping of uneducated and educated parents posed a few dilemmas. Some parents thought that having had a few years of schooling automatically classified them as educated, despite the fact that they struggled with literacy and did not complete primary school at the very least. Ultimately the categorisation of parents' education was done by simply following parents' prior education attainments and their literacy status. Parents who had several years or completed primary school were categorised as educated while those who did not have any primary education were uneducated.

Similar issues arose when it came to categorising children's schooling status. Categorising children who were in school was straightforward. It was the categorising of children who had dropped out of school and did not continue further that posed difficulties. As previously noted, people in the communities mainly associated education to primary schooling only. When enquired of their children's education status, many parents did refer to children who did not finish primary school as drop outs but did not include children who completed primary school and did not continue to junior high school. As long as they graduated from primary schooling, the next level seemed to be considered as extra education.

The majority of the parents interviewed were either uneducated or primary drop outs and most of them were illiterate or had recently acquired literacy skills. During interviews conducted in bahasa Indonesia, only a handful of parents could understand and respond well in this language used in schools. More frequently the interview questions had to be simplified and asked in bahasa Indonesia and Konjo dialect interchangeably. And, as expected, there were several instances where interpreters had to facilitate the process to get the questions and responses understood by both the researcher and interviewees.

A general impression that could be derived from the interview process was the higher the level of parents' education, the more likely they would master bahasa Indonesia and convey their opinions well. When asked the questions or invited to give more details, educated parents comprehended the questions faster and easier without further simplification whereas with the uneducated parents the questions were frequently simplified, shortened, and translated. Interestingly, there were several 
occasions when even the interpreter struggled to get the message across or obtained related responses.

Parents who had education (based on the categorisation established above) were more confident and spoke more firmly during interviews. They would proudly exhibit their ability in speaking bahasa Indonesia and were sometimes reluctant to be helped by the interpreter. And because they generally had little trouble understanding explanations about the research, interview process, and their rights, they were more confident with their answers and the researcher could seek further details.

Uneducated and illiterate parents usually were more submissive and reserved during interviews. Some would try speaking bahasa Indonesia at the beginning of the interview but as soon as they struggled understanding or answering, they immediately resorted to the interpreter for assistance for the rest of the conversations. Because of their timidity, interviews were occasionally cut short in order to relieve them of their discomfort. There were instances of the researcher intentionally whispering and lowering her voice for fear the interview process would come across as patronising or overwhelming for the parents with many people watching the interviews.

This general idea of parents' educational level and their language ability was important to note as it inevitably influenced parents' decisions on their children's education. As could be seen from the Community Data in appendix 1, children with parents who had primary education or higher children stayed longer in schools than children with parents who had less education.

In Batu Lapisi, although there was little discrepancy in the numbers of drop out children from households with educated or uneducated parents, the number was higher among children with parents who had no education or did not complete primary education. Similar trends could be seen in Kampung Baru where all but one parent who participated had no or did not complete primary education. The exception was one parent who completed primary school but did not continue further. Furthermore, as research information on the community in appendix 1 indicates, families in Kampung Baru in fact had more children than parents in Batu Lapisi, corroborating the pervasive notion that uneducated parents tended to have more children, and thus, building higher levels of poverty. 


\section{Community's Perception on the Value of Education}

Although the focus of this thesis was specifically on primary school, the community indeed strongly related schooling or education commonly to Sekolah Dasar (SD) or primary school. This could be observed during interviews when parents continuously referred to education as primary schooling only, presumably because primary education was the first conventional level of schooling.

A national policy required a pre-school certificate before a child can enrol in a primary school. At present, the only and newly established kindergarten in Batu Lapisi was still unable to recruit all children of both villages it served despite its very modest fee. Donated by a doctor from Makassar whose villa was right in front of the pre-school, it only asked for a monthly contribution in form of a litre of rice per month, converting to US 37c, and of which was never cited as the reason for parents' objection. However, just as the school was new, parents were still alienated with the concept of sending a four or five year old to a school, particularly when primary education was still perceived as optional. Letting a little child walk a long distance for an incomprehensive purpose was a major reason for the low attendance in the kindergarten. Some children living in the village would take about 20 to 30 minutes walk while children living in Kampung Baru would need about one hour or more to reach the school.

"To be smart" was the most common answer interviewed parents gave when asked about the meaning and purpose of primary education. Other answers were more general, citing the classic nationalistic response of "to be a valuable and useful individual for the country" or being able to read and write so that children "can help parents shop for the correct items." Just a handful of parents related education to higher education attainment and future employment. These responses could somehow indicate parents' lack of understanding about the goal of educating their children or the longterm positive effects it had on children's lives.

Nearly all parents thought that primary school was education enough for their children "as long as they can read and write their own names." Attending primary school was also a privilege and a status booster for the poor as not able to send children to school was loosely associated with stupidity or poverty. Thus, there was an impression that many of these parents did not quite comprehend the motive of schooling 
their children but merely followed a trend in the community and the practice of six years schooling.

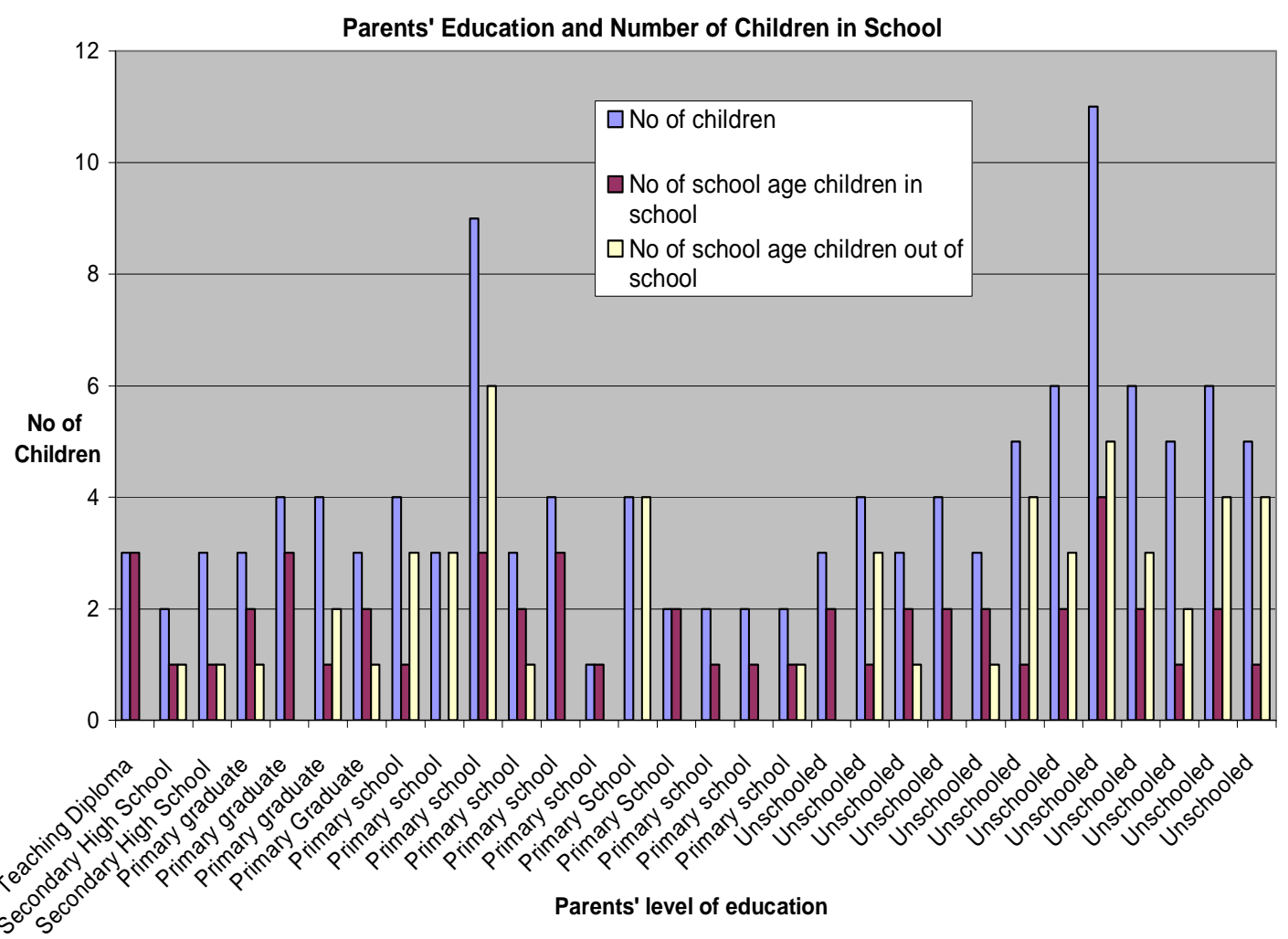

Figure 2: Level of parents' education in relation to number of their children in school and out of school (total of 30 parents)

Parents' level of education is a detrimental factor in determining their children's education and its continuation. In this research, 30 parents interviewed in the communities had varied education background. Some parents never had access at all, some received primary education (drop outs or graduates) and only one had a diploma. This graph attempts to draw a connection between the levels of parents' education to the number of children they have and number of children in school or out of school. First, it shows that parents who had no education (the group at the far right side) generally had more children than parents with some education or higher (the group at the left side), which reinforces the view that to be able to control population young girls should be educated and stay in school longer.

Although it does not show great discrepancy, parents' level of education determines the duration of schooling their children received. Parents with primary education of higher had relatively fewer school-age children who were not in school 
than parents with no education. The implication of this may point to the fact that uneducated parents might be less well-off economically and, thus, were not able to provide enough education for their children or maintain all of them in school during school age years. On the other hand, the lack of difference in the trend between parents with primary education and parents with no education is somehow alarming. It may suggest that primary education may not be that influential and beneficial in improving its receiver's future economic prospects. This pattern can be a barrier in advocating basic education in rural areas where parents or adults who have previously received primary education still live in poverty and do not see how it can assist their lives. As a result, these parents may not be as enthusiastic and encouraging in sending their children to school or maintaining them throughout the school age years.

Most parents had positive notions about primary education. However, it gave the impression that their association of schooling was limited to this level only. When parents were asked about the level of education they hope their children could attain, most of them pointed to junior high level as the ideal level. Some mentioned high school or teaching college as the level of education they hope their children would reach. There were similar numbers of parents, however, who thought primary schooling should provide sufficient education for their children's future.

The assumption was that many of the parents perceived school as the place which could provide a child with the skill of reading, writing, and simple arithmetic. Perhaps past experiences of other people in the family or community referred to this fact, that these rudimentary skills were all they could obtain out of six years of schooling. And because many people in the rural areas were poor and could hardly afford further education higher than primary education, this was all the impression they had about education and going to school.

This belief was not without substance. While the standard of education in the city was always higher and stricter, primary schools in rural areas had a more flexible approach. Some of the key rationales will be examined below in Chapter 6, but in actuality, it is not uncommon to find a sixth grader (commonly aged 12 years), who is in the last level of primary school, that is still struggling to read and write. Thus, how could a sixth grader in reality fathom science and other more complex subjects when she had not even mastered reading? How could a student in this level be prepared for a 
junior high education if her basic learning skills were far below the standard? It was no surprise that many of the primary school children interviewed without hesitation stated their reluctance to continue to junior high school and pointed out to "difficulty" as the number one reason. This basis should not be acceptable by any parent of pupils, or for the education criterion.

One parent in Batu Lapisi hoped her son would become a teacher or doctor. When asked about her idea of highest education for her son, her reply was 'high school'. Her explanation was that finishing high school would be enough of a qualification for her son to take job as a school teacher. Even though there was nothing wrong with her aspiration, the fact that she thought a high school graduate could be eligible to be a (civil servant appointed) teacher could be a general indication of the community's lack of knowledge in the education system ${ }^{9}$.

One of the main interview questions asked the parents and their children about their aspirations for their children (and children for themselves). There was discrepancy of responses from parents in both communities, despite the fact that parents in Batu Lapisi had slightly higher education attainments. Figure 4 below is a chart showing the distribution of choices of aspirations by parents. ${ }^{10}$ Teacher, doctor, and solider (for sons) were the main choices of the parents. Unsurprisingly, there were several parents who perceived working in city as an improvement for their children, regardless of the type of work. Work in the city involves, as cited, work as housemaids, shop attendants, or construction labours. It was stressed that these forms of employment, which were in high demand in nearby Makassar city and would generate "cash" income and indicate success for the parents. Children had similar ideas of their future aspirations as their parents, which can be seen in the following chart (figure 5): teacher, soldier, doctor, and manual labour, conforming a few parents' simple notion of aspiration.

\footnotetext{
${ }^{9}$ It was presumed that in the past there were teachers holding only high school qualifications, but this practice no longer continues.

${ }^{10}$ Aspiration choices were supplied by parents (and children) themselves. A few parents and children did not supply any response.
} 
Figure 3: Parents' aspirations for their children $(n=29)$

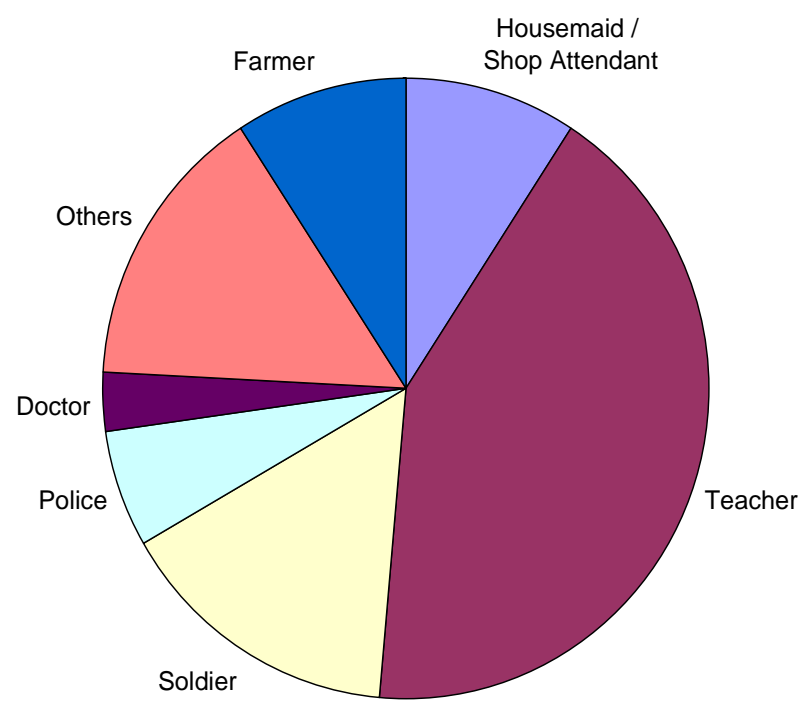

Figure 4: Children's aspiration for themselves $(n=27)$

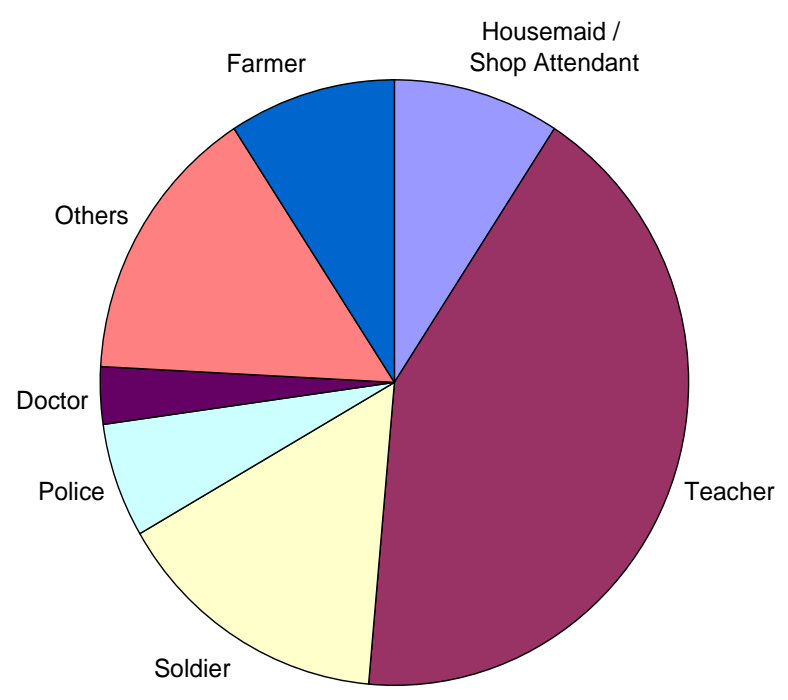

These two charts clearly illustrate similarity of views and ideas between parents and children, which can imply that children have a tendency to think like their parents and become what their parents believe they can be. This can be a positive argument when looking at the ambitions and ideas above. In this case, however, it is speculation whether all these parents truly believed their children' capabilities to take up the roles and positions. This supposition arrives when looking at responses parents gave during interviews regarding the highest level of education they thought would be enough for their children. As pointed out earlier and can be seen in appendix 1, the ranges of answers were mostly from primary school to high school levels. Logically, especially in today's highly competitive workforce and higher standards of competencies, it needs more than high school competency to achieve some of these aspirations. In other words, 
local communities may not be aware of this aspect or, as mentioned, do not genuinely consider their children to reach these targets.

Of all the children asked about their future aspirations, only one gave an unusual desire. A girl desired to become a singer in KDI (Konser Dangdut Indonesia), a television programme involving a singing competition programme featuring the Dangdut music genre. Dangdut was well-known among and somehow catered towards the country's middle and low-income group, and is especially popular among rural populations. This programme was highly influenced by and was created after a more widely popular Indonesian Idol, Akademi Fantasi Indonesia (AFI), and Mamma Mia singing competition TV programmes. Clearly both Indonesian Idol and Akademi Fantasi Indonesia were duplicates of Western programmes.

$K D I$ itself was popular for its overdramatic and sensational contestants and panels of jury. Many of the contestants claimed to be regular citizens recruited for their talents and other considerations. They came from all walks of life and were recruited from districts and villages throughout the country, a strategy that certainly appealed to rural populations. On the show, contestants would be given total make-over, with urbanstyle costumes and hairdos. Families, relatives, and friends would be invited to the programme to display their support for their contestants, frequently shown on TV when broadcasted nationally.

The girl who aspired to be a KDI singer was very confident that she would one day appear on the programme. She mentioned her regular singing practices at home and her willingness to take any work as long as it was in the city because being in the city opened her greater chance to be recruited by the show. Such determination was absent during interviews with other children, and even parents.

Another key question that was needed to be established in order to verify the objective of this research was the importance and returns (primary) education could bring to children's future. While some were unable to answer, many parents, despite their educational backgrounds and the status of their children's schooling (in school, drop out or unschooled) did believe that primary education, and education in general, was beneficial and important for the future of their children. They often related their 
current poor conditions to their lack of education and wished their children could have better lives through higher education attainment.

Ahob from Batu Lapisi, for example, dropped out of school in the third grade and all his five children did not finish primary schooling. He regretted the conditions and stated that "primary education was the key to prosperity and without it, one could not go further and there was no way out (of poverty)." He saw many cases of people who further their schoolings and could go anywhere with their education, whereas for him, he "only ends up on the farm." Ramu, from the same village, agreed that poor parents needed to try harder in supporting their children's education so they could secure better living conditions for themselves and their families. A primary drop out himself, he struggled to support his oldest son graduate from high school who now worked in garage shop and earned his own income. Through his son's situation, bapak Umar believed that education equipped someone with skills and ability to be knowledgeable with different issues, like business of selling and trading.

Although primary education generally provided learning only at the basic level, it was the fundamental stage in the education ladder. Parents recognised the positive effects primary education had on their children's mindset, skills and, not less important, their level of contribution to households. Schooled children were helpful to their illiterate parents when tending affairs that required literacy skills. At the very least, parents admitted, the children could go shopping and return with the right items because they were able to read and count properly. Today many children wanted to continue to junior high school or even higher because the multiplying advantages they saw from relatives or other community members who had higher education, such as the local teachers at their schools. Many parents revealed that with at least primary education, their children would not be teased as stupid and would not be easily tricked by others.

Overall, the majority of the parents had accepted the relentless campaign of primary education by the government. Parents acknowledged the potential benefits education, or primary education specifically, could contribute to the improvement of their conditions. Many had realised that the mere "paper" key, in forms of diploma, could have an enormous impact on their children's future, like having wage-earning jobs. 
The level of physical activities of a job seemed to have strong influence on parents' and children's notions on better future. Parents from very low income groups who had always been working as farm labourers regularly associated village work as gruelling and tormenting. They complained that because of their lack of education, they would "continue breaking their backs in the farm through their old age." They pointed to the education and skills deficiencies as the reasons that there was hope for them to survive their current conditions. Working in the farm would only generate food, they claimed, but not cash income. The problem was in today's era everything had its price and was cash-related, even basic food supplies and daily necessities. Being short of cash meant inability to secure these items. On the other hand, the urban economy and dynamics evolved around cash, was the reason why rural people insisted on migrating to cities and looked up to urban residents as successful.

Parents', and children's, desires of being a teacher, doctor, or a shop attendant in the city believed at the very least these occupations were without labouring under the scorching sun and arduous activities. Rural children, whose normal chores included working in the paddy fields, fetching grasses for cows, rearing younger siblings, definitely found more appealing in the cleaner, less strenuous, status booster occupations. For parents, working as a teacher or department store employee would certainly ensure secure monthly cash income.

Parents and children participated in the research had mixed notions about moving away from the village and living in a city. Some parents wanted their children to stay in the village, either for school or work, so they could be near and help parents with various chores. Other parents would allow their children to move to the city for both purposes. The Community Data table in appendix 1 reveals a trend that can correlate parents' level of education and their views on (their children) working in cities. From the table it can be concluded that parents with higher level of education (as in Batu Lapisi) were more accepting of (if not endorsing) their children living and working in cities despite some sacrifices they would have to bear. Parents who had little education (as in Kampung Baru) were more reluctant to the idea. A few parents who insisted their children stay in the village consider tending cows and working on rice fields should be enough, or better, for their children' future lives. Parents who supported their children living, studying and working in cities believed that schools in the city would provide better learning facilities and higher education for the children, thus, 
offering more chances for children to attain higher qualifications and better employment. The city, claimed many parents, was the place to obtain cash. If their children were to stay in the village, they might as well expect to be in the fields the rest of their lives. And so these perspectives were embedded in children's conception of village lives. Living in the village, other than to be near parents, was about being trapped in poverty, a condition they had long gotten accustomed to but yearned to escape from. From the same table in appendix 1, children's responses were similar with the parents'. Children with higher level of education goals aimed to live and work in cities, while those with no desire of continuing or reach higher education preferred to stay in the village.

\section{Barriers to Children Education}

Child marriage is an intricate yet difficult issue to avoid when talking about education continuation in the traditional rural community. In addition to previous discussion on issues of marriages in the communities, many young girls in Malino get married by 15 years old (and occasionally fresh primary school graduates, aged 12 or 13). It was in the "dowry" offer, as they say, whether the price is good or not. This definitely seems degrading, but many poor families were happy enough to know their daughter could generate decent a dowry before she grows too old and that they can relinquish their responsibilities of their daughters' lives. The implication for this trend is that many young girls who are approaching the end of primary school do not seem to have the incentive to continue schooling, as they know they are just waiting for the offer to get married. After all it seems that the sooner one gets married, the better status it gives to her family.

While this research was carried out, the community was celebrating a wedding. The bride was 12 years old and had just completed her primary school, and the groom was a 21 year old who tended cows for a living. This is an example of the common future young girls in the community have come to accept. During the research, female primary students in fifth or sixth grade (or girls who did not continue to junior high schooling) frequently stated that they thought primary education was enough for them

Just as primary school has become a universal campaign, a family's poor economy is the main barrier why there are still millions of children in the world who cannot access school. All parents interviewed from both villages pointed to their 
inadequate funding as the reason their children could not go to school or had to drop out. In addition to having limited resources, parents claimed they often needed their children's assistance either along with them in the field or at home taking over parents' tasks, like cooking or look after younger siblings.

During planting and harvesting seasons, parents often needed children's assistance in the field or at home caring for younger siblings. However, because the school's curriculum did not cater for these activities, children had to skip school for days or weeks at a time. Consequently, children were sometimes left behind in learning courses and this affected their performance. Although several parents admitted to having their children absent from schools for these reasons, they believed that the family's economic survival was more important than anything else. Thus, putting all the resources for these economically vital productions justified their decisions. After all, going to school had never brought rice to the table so skipping it for a week should not make any difference.

All of the parents from both villages agreed that the costs incurred (uniforms, shoes, notepads, etc) to educate their children were a burden for them. However, they also believed that children's education was the parents' responsibility. Regular expenses that parents had to cover included uniforms, shoes, hat and tie, and notebooks. Although school fees and other extra costs in rural areas were not as much as in the city, considering parents' meagre income and financial stability, all of these often put heavy burden on parents. There were not a few parents (and children) who admitted that their children regularly wore only sandals or went barefoot to school. Parents further stated that they often felt distressed by the fact they could not provide their children proper uniform or shoes. They recognised their children's feelings of humiliation, which often became one of the reasons they dropped out of school, but their resources were just not enough to spare for those items.

One issue that was asked to gauge parents' views on school attributes was the question of school uniform. Unlike many countries, the Indonesian government requires uniforms from primary school through to high school. In addition, there were also sports jerseys and scout uniforms to be worn during particular extra-curricular activities. For most rural households one set of uniform per child would be enough of a strain for their resources, and extra outfits requirements caused parents stress. During visits to schools, 
it was normal to find children with uniforms that were already worn out, torn apart, too small, or with missing buttons. These were expected knowing that they wore the uniform every day, six days a week, for the last year or two. Normally younger siblings were passed down the small uniforms when their older siblings got new and bigger ones. Sometimes children just waited for hand outs from their older relatives (who dropped out or completed primary school) or urban families. Parents explained that during rainy season, when the uniforms could not dry fast enough, the children had to wear their own clothes. This solution was the same when parents were unable to find spare resources to replace worn out uniforms. The price of the uniform set was about $\$ 4$, but majority of the parents claimed they were struggling to fully provide these to their children.

Uniquely, despite these burdens parents still insisted that schoolchildren should wear uniform. When asked whether or not uniform should be eliminated for the benefits of these very parents, the majority opted for the uniform to stay. The most popular answer to this was so the "schoolchildren look nice." They argued that without the uniform children would appear ordinary and not like they were going to school and because seeing their children in full uniform made them proud. There were only a few parents who agreed on the elimination of school uniform.

The sports jersey was another matter requiring extra money. While the national uniform could normally be transferred from one child to another regardless of the school origins, it was difficult with sports jerseys. School often ordered jerseys with specific design, colours, pictures, or wordings, and this made it very difficult for students of different schools and locations to transfer jerseys. The alternative was to wear their own home clothes, a sight the parents would not be content with.

Because of their acceptance of uniforms, many parents would struggle hard to secure money for them. It was the pride of the children, and naturally of parents, that needed saving. Most parents, despite their difficult conditions, would avoid humiliating their children by not able to provide them with decent uniform and shoes. They either found ways to secure the resources or merely waited for their and their children's pride to be deflated, by which time the easy way out was to pull the children out of school and point out economic difficulty as the reason. This chronicle was quite prominent within both communities. 
Parents faced similar predicament with school related fees. Firays, a 35 year old father from Batu Lapisi conveyed his discouragement at the fact he did not have enough money to pay for the Committee Funds. His children became embarrassed and gradually became reluctant to go to school. He further mentioned his family's humiliation when they could not afford items other families bought. His oldest son did not continue his schooling for reasons that he felt humiliated with his family's underprivileged conditions.

Because economic reasons were the main reason for children's lack of schooling, families in both communities tended to regard primary education as a relay baton. When their time was up, older children had to pass on the baton to younger children. As continuously repeated, because primary schooling had generally been the one level of education children could have when parents had extra money, older children who had been in primary schooling for several years or near completion would merely discontinue their education to pass the chance to their younger siblings.

The question of why continuing to junior high school is such a distant hope for many rural children has much to do with the distance itself. Malino district had only two junior high schools and one senior high school. Both of the junior high schools were in the centre of Malino. Many of Batu Lapisi children had to walk about 1.5 hours to reach the school or paid about Rp.5000 (US 50 cents) per trip if they used motor taxi, an enormous monthly expense for these poor communities. For children living in Kampung Baru, it took more than two hours to the school and a more expensive motor taxi cost.

Haikur tried to support her son's education. However, he refused to continue after graduating from junior high because the high school was even farther away. Her son regularly complained about exhaustion from hours of walking to and from school. Haikur joked that her family sometimes wondered about her son's whereabouts if he had not arrived home by evening.

All of the children interviewed replied "far distance" as their main concern for continuing, or not continuing, to junior high school. Although their current primary schools were within the community, distance was still a challenge for young children. 
From the centre of Inner Batu Lapisi, it took almost 45 minutes to the nearby Batu Lapisi Primary school. It was much farther for Kampung Baru. A child living in Batu Lapisi would take about 1.5 hours and through a river, paddy field, and rocky steep pathway up the mountain to reach Kampung Baru school. These were the conditions young children had to go through daily in the mornings and afternoons, braving rain and heat and suffering from hunger and exhaustion. Quitting school seemed like a reasonable, or better, alternative.

\section{Sustaining Primary Education for the Community}

During interviews most parents showed their confidence in the importance of (primary) education for their children's future. They realised school's expectation of them to endorse and encourage their children to receive education. Yet, it always came back to the issue of economic difficulties.

One inquiry about parents' preference of assistance should the government ever offer established a basic idea of how desperate these parents were. Two of the main assistances laid out for the parents to choose were either money or school items. The choices were evenly divided. Some parents preferred bulk money because they could arrange the fund based on their own priorities. Completely for the opposite reason, other parents preferred school articles reasoning that they concerned the money would be spent for something different.

All parents agreed that while they supported children's education, schools and government should partake in the costs incurred from schooling children, such as expenses of uniforms and books. A few parents mentioned scholarships awarded to students with best performances; however the Rp. 60,000 (US\$ 6) per semester reward were relatively small and not consistent as only the first rank student would receive it.

SMP Satu Atap (One-Roof Junior High School) and Paket A/B were still finding consistency of interest and commitment from the communities. The fact that these were schools were established only as an alternative for adults and children who were unable to attend formal schools. However, many parents voiced out their enthusiasm and gratitude for the school's presence and effects on their lives. Other parents who openly admitted their lack of resources to fund their children's schooling had turn to these establishments as alternatives for their children. 


\section{Conclusion}

Batu Lapisi and Kampung Baru are communities that rely on an annual paddy harvest and regular crop yields. Unfortunately, these resources are often inadequate to support families' basic needs. Children's education, however important it is stressed, is continuously placed aside as families struggle with their economic survival.

There are various factors faced by the communities that challenge them in educating their children. The demands of customary traditions, the of rice production cycle or wedding expenses are among the main elements seizing resources from children's education. Moreover, when children are allowed schooling, the costs school significantly taxed poor households' already meagre resources. With other pressing needs, parents are frequently confronted with the choice of bringing their children's schooling to a halt to relieve families' burden. The communities' situations and futures are in the hands of schools and governments to try to bring in more support. 


\section{CHAPTER 6 \\ RURAL PRIMARY EDUCATION IN INDONESIA: \\ PRACTITIONERS' VIEWS}

Primary education for all rural children is the main challenge facing the Indonesian government in implementing the goal of universal basic education. In the previous chapter, the two communities of the neighbouring sub-villages in Malino illustrated the typical primary education dynamics occurring in many parts of Indonesia's rural and remote areas. Characteristics of specific customs and environment inevitably contribute to people's perspectives on education.

This chapter will explore various views and arguments of individuals who have been involved in the education sector, at local or regional levels, as direct practitioners or technical advisors. As selected key technical informants, they offer additional perspectives on the conditions and challenges faced by rural communities in educating their children, based on their experiences and beliefs. A later section of the chapter will summarise their suggested interventions that are needed in order to enhance education access for rural children.

\section{Profiles of the Practitioners}

The intention of including practitioners in the thesis is based on the consideration that their experiences in the sector can offer a balance and alternative perspectives of the researched communities. It is expected that the discussion of both sides can help formulate the issue more comprehensively.

The first important practitioner perspectives in this section are the school teachers of the primary schools in both communities. Two of the senior teachers are seasoned educators with combined teaching experience of 56 years and they have been teaching in the area for most of their teaching careers. They have seen the transformations of the schools and observed former students in their lives. All teachers that participated in the research know their communities well, including students and their families' backgrounds and conditions. They comprehend fully how education, even primary education, can have an impact on lives of rural families. Their duties as teachers of the schools are continuously challenged by the communities' customs, and they have to employ various approaches in dealing with the problems without reducing the communities' enthusiasm for education. 
Five other professionals participated in the research and are from different organisational backgrounds. Three are from different international aid organisations and are responsible for education, and basic education, programmes in Indonesia; one is a senior human resources development staff of a planning body; and another one is a senior academic at a state university.

As per the researcher and participants' agreements, it is important to emphasise that all the opinions and comments expressed by the informants were strictly their own personal views and that they in no way represented or reflected the opinions of the organisations they work for. Their names are not revealed for protection of their identities.

\section{Challenges of Primary Education in Rural Areas}

There are various issues the education institutions in Indonesia are facing, particularly when it comes to education in the country's rural areas. The discussion below will concentrate on village-based issues in relation to policies and curriculum application set by the government.

\section{Cases from Batu Lapisi and Kampung Baru}

The preceding chapter discussed the researched communities' views on and attitudes toward primary education. This chapter attempts to provide complementary insights into those attitudes.

Data from the Student Registrations Report from both primary schools for the last five years shows that, although Batu Lapisi Primary School (PS) has slightly more students that Kampung Baru, there is little discrepancy in the students' attendances and completion rates. The average number of pupils leaving the schools by the end of the school years is about 10 students in both schools. However, over the years there are fewer pupils enrolled in Batu Lapisi PS and more in Kampung Baru PS. This is due to the invisible boundaries between the villages and other areas, resulting in children moving easily from one school to another without significant issues.

Both schools' registration reports show a worrying tendency of enrolment discontinuation. Every year there are at least 10 students from the schools who 
disappear from the charts, and this does not include pupils who are repeating classes. And for the last stage of this basic education, normally the percentage of graduates who will continue to junior high school stands at only 80 to 90 per cent. An observation from research has pointed out that this number, however, does not guarantee full completion of junior high schooling.

\section{Poverty, Customs and Lack of Commitment}

One senior teacher reveals that the three main challenges faced by the village schools nowadays are poverty, local customs and parents' lack of commitment to their children's education. And both the communities and the teachers acknowledge poverty to be the principal reason why many rural children do not complete primary education. Poor parents who are desperate for economic survival often indirectly sacrifice the interests of their children. One source, who is a leading academic, reveals a work migration trend of rural populations. Desperate with the impasse in the village, many rural people have taken work in cities or foreign countries, forcing them to leave their families behind. The earnings may be beneficial for them; however, the effects on the children are debatable. According to this informant, children whose parents work away often miss out on necessary attention and proper care. They are being left with relatives or aged grandparents who are also busy with their own families and may not be attentive to these children's health and education. While their parents away earning money, their children grow up uneducated and unskilled.

As discussed in depth in Chapter 5, there are a few remaining customary practices that dominate life decisions of the village communities. One is the custom of rice production. As the planting and harvesting seasons approach, the schools frequently lose a number of students for days or weeks as the children "would almost certainly join their parents in the field regardless of whether they are permitted to take days off or not," complained one senior teacher. A similar problem encountered when there is a wedding celebration in the community. A few days prior to a celebration, children can be found lingering at the house of a wedding venue instead of attending school. They normally stay there until the celebration is finished, by which time the children had already missed a week of classes.

A teacher pointed out that students' absences affected the progress of the school's learning programmes. When the class is divided with students who are up with 
the programme and students who are left behind due to their absences, it disrupts the programme plans and disadvantages other students' efforts.

For the schools, these are difficult practices to deal with and teachers admitted being compelled to having to find different approaches that can encourage the communities to be flexible and prioritise the children's schooling over these traditions. All four school teachers indicated parents' lack of understanding of, and thus commitment to, the importance of education as key causes. Teacher $\mathrm{AH}$ asserted that parents struggled daily with strenuous work and only encountered other poor farmers who helped perpetuate the belief that their children's futures will not be any different to theirs. He mentioned of a naïve yet widespread belief of farmer parents, which somehow explained their reluctance in supporting their children's education, that "there can only be one president," and because their children will not stand a chance to be a president, governor, regent, etc, there is no use spending families' sparse resources on their education. These parents expressed to the teacher that "they only need three skills out of their children's schooling: reading, writing and counting." And because these three rudimentary competencies can be acquired during primary education, teacher HA saw parents' tendency to disregard the next levels of education.

Rural parents' views towards education's outcomes are also induced by the false dreams of life in cities. Village parents are hopeful that their children will acquire employment in the cities knowing that the city is cash-oriented. There are parents who fought to get high school education for their children hoping it will bring high wage returns to the children and families. Unfortunately, a high school diploma can no longer offer leverage anywhere as it has become the minimum standard of education for even the lower levels of wage employment. As rural parents are confronted with this newly raised standard of education and the higher costs required for their children to reach the standard, many of them ended up rejecting the reality and retracting their children. An informant, who is responsible for education planning in the province, points out that this expectation is not in harmony with the lack of employment available, either in cities or villages. A lot of rural parents regret the efforts and lose confidence in education's promise of better economic prospects. Such dismay and pessimism affect the education opportunities of their younger children and influence surrounding communities' views on education. As a result, poorer parents who are not fully committed to schooling their children will be easily influenced and they claim that if they have to sacrifice their 
children's contribution to household's income generation efforts for schooling, the government has to offer compensation for it.

Because most rural parents spend most of their time in the field and struggle to support families, they rarely give encouragement or attention to their children schooling, such as helping them with homework or preparing for examinations. This is also mainly because many parents themselves are not educated so are unable to help and avoid the humiliation of their children. Because of this, they concentrate and encourage their children more on helping them to "put and sustain the fire in the kitchen," a matter that they surely know and do better.

Moreover, according to the village teachers, in struggling households parents are less willing to release their children from tasks that have proven to be a hindrance to their education. Teacher AH claimed that, although the school fully empathizes with parents. Parents regularly demand their children's participation in household duties. The decision of prioritising household's economy above their children's education virtually deprives children of their basic rights and chances to establish a better future. This situation leads to some children feeling reluctant to fully commit themselves and concentrate on their schooling, viewing that it is only an extra activity among their household chores. All these aspects make life complicated for these village educators as they have to find strategic compromises, yet are constantly pressured to accomplish schools' programme goals.

Commitment, the local primary school teachers plead, is the only obligation required of the parents. These community teachers believe that even if parents do not fully comprehend the value and long-term effect education can bring to their children, their mere willingness to let their children routinely go to school is a crucial instigation and can prove a significant boost to the community. However, this is not a simple wish to be asked from economically-deprived parents. Teachers cannot simply compel parents to oblige either, as this has proven to backfire at the schools. Senior teacher PS recollects many instances of parents literally pulling their children out of the classrooms out of humiliation or anger at the schools. As previously mentioned, parents' lack of commitment can be seen from rising numbers of students' absences during planting or harvesting seasons. When teachers refuse parents' requests to take their children out of school to work for several days, "they immediately threatened or decided to discontinue 
the children's education." This senior teacher's fear is not unwarranted. There was an incident where a parent practically dragged his child out of a classroom due to a similar reason. Parents often exercised the same strategy when feeling humiliated over reminders of their children's late tuition payments or over incidences of teachers' reprimanding their children.

An aid organisation's basic education project manager corroborates the importance of fostering commitment for basic education in rural areas. He referred to the success of one rural community and primary school in Sulawesi which is one of the selected participants of his organisation's programme. With continual support from the programme, the community has shown a growing commitment through its involvement in the local school and there has since been an increase of students' enrolment of more than 100 per cent. To emphasise his point, he indicates that this progress was attained without “any changes, or increase, in local community's economy, parents' income or teachers' salary." Nevertheless, there was a big improvement in enrolment rate and learning and teaching process. Therefore, he believes, teachers' and community's commitments are keys to better quality of teaching.

One of the local schools' junior teachers agree that parents' motivation is crucial to their own children's motivation to education. He revealed that educated parents tend to give motivation to their children more than uneducated parents. Thus, the effect of education is long-term and twofold over generations.

\section{Remoteness}

As always the case with rural and remote areas, distance is another contributing factor why schools struggle to maintain students' attendances and enrolments. The schools acknowledge this factor but admit they cannot risk losing the children's enthusiasm. For example, the primary schools have a daily ceremony at 7 a.m., but will tolerate students arriving late. One of the senior teachers tolerates this because he knows many of the students come from other villages several kilometres away and have to leave home before dawn and cross rivers or rice fields to reach the schools on time. Transportation is not available or is unaffordable. He is pleased enough that children still maintain the enthusiasm to go to school despite having to endure difficult journeys. 
With several primary schools in the district, recruiting and keeping schoolchildren in primary schools still proves to be a daunting task. Teachers at Batu Lapisi and Kampung Baru primary school are particularly concerned that their efforts will stop short at their primary schools. The two-hour walk required from the village to reach the two junior high schools in the centre of Malino causes the village children, and their parents, to bail out.

Such situations are prevalent in many remote areas, especially in the eastern region of Indonesia. One source from a child international organisation mentioned his experiences in areas of Sumba and West Timor where children have to walk 5-10 kilometres to the nearest schools. Similarly, the senior academic stated that shortage of schools has detrimental effects on the sustainability of children's education, which he often saw during field trips to other remote and isolated places. He mentioned one community that is living on the other bank of the river and opposite of the only primary school in the area. As a result, young children of that community have to cross a large and deep river using only a makeshift bamboo raft to attend the school, if not trying swimming. He once saw two small pupils almost lost control when trying to manoeuvre their bamboo raft while crossing the flooded river in harsh weather. Such conditions and risks, hours of the exhausting walk or high transportation costs are unpleasant situations and sacrifices that lead many children and families decided to complete education efforts at primary school.

\section{School's regulation and "hidden" cost of education}

Local schools continuously make compromises in order to perform their actual responsibilities and roles. Primary schools are increasingly under pressure to accept only pupils holding kindergarten certificates. However, the schools sometimes are unable to comply with the policy. Aside from having only one kindergarten serving children of faraway villages, parents are still unfamiliar with the notion of sending children under-five years old to school and sympathize when their little children have to walk a long distance. As a result, the primary schools have to overlook this requirement because they do not want to risk dissuading parents and block the only opportunity for the primary school-age children, who are not kindergarten graduates and are majority of the children in the villages, from enrolling at primary schools. Encouraging parents to enrol their children in schools is already a daunting task for the village teachers. 
However, village schools' attempt to prioritise access over entry qualifications to primary school does not always lead to positive outcomes. The senior academic explained this as a contributing reason why rural pupils are academically behind urban pupils. Because primary school instruction plans are instituted on skills pupils are assumed to have obtained from pre-school (kindergarten), such as the alphabet and numeric introductions, village children who skip pre-school trainings often struggle to keep up with the lesson plans. Because many parents are illiterate and unaware of this standard, most first grade teachers still need to prepare new pupils with the above basic instructions to level the standard of classrooms, which can lead to disruption of lesson plans and goals. The implications of this are slow progress, possible frustration for teachers, and low students' performance.

Schools also have to deal with issues regarding school attributes and their extra costs. When children were reluctant to attend school due to parents' inability to provide uniforms or shoes, teachers will approach parents at home and allow their children to attend classes without them. Schoolteachers regularly have to immediately intervene when children and their families encountered problems regarding school matters knowing that parents' scepticism and apathetic attitudes toward the implication of education can easily overpower their compromise on schooling their children.

\section{Welfare of and Supports for Rural Teachers}

It has been a stereotypical view that one of the reasons why village schools have low quality of education is because government pays less attention to the welfare of teachers stationed in rural areas. This accusation is not without some truth.

While some teachers working in villages are civil servants carrying out their placement directive, many teachers are actually locals of the communities and have their families in the areas. Besides having stable employment and wages, they also manage their own paddy field and vegetable crops. In truth, many teachers have to rely on these traditional resources. While senior and civil servant (government employees) teachers have sufficient wages for rural standard, honorary teachers receive very little stipend. Sadly, there are usually more honorary than civil servant teachers in a school, making the matter of teachers' low income affect learning progress in schools. 
During regular trips to rural areas, one informant was astonished upon seeing a teacher coming to school several hours after the normal school hours start. The teacher apparently had just gotten back from his regular morning labour at his own vegetable crops. Previously a teacher himself, this senior academic confronted the teacher about his late arrival and his wasting hours of teaching instructions, stating that as a teacher he should be at the school by 7 a.m. The teacher then said that "he was willing to do so only if the academic promised to send him the substitute monthly extra money he generated from his vegetable garden." Lack of substantial side income leads this teacher to resort to his vegetable garden, an occupation he needs to tend to as early as 6 a.m. before going to work at the school. The senior academic raised his case.

This was a very ironic situation in which the rural students, having to obtain approval from their parents and probably travel long distance to go to school, arrive at the school without teachers to teach. However, teachers cannot be blamed for prioritising their families and trying every effort to sustain them. When the job requires more time and effort than compensation, teachers have no choice than looking for alternative resources.

The discussion of teachers' secondary jobs cannot avoid the highly popular tutoring or "private" lessons. Some of the practitioners acknowledged this and some pointed to this extra-income appeal as the major difference between teachers in rural areas and cities. One teacher from the local primary school complained about the discrepancy of extra earning opportunities between teachers in rural and urban areas. City teachers can rely on this side income and many urban parents are willing to provide funding for their children's extra instruction. This mechanism, unfortunately, has never existed in rural areas. Rural parents are already struggling with and complaining about the minimal "hidden" costs of schooling, teachers cannot see these poor parents can ever spare another cost for the "extra schooling time." Consequently, rural teachers are left without alternative cash resource other than working on their plots, which periodically required more priorities than the teaching.

This dilemma also leads to the assumption that non-local or urban teachers are reluctant to be stationed in villages. Shortages of qualified teachers also contribute the issue of high workloads of teachers in rural areas. As one senior teacher confirms, generally non-local teachers will use village appointments as a stepping stone to further 
their careers in more developed areas. These teachers will undergo the assignment for a few years before moving to schools in cities.

However, while acknowledging the issue of low pay, one practitioner was strongly opposed to the speculation that level of salary and level of quality has a cause and effect relationship. From years of experiences as a manager of basic education programme, he has come to a conclusion that higher wage does not translate to better teaching quality or higher commitment from teachers. Field trips to many rural schools have brought him to meet many underpaid teachers who have strong commitments to their professions.

This practitioner, nonetheless, agrees that teachers without support and attention from the government will struggle to offer quality education to children. He argues that giving teachers directives and targets without regular technical guidance of how to achieve them is not constructive and does not encourage teachers to commit to their work. He points out to a typical teachers' training seminar where 500 teachers gathered to be bombarded with hours of PowerPoint presentations and theory. There were no follow-up monitoring or support to guide teachers to apply the training. According to him, government is responsible to provide periodic supports to teachers, especially those who work in remote and isolated areas, and encourage them to enhance their skills and techniques through seminars or workshops.

In spite of widespread modern technology applications of computers, informants argue that the government cannot demand teachers to introduce and equip pupils with this modern skill without any support. Rural schools' lack of actual computers, and electricity for that matter, and training to utilise them do not maximise the government's new-age education program or internet-based support and information.

Support and attention also refer to facility and material supports. Other practitioners asserted that the government needs to supply equal learning facilities to rural schools if it desires a nation-wide success. As some of the village teachers claimed, the schools are always short of learning materials and assistance kits but they cannot rely on the communities to meet the scarcity. In the past the School Committee, a body that manages a school's operations, experienced difficulties in obtaining contributions from parents. The students in the communities have to alternate to borrow 
lesson books due to supply shortages or parents' lack of funds to buy them. The teachers voiced their predicament in getting parents' support. "When parents are asked for costs to buy materials for students' science class experiments or projects, the school rarely receives any," a senior teacher noted. This issue has put the school in a difficult quandary as it risks of overspending school's budget or not providing valuable of learning materials to students.

Underpaid and neglected educators will in turn produce unqualified students, which can escalate the growing distrust of rural communities on the importance of education.

\section{Discussion on the Education Decentralisation System}

Two of the practitioners from aid organisations think that decentralisation of education in Indonesia should have been implemented years ago. Yet, the progression of this decentralisation has not been as pleasing and efficient as it was expected. Nonetheless, these sources are adamant that this is an appropriate change that the sector needs and the country should allow time for the transformation to function.

As a professional overseeing development programme in Indonesia, one informant contemplates that if the government of Indonesia had been comprehensive and attentive to each individual region's characteristics the confusion and "hiccups" in executing the policy would not be as complex. Capacities of schools and teachers were not fully and evenly prepared nationwide. Consequently, rural schools, which did not have reliable and prepared self-supporting mechanisms at that time, suffered badly.

Particularly in rural and traditional communities, there are difficulties in not only in relinquishing responsibility of school management to local community, changing the notion of education to be part of community is like changing traditional norm. The practitioner indicated the decades of government's absolute control in school management as the underlying factor of this reluctance. The society as a whole has been accustomed to traditional doctrine and practices that there was a demarcation line between society and school as government's liability. For this reason, society developed to be an outcast, unaware and ignorant of education development of their children. 
One senior officer of a planning body discussed the transformation of the education sector. As mentioned in Chapter 4 with regard to the centralisation mechanisms, he asserts that the weakness of this system is that it spoon-fed the regional administrations central-based material, from curriculum to lesson plans, which should be developed consistent with local needs and conditions. This leads to regional administrations being dependent and a lack of credibility to manage their own curriculum and resources. With decentralisation, it provided opportunities for regions to be autonomous and enhance their resources. The problem with this, he pointed out, is that without well-prepared and established human resources and capacities, regions will struggle to develop properly as they are not used to self-sufficient. Schools and teachers will be in the dark regarding how to manage their schools and curricula.

Several teachers and the senior official source reiterate the imperative of support and infrastructure access for schools' managements to build their capacities. The lack of electricity, hence difficulty in using computer and internet access, and reliable transportation are among the main elements that create differences in capacity building opportunities of schoolteachers in remote areas and cities or urban areas. These key sources acknowledge that although the government has tried to offer training and courses for teachers to improve their competencies or update the curriculum, not all rural teachers can use the opportunities. Announcements of such events will normally reach rural areas days later through the lines of bureaucracy and information on newspapers or internet is not easily obtained in remote areas where road access is nonexistent. Moreover, even if teachers are self-supporting in attending the trainings, with the complication of bureaucracy, it will normally take days or weeks before supervisor's approval can be attained. Such barriers can be a factor why rural teachers often miss out on seminar or training events, which are mostly held in cities or larger towns.

As parts of the efforts to support to teachers' welfare and capacity, currently the government is introducing a certification system where teachers will acquire certification once they obtain standard qualification degrees and, as civil servants, they will improve their positions and wage benefits. A senior teacher admitted that nowadays the government has put more attention to rural schools and has implemented several policies to boost rural teachers' welfare. There are many primary school teachers, with poor qualifications or only teaching diplomas, who try to obtain Bachelors degree to qualify for the certification. However, the senior academic points out, government does 
not offer assistance to teachers to fund the extra education for the qualification, costs that are substantial to them, and the courses are mostly offered in cities. Teachers, especially those who have families, work in villages and with less opportunity for extra income, as a result are not able to pursue this requirement as they are more inclined to use the funds (course fee and transportation costs) for their children's schooling. In the end, government's efforts may only be beneficial for some groups in certain areas.

Decentralisation also affects the line of authority and policy efficacy. Because school authority is no longer under the provincial administration but of regency office, the appointments of positions or seminar attendees have now been decided by the regent. The concern here, according to the senior official of the planning body, is not all the regents have an interest in education issues. So when education organisations or bodies at provincial levels requested participants with specific skills prerequisites for trainer's training, it is not unusual for the regent office to appoint someone without the required skills, hence are not appropriate trainer candidates and deprive chances for other potential trainers to receive training.

This practitioner further talks about the connection of appointment decisions and policy efficacy in the regional autonomy system. The matter of arbitrary or subjective appointment sometimes can lead to long-term ineffectiveness to education programs. He revealed that of all the officials who are responsible for education at the regency level, from the 27 regencies in the South Sulawesi province, less than 10 officials are from the education discipline. He questions the competencies of the non-education based officials as policymakers and their effectiveness in formulating strategic measures and planning if as managers they are not knowledgeable about education itself. The paradigm now, he pointed out, is that these non-educator managers expect their staff and subordinates, who probably have little education background, to feed them the necessary information. However, many subordinates are not used to working on their own initiative and without instructions from the top, will struggle to furnish quality work to the managers. The source finally stresses that a more critical issue nowadays is the tendency among office leaders to adopt development programmes that are oriented to physical development. Human resource development is a longer term process and the outcome cannot be seen for at least five years. And because these managers or government leaders need to sell their programmes, they tend to support programmes that may have instant returns but not sustainable. 
At present the province of Sulawesi Selatan has been promoting free primary education, a proposal which was strongly adopted by the current Governor of the province in his campaign for the position. This is in line with the goals of Education for All and the MDGs and is expected to increase the primary enrolment rate. Yet, some of the key sources wish the government to be cautious with this campaign of providing access. They argue that having access to education is not equal to having a quality education, a predicament government should avoid. One of the sources who has been exclusively managing the basic education program in the province mentioned an anecdote circulating in the sector regarding the famous free education campaign: "access is free, quality is relative." The campaign of free education should be considered more carefully because of the implications and long-term impacts it can bring. As one of the key sources pointed out, society is still unsure of the meaning of free education. Many people think free education means that there is absolutely no cost for school children, which is seriously misleading, because there are still components of schooling that parents still have to be responsible for, such as uniforms, books, etc., while school operational and other costs are covered by the government. This misconception can backfire to the school as many poor parents, who initially think they no longer have to spend anything for their children's schooling, suddenly realise that this is not a sincere effort on the part of (or is a trick of) the government and they may abandon their support for their children's education.

\section{The Importance of Primary Education}

All practitioners agreed that poverty and lack of education constitute a vicious cycle. A lack of or a minimal level of education could lead to poverty or deny chances to escape it. Although there is no direct statistical evidence that basic education can alleviate poverty, all of them are confident that this key element of individual enhancement is a worthwhile asset and has valuable long-term implications on an individual, families, communities, and countries. One senior teacher stated that even primary school has an impact on a child's way of thinking and provides avenue of opportunity regardless of whether or not she will further her education. Primary school, as its title refers, is a mean for children to attain fundamental guidance in enhancing character, potential and basic skills for the more complicated competencies. 
Another practitioner from an international aid organisation further emphasises the importance of motivation primary education can generate. From experience, she can see how schoolchildren's motivations have strengthened over time and they have better outlook within themselves. She stresses that having a self-motivation will ease the initiative to step forward away from poverty and lessen the hindrance factor.

The local teachers reiterate that primary education, however basic they are, will always be beneficial for their children, their minds, and their families. When asked about their observations on their former students' lives they are convinced that students who continue to higher education, high school or university, are now in much better state while students who dropped out or stop short at primary school typically end up in the village working on the farm. One senior teacher claimed that based on his observation of former students, those who were able to complete high school education turned out to be better farmers. If they came back to farming in the village, they did better because they knew how to use the fertilisers properly and yield good crops, whereas those who did not have education fertilised erratically and often achieved low yields. Even former students who only completed primary school normally would turn out to have better economic outlook than children who were unschooled. According to one junior teacher, "education is a device to uplift human beings to a better state." He revealed that his outlook on life and future changed once he was involved in the education sector, a transformation he admitted only knowledge can bring and he believes that education is imperative for a better future.

A professional who manages a basic education programme corroborates this connection that "by denying access to education for children it denies their opportunities for employment, ability to work on their situational analysis, problem solving and social skills" particularly in today's new era where team work and modern technologies are the dominant working paradigms. Another source that is responsible for government education programmes in the province pointed out that with a higher level of education a community is more likely to be successful in tackling its poverty problem.

\section{Interventions and Strategies to Improve Rural Primary Education}

Despite all the challenges and complications, the government and schools have made efforts to improve access and quality of education for children, especially those 
living in rural and remote areas. After all, poverty will bring about more harmful implications if the business of basic education is ignored.

One practitioner from a development agency straightforwardly indicated that "in the country's Constitution it states that education is the right of the citizens and that the responsibility lies on the government to fulfil this right." If there are some pockets of society who are still without basic education, then government is accountable to realise this responsibility.

The case study in Batu Lapisi and Kampung Baru has revealed different issues and impediments. However, local primary schools and teachers have tried to make exceptions and facilitations to encourage students' enrolments and maintain their attendances, such as waiving the kindergarten pre-requisite for first graders or be flexible with students regular drop out and re-enrolments. As has been discussed, local teachers believe that the main priority is to recruit as many rural children and maintain them in schools.

These local teachers are pro-active in their efforts and commitment in their communities. One of the strategies they employ is school's active approach to local families. When schools notice there are students who have been missing from schools a teacher will visit the students' parents at home and try to find the cause of absences. Frequently teachers have to make exceptions or adjustments to solve the problems and bring the students back to schools. The schools try to be flexible with the uniform requirement and tidiness of students, overlooking the sandals and casual shirts some students are wearing. One of the schools has taken the initiative and approached the government's Women Organisation to donate used uniforms (of their children's or relatives) for pupils in its school. During this research, Kampung Baru primary school was missing one of its top students due to her family's severe economic problem. The school immediately sent different teachers to talk to her mother and, after many persistent visits, the girl was back in school.

Similarly, prior to the planting or harvesting seasons, schools will anticipate the absences of pupils and will try to counteract this before students start missing school. One senior teacher said that he and his colleagues will commence "Silahturahmi" visits (refers to friendship or family visit) to families, which tend to take their children out of 
school during these periods, and negotiate with them on numbers of days they will "borrow" the children out of school. Instead of skipping school ten days consecutively, they will ask parents to lessen the numbers and do it in intervals of two or three days at most so that children will not suffer badly and miss too much.

These teachers claimed that traditions and mindsets cannot be changed overnight and cannot be imposed upon poor communities who are struggling with food security. The best strategy, the teachers believe, is persistent community approach to gain parents' confidence through consultations and commitments from school. As one practitioner conveys, the most critical effort is to give understanding to parents and families, who have long been and immersed and entrapped in the dark reality of poverty, that there are better opportunities and futures for them. If a school can successfully bring its communities up to this phase, it has performed its task effectively.

Commitment from teachers also requires support from the government. Some key supports have been mentioned in preceding sections, such as welfare, training and facilities. It is clear however that many rural teachers are struggling economically, and without much choice to obtain additional income, local schools are at risk of losing local teachers' enthusiasm and commitment. Some practitioners endorse rural teachers' appeals for more welfare support and attention from the government.

While decentralisation offers autonomy to regions and schools to develop their own lesson plans, the government cannot ignore the fundamental deficiencies in infrastructure and facilities in rural communities and schools. Government needs to prioritise these facilities in order for the schools to be efficient and effective for their communities, such as accessible roads and transportation supports, electricity, and more school buildings.

Instead of modelling instruction on an urban-based curriculum, the government (at central, regional and district levels) should encourage education policymakers and schools to focus more on individual areas and available resources. One of the researched schools has designed its own lesson plans with full involvement of the school's staff in the process. The Mulok or local content has been incorporated, and decided by the school itself, into the curriculum. The Mulok for the previous year involved a regional dialect and the school is expected to expand on English language in the coming years as 
an alternative. Even though such optimistic attitude is appreciated, its effectiveness and worth need further consideration.

Because a majority of the country's population are in rural areas and in the agriculture sector, education should promote these components. The senior academic refers to various regions' special commodities, like cocoa or corn, which could be assimilated into local school curriculums. Responding to a parent's concern of the next generation's reluctance to be involved in agriculture and farming, one of the local primary school teachers said the rural lives can be aligned with education. He insists that "a farmer's child can have an education and become a farmer himself; he does not, however, have to be the same deprived farmer and only depend on physical labour. But he can be a knowledgeable and educated farmer, combining modern applications and local resources." This teacher proposed that the government needs to promote agriculture and provide infrastructure to rural communities. With government's support, he hopes that the communities can generate their own agriculture specialists instead of mere low-class workers competing in cities.

A major reason why rural parents are reluctant to fund their children's schooling is the no-return element. Several informants offered inputs on how the government should address this scepticism. The government needs to make an overall plan of the nexus between the needs of the country and the role of education in fulfilling these needs, for example the growing needs of skilled human resources in technology or agriculture. This needs have to be relayed to the education sector so that graduates will have avenues to apply their skills and earn their livings.

The senior official from a planning body explains about the situation of high schools and vocational schools. The present situation has shown society that high school graduates will struggle to find work in the highly competitive employment fields because they do not have specific competencies. According to this informant, the current ratio of 70 per cent high school versus 30 per cent vocational schools has to be reversed if the government wants to yield trained and competent workers. The topic of life skill education, hence, comes into place and has gained interest from both education and development sectors. He argues that for the government to promote dynamic and growing economic development, it has to invest appropriately in the training of human 
resources. When education, training and economic demands are in harmony, hopefully the unemployment rate will decrease and investment in education will intensify.

Another informant, from an international aid organisation, is confident that once the environment is conducive the society will have its own capacity to address the issue of economic development and poverty. To reach this stage, this person asserts, the government needs more than initiatives and commitment; it has to make sure their commitments are translated in the fields. At the same time, she claims, development and aid organisations need to shift its roles from the classic procedures. Concerns of aid recipient nations' dependency on donor countries and organisations should be addressed immediately if sustainability of development programmes and long-term implications are the ultimate goals. She points to the increasingly embraced but simple strategy of gradual retreat, the idea that donor organisations step back from project operations' front lines and function only as technical supports, while letting the local resources and community step up to be the main actors and administer the programmes on their own.

Like in other areas, the schools in the community strive to secure education continuation of children by establishing the government's program of "SMP Terbuka" (Open Junior High School) and "Paket B." SMP Terbuka is commonly called distant classes. They are junior high school level classes but are not held in an actual junior high school but at houses in the community. The goal is to provide opportunity for primary graduates to continue their education without having to deal with distant junior high schools, a major barrier for rural areas with shortages of schools. This programme is taught by the same teachers and uses same module from the main junior high school; it is more flexible as students can study anytime and anywhere and convene at specific days and times to discuss the lessons.

Similarly, another strategic intervention is "SMP Satu Atap" (One-Roof Junior High School). SMP Satu Atap is an actual junior high school in the same location as a primary school, hence the term one roof, but on alternate times. The objective is to establish junior high school without having to exhaust infrastructure budgets by building a different school. The benefit is primary graduates living in the area can directly enrol in this school without having to worry about distance. 
"Paket A" (for primary level) and "Paket B" (for junior high level) are out of school programmes set for children or adults to continue their education in the surrounding community. The intended participants are those who drop out of primary schools and illiterates (for Paket A) and those who want to continue junior high education (for Paket B). These programmes are free and learning materials are provided to the participants.

The senior academic emphasises in the importance of self-initiative. He shares his previous experience in dealing with unschooled children in a poverty-stricken urban area. Concerned with the futures of wandering unschooled children in the community, he solicited assistance from a successful businessman in the area. The monthly donation is used to fund the poor children and this scheme has since continued and even after he left the area.

All these programmes have benefitted many people and offer second chances for those who want to return to school. During this research, the key benefit to this can be seen as parents who participated in the programmes above are more confident with their newly-acquired skills and had more positive viewpoint about education than parents who are uneducated and not involved in the programmes. Because as repeatedly stated, the level of education of parents is highly influential in their children's education status.

\section{Conclusion}

The Government of Indonesia has struggled to provide access to quality education to children in all areas of the country evenly. Remoteness, on top of rural poverty, is the main challenges to this quest. This chapter provides discussion of concerns and issues faced by professionals who work in education sector, either directly involved with rural communities or from education planning standpoints.

This research's case study is once again discussed as the local teachers reveal their challenges and efforts in order to promote the value of basic education to the communities. Aside from having to deal with barriers from the communities' customs and economic quandaries, local teachers also have to cope with issues of bureaucracy and support scarcity. The complexity of primary school in rural communities is furthered elaborated by other informants from various backgrounds who have been working on the issues. And despite many revealed problems rural schools and 
communities are facing, the government and the schools have been making efforts to promote and encourage basic education. After all, by advocating primary education, government is contributing to poor rural people's initial step on the ladder of development. Basic education is in essence the fundamental stage of education training, the basis to a capacity development of a country's human resources asset. 


\section{CHAPTER 7 \\ CONCLUSIONS AND RECOMMENDATIONS}

The road to achieving the MDGs may be a little more complicated that expected but at least this worldwide campaign has directed the world's attention towards, and encouraged efforts to deal with, global poverty. Similarly, achieving 'universal primary education' is not as straightforward a goal as may first appear. While governments and development organisations readjusted their programmes to fit to this basic goal, the mere concentration on primary education has generated criticism and fears that it may in some ways divert attention and resources from the overall goal of poverty alleviation.

This chapter will recap the key questions of this research: What is the importance of primary education according to a rural community? Is primary education a key for them to escape from poverty? Do the views of rural people themselves accord with those of practitioners and policy makers? It is important to establish how education affects traditional and poor rural communities and this is particularly important for Indonesia since almost half of its population live in rural areas, are poor and rely on agriculture.

\section{Influence of Urbanisation on Rural Poverty and Development}

The appeal of life in a metropolitan city is like a fireworks display for rural people whose countryside seems little more than a rough backyard view. Poverty occurs in both settings, yet rural poverty perhaps is more complicated to tackle.

Rural poverty is complex and liable to intensify especially as influences, such as changing market conditions, are felt. Lack of necessary infrastructure makes development in rural villages difficult to achieve. Rural communities are increasingly facing difficulty with their traditional source of livelihood, agriculture. Years of government-promoted rural development, involving the application of chemical fertilisers and greater attachment to markets for both inputs and surplus production, have largely failed to alleviate rural poverty in many areas and may have contributed to accelerated environmental degradation and falling soil fertility as well as greater social differentiation. Prices of basic commodities of food have increased as well as the prices of modern goods and refined products. Periodic cash earnings from vegetable crop sales are quickly used up to acquire other everyday goods, like coffee, sugar, cigarettes, etc. Such economic struggles intensify pressures on rural households to survive, which 
ultimately require children to sacrifice their education and to contribute to the households' survival.

The persistence of poverty in rural areas cannot be detached from root factors of the community's staunch commitment to traditions. The case study of two sub-villages in Malino in chapters 5 and 6 has illustrated the possible detrimental effects of maintaining some customs when cash has become the language of the economy and basis of many aspects of daily life. Traditional mechanisms of barter or trust-based exchange are disappearing and rural communities are forced to cope with the demands of money-oriented business. Meanwhile, the practice of selling necessary portions of rice reserves when in need of cash has also challenged household's economic security as prices fluctuate. In the meantime, a typical adat (custom) wedding party is now valued at Rp. 15 millions (US\$ 1500), about 10 times a yearly earning of a regular household in the communities. Families constantly put themselves in life-long debt or relinquish their inherited properties in order to avoid tainting the families' honour and status for years to come. Concurrently, customary practices such this is are particularly disadvantaging for teenage girls who are stripped of their schooling opportunities. Yet for many rural families, this is the manner daughters return their gratitude to parents and, at the same time, release parents from their responsibilities.

Above this, there is the irresistible urban lure that makes rural villagers feel deprived and excluded. Thus, mobile phones, refrigerators and television sets have increasingly made into the list of supposedly necessary appliances for poor rural households. Ironically, the more they try to catch up, the more problematic life has become. Lifestyles depicted on the television programmes, which are mostly based and produced in Jakarta or a few major cities in Indonesia, are enormously different to the reality in the village. Hours of nightly drama series promote high cost of city lifestyles and TV advertisements bombard viewers with thousands of commercial products. While electricity is rare and gasoline prices are rising, villagers strive for mobile phones and motorcycles. Occasional trips to nearby city of Makassar returns with new commercial items. Urban influence has played parts in the economic priority of rural households.

Since the stability of agriculture earnings has been shaken in the last few years and the glittering image of cash-oriented city is enticing, and many rural villagers, especially the younger generations, have switched their aspirations and focus towards 
urban living. They have come to believe that urban areas will provide chances for stable wage employment in addition to evade the strenuous daily grind of farming for cleaner and pride- boosting city jobs.

One of the most important observations that can be drawn from the research is the correlation of the concept of education (in general) with its application to employment prospects. It is undeniable that the more facilities, technology and access a society has, the higher the level of education standard and competencies it has. This has surely materialised over the last several decades and, unfortunately, society simply has to accept the fact and aim to reach the standard in order to allow more opportunity for employment and monetary security.

The conventional notion of primary schooling equipping its graduates with general rudimentary skills of reading, writing and counting is fading. The current era of high technology and globalisation demands more than these three basic competencies. In Indonesian cities and major towns tutoring companies are flourishing with offering academic-oriented extracurricular courses like exam preparation, computer skills and English language training from primary to college levels. These are not inexpensive, especially if it is on top of formal school fees and expenses. Many urban parents, however, will make every effort to enrol their children in such courses. The result is apparent. City children gain better competencies and catch up better at schools and are better prepared for the modern demands of the workforce.

This trend is not representative of all areas in the country. Chapters 5 and 6 described the different factors that hinder rural students from benefiting from similar learning facilities and ensure continuity of their schooling. The remoteness and scarcity of nearby schools mean that students have to endure hours of walk daily. Moreover, higher education for rural children is expensive. The pursuit of college education means many students have to move to and live in cities where higher education institutions are available. Some rural students are able to live with relatives in the cities; otherwise, parents have to fund accommodation, provisions, and transportation. As many rural parents complained, these costs are substantial for them, particularly as most rural communities do not have regular cash income but rely more on periodic sales of their annual harvest reserves. 
In the past, previous education standards of high school graduates were enough to offer decent urban employment and wages. Nowadays, a bachelors degree and computer proficiencies are the prerequisites. Computers are basically non-existent or a rare privilege in rural areas, especially considering the lack of electricity. Rural children with high school degrees are now faced with choices of taking low-paying jobs in cities, such as shop or restaurant attendants, or returning to their villages, in which they are most likely to work on their families' farms. While working in cities provides regular wages, it is not substantial enough to be helpful for their families in the villages. Monthly wages can be easily exhausted to merely cover the high cost of urban living, leaving little to give to families in the villages. Another trend is that many young girls, unschooled or with primary education, leave villages to work in cities as housemaids or other low paying jobs. While earning low wages, accommodation and food are provided. Their wages, however, are often exhausted with expenses such as mobile phones credits, clothing, or beauty products. Being in cities means more exposure to modern urban lifestyles and attitudes seen from TV programmes and advertisements and weekend mall outings.

\section{Rate of Return of Basic Education to Rural People}

Being the first stage of formal education, basic education lays the most fundamental competences for further education. The return, however, may not be as apparent and practical as the other levels. Unlike high school graduates, most primary graduates will not obtain formal employment or be qualified for any vocational institution. The direct economic return, therefore, is low.

Despite this apparent poor economic return of basic education, many practitioners stress the invisible worth of educating children and the multiplying effects of basic education, in fighting poverty. Children who are in schools are more likely to be more self-confident and, at the very least, be able to be more of a help to their families aside from physical labour. Once children are in primary school, there is a prospect for them to carry on to higher education. In chapter 6 , local teachers in the case study verified that they saw differences of living conditions and life prospects among local young people who were educated as children. Children who were unschooled tended to reproduce their parents' poverty or become worse due to less land ownership and worse economic conditions in general. Former students who had high school or higher education had better chances at employment and, even if they remained in the 
villages, they practiced better farming and subsequently achieved better crops and incomes.

The benefits of remaining in school longer particularly affect girls from rural areas as the literature review on chapter 2 discussed. The longer they stay in school, the less likely they will get married early and, thus, become teenage mothers. There is also a tendency for teenage mothers to have more children than older mothers because younger mothers begin having children earlier, and are during productive child bearing period, which means longer years of productivity. Teenage mothers are prone to high risks of maternal and child mortality. Uneducated mothers, many of whom are teenagers and poorly educated, tend to have less knowledge about infant health and thus risk their babies and young children to grow up malnourished and prone to preventable diseases.

The literature reviewed strongly endorsed the importance of basic education and this was supported by the research findings. Awareness and understanding of the needs for education and its outcomes are vital to gain consideration and long-term commitment from parents and community. As local teachers emphasise, parents who have at least primary education will have more tendency to enrol their children in school as they reach school ages compared to parents who have no schooling experience at all. Moreover, parents with higher education (high school and above) are more likely to invest more in their children's education as they aspire their children to gain better education and wage employment than they do. As trends show, individuals with more schooling and competencies expect to have opened more employment and economic opportunities.

Ultimately, it is the power of knowledge that generally reveals the worth of basic education, and education as a whole. Throughout the research a sense of frustration arose on the part of the researcher when confronted with rural people's ignorance about education, the apparent lack of initiative and a fatalistic attitude towards poverty. These attitudes were seen in things such as the crippling cost of local's adat weddings, multiple marriages and child marriages, expenditure on modern appliances and gadgets and the parents sacrificed their children's schooling so they could help with farming or domestic duties. The researcher often wondered why the community did not think more about the impacts of these phenomena on their poverty. 
Yet every person has the right to decide on priorities in her or his life. Poverty in rural area is depressing and the lack of attention from the government makes life further discouraging. People seem accustomed to their poverty and tend to cling to customs as they often divert attention from their despair and provide welcome and reliable forms of social interaction to brighten their lives. Their dependence on customary celebrations justifies to them the often great expense and sacrifices. On the other hand villagers seek to pursue some of their modern dreams by bringing some aspects of modernity into their lives. Costly expenses on coffee, cigarettes, television, and mobile phones are to be seen in this light and many now regard these as indispensable. These are the very few indulgences rural people hang on to make lives easier and less mundane.

This context helps explain both why commitment to primary education at the village level is often patchy but also why it is so crucial because the mere ability to read and write can have immeasurable outcomes. The significance of reading books presents opportunities for children to recognise external environments and realise that there are other lives, futures and surroundings than their existing world. Educated children will grow up equipped with a broad range of knowledge that can be advantageous in deciding their future course, for example the importance of family planning and birth control or the production of organic compost. All these are not only enormous value to their family's welfare, they are also key attributes in the efforts to reduce poverty.

In addition, learning, and the routine of it, is supposed to cultivate habitual knowledge and thinking. The longer children are exposed to new knowledge and habits of learning, hopefully the more they will be used to the notion that they need to keep questioning issues around them and seek answers. This is very much in line with Paulo Freire's conscientization approach to learning. However, this optimistic suggestion works only if schools and teachers alter the former teaching methods of dictation and memorising to methods of learning by doing and questioning and greater studentteachers interaction. Supposedly younger generations who are exposed to the culture of questioning and self-searching solutions will grow up to be adults who are receptive to various alternative manners of thinking, working or coping with issues instead of just succumbing to the common justification of fate. Without education and an optimistic mindset poverty will never be reduced, as people will keep accepting their fate of being poor. 


\section{Decentralisation and Community Participation}

To this day, basic education in Indonesia is not free and with decentralisation autonomy involves not only management but also financial responsibility. The transformation from strict centralisation to unprepared decentralisation has brought burdens for the regions, despite their longing to grasp the long-awaited opportunity. Decentralisation of education is an important step to ensure capacity development and local-sensitivity of human resources. However, as discussed in chapters 3 and 6, this new system can instead weaken the intended regional resources due to lack of necessary preparation and support.

Community involvement is not a new concept in Indonesian society. In fact, this mechanism is part of the nation's culture: gotong royong or the community's working together in building mosques or schools; and ronda or night patrols to ensure security around the community are among many traditional practices in communities, particularly in village areas. Therefore, the campaign for community participation in education of children is not a foreign nor unrealistic expectation. With enough support and attention parents and local schools can produce a committed community to improve education for local children and welfare for the whole community in the long-term. A few examples revealed by some practitioners in chapter 6 are proof that it is attainable. Once the community and the society as a whole have taken in responsibility for their children's education, sustainability will be ensured.

Therefore, as written in the country's constitution, the Government of Indonesia needs to realise its mandate and commitment in providing education to all children. The education sector at present only acquires half of the mandated 20 per cent of the government annual budget, and years of uncommitted promises have generated upheavals and instability in the education sector particularly in rural and remote areas.

\section{The Road to Achieving the MDGs}

Despite many criticisms of the MDGs' over ambitious goals, they have served as a focal point and motivated governments and organisations to plan their efforts better with the ultimate goal of poverty alleviation. Perhaps the sole concentration on basic education has created a few conundrums in overall education programmes, or even in some ways taken attention away from the MDGs' overall objective of poverty reduction. Needless to say, basic education campaigns have a crucial role in fighting the 
many dimensions of poverty (UNDP, 2008) and each government has responsibility to provide its children with education if it desires to ultimately reduce poverty. Assuring basic education for all children is an essential condition for poverty alleviation but alone it is insufficient.

Finally, the global programme and development organisations working to achieve the MDGs need to look further into the long-term strategies involved. Implementing inappropriate strategies will lead to growth that is unstable, unsustainable and prone to collapse. The world development strategy should move to approaches that are sensitive to local conditions and are tailored to match and enhance local commitments to enhance their own capacities. Education as a knowledge enhancing and self-development device is without doubt crucial to this strategy. Furthermore, development at all stages needs a community's awareness that the local people have to earn and be accountable for the progress they desire. Failure to gain such commitment will only result in lack of local involvement and support and ultimate failure.

\section{Concluding Remarks}

The case study in Batu Lapisi and Kampung Baru reveals more than the multifaceted links between basic education and poverty. There is a complex relationship between a local community's staunch commitment to traditions and customs on one hand and the desire to adopt more modern and urban-based ways of life on the other. Education strategies are at the centre of this relationship, changing people's attitudes and aspirations yet also being affected in turn by the dilemmas over resources that households face as they negotiate life between these two worlds.

There are many alternative ways of looking at nexus of rural poverty and development trends. How traditions are adjusted by modern development, how patriarchal customs are compromised by economic needs or how child marriage can be economically beneficial for the girl and her family are some examples of difficult issues to be faced. As the MDGs underline the importance of technological advancement, it will be important to observe how effective television, computers, the internet or mobile phones facilitate the development process of people in rural areas.

Three recommendations can be derived from this research in order to enhance rural communities' opportunities in education and, ultimately, to counter rural poverty. 
First, the government and education sector (including various organisations in the field) have to acknowledge that basic education is not merely a campaign or a target measured by statistics but rather a fundamental right of every child. As the first level of formal education, primary education is a key device for any person to gain fundamental knowledge and competencies. The effort to gain primary competency have an amplifying effect to a person's consciousness. Paulo Freire's widely recognized term "conscientization" (in UNESCO, 2000) is an important concept in this understanding. Freire argued that education should be employed more than just as a set of pedagogical techniques but also as a mechanism to instil self-belief in a person's ability to achieve self-development. As discussed in the UNESCO World Education Report (2000), Freire's advocacy of using education to enhance learners' consciousness in improving themselves will have constructive effects in the long term, which in the current era may be referred as "empowerment" (p. 35). Empowered individuals will have self-initiative to seek knowledge and competencies to improve themselves and create their own economic opportunities, a critical factor in escaping poverty. If basic education is emphasised and oriented on this element, society, and especially poorer communities, will pursue education for self-expansion and for longer term benefits and development, rather than for narrow vocational training.

Second, traditions and customs are inseparable parts of rural communities' lives, despite efforts to change or eliminate them. The government should not concentrate their poverty efforts to remove traditional practices as impediments to development but instead develop strategies that embrace positive elements of traditions to facilitate alternative forms of development and attain commitment and participation of the rural communities. There are numerous customary practices that are in fact beneficial and sustainable. In one aspect, Indonesia as an agricultural nation should refocus on its enormous land areas and revitalise its resources. Educated, knowledgeable and adept rural people, such as teachers, are the government's best assets in advocating necessary developments that are traditionally sustainable and self-sufficient. The government, therefore, has to support and empower these potential agents in their efforts to bridge government's policies and the needs, aspirations and resources of local communities. At the same time, this reorientation of empowering local resources can stimulate development and capacity building of human resources in all areas of the country equally. Educated and confident rural communities, hence, will be able to determine their own development according to their needs and identities, which in the long term 
can strengthen rural-based occupational sectors (especially beneficial for rural people) and minimise the problematic issue of urbanisation.

Third, Indonesia with its widespread areas and resources needs to consider the decentralisation efforts more strategically and seriously. Diverse resources of the country need different strategies and management. The time has arrived for the government to promote regional empowerment and self-sufficiency in order for the country to develop evenly and sustainably. Decentralisation does not mean full detachment of central government. Decentralised systems can be effective and productive when regional governments are able to empower, utilise and nurture their own local resources with the support and guidance from the central government. Right now regional governments will have to look beyond physical development - although things such as infrastructure are still very important - and concentrate more on strengthening human and natural resource development. This long term investment scheme will produce mature, competent, resilient and sustainable resources for the regions, which can be effective strategies in improving economic and social development and combating rural poverty.

This research argues that poverty in rural areas has detrimental effects on the overall development of the nation. Tackling basic education in rural areas in isolation from wider rural development considerations will not achieve the long-term goal of poverty alleviation. Indeed, the MDGs may, in fact, be detrimentally affecting this goal by focusing on specific activities and targets in ways that are not integrated and which neglect other vital needs in rural areas. For example, we have seen how infrastructure and communications (largely overlooked by the MDGs) are critical in affecting decisions of rural people regarding being able to send their children to primary or, especially, secondary, school. Similarly, efforts to make agriculture more productive are not targeted by the MDGs but are critical in raising rural incomes or decreasing labours demands on rural children. Finally, raising the status of rural living would be an important way of reducing the supposed attraction of city life for poor rural people and help counteract the mounting urban problems of congestion, unemployment and poverty.

On the other hand, the role of education in helping promote these wider rural development strategies also needs to be recognised and supported. Awareness raising is 
vital as is a revival of teaching rural skills, such as farming. An economically successful and educated society tends to have fewer children but they are better educated and healthier. A slower rate of population growth, and a healthier and more knowledgeable next generation are the key to ensure that poverty will not grow but diminish.

Finally, it is important to emphasize that the menace of poverty must be alleviated because, simply, it violates human rights. It is shameful to witness deprived people who have come to believe that poverty is their life's fate and who do not have a glimpse of hope that another better future is possible. Millions of today's younger generation should not grow up with such a helpless mindset and therefore recycle the condition of poverty. It is true that poverty is a very complex phenomenon with no simple solution. Meeting the MDGs alone will not deal with the root causes of poverty and they may even divert attention away from some critical needs and activities. Yet we should not be distracted into inaction by past failures or the confusing arguments about causes and solutions. Most important is to avoid poverty to modernise and transform further to be a more entangled web of problematic puzzle. If global society allows poverty to linger it is not improbable that generations to come will live in a more impoverished state and even surrender to poverty as an acceptable way of life. Therefore, today's generation is responsible to ensure that this violation of humankind, at the very least, does not worsen. In this sense, education of children in poor rural regions - even if it is a complex task facing seemingly intractable obstacles - must remain at the forefront of our actions. 


\section{REFERENCE LIST}

Bonal, X. (2004). Is the World Bank education policy adequate for fighting poverty? Some evidence from Latin America. International Journal of Educational Development, 24, 649-666.

Bowden, R. (2002). Young people, education and development. In V. Desai \& R. B. Potter (Eds.), The companion to development studies (pp. 405). London: Hodder Arnold.

Buarque, C., Spolar, V. A. M., \& Zhang, T. (2006). Introduction: Education and poverty reduction. Review of Education, 52, 219-229.

Burnett, N. (2008). The Delors report: A guide towards education for all. European Journal of Education, 43(2).

Carmen, R. (2002). Adult literacy and development. In V. Desai \& R. B. Potter (Eds.), The companion to development studies (pp. 409). London: Hodder Arnold.

Elliott, J., A. (2002). Development as improving human welfare and human rights. In V. Desai \& R. B. Potter (Eds.), The companion to development studies (pp. 45). London: Hodder Arnold.

Hettne, B. (2002). Current trends and future options in development studies. In V. Desai \& R. B. Potter (Eds.), The companion to development studies (pp. 7). London: Hodder Arnold.

Ibrahim, F. M. (2007). Primary education in EI: Homework that has been forgotten? Makassar: BaKTI.

Kothari, U., \& Minogue, M. (2002). Critical Perspectives on development: An Introduction. In U. Kothari \& M. Minogue (Eds.), Development Theory and Practice: Critical Perspectives. Hampshire: Palgrave Macmillan.

Kristiansen, S., \& Pratikno. (2006). Decentralising Education in Indonesia. International Journal of Educational Development, 26, 513-531.

Krueger, A. B., \& Lindahl, M. (2001). Education for growth: Why and for whom? Journal of Economic Literature, 39(4), 1101.

McMichael, P. (2000). Development and social change : a global perspective (2nd ed.). Thousand Oaks, Calif.: Pine Forge Press.

Mehrotra, S., \& Delamonica, E. (2002). Public spending for children: An empirical note. Journal of International Development, 14, 1105-1116.

Mulyasa, E. (2008). Standar kompetensi dan sertifikasi guru. Bandung: PT Remaja Rosdakarya.

Narayan, D., Patel, R., Schaaft, K., Rademacher, A., \& Koch-Schulte, S. (2000). Voices of the poor: Can anyone hear us? Oxford: Oxford University Press.

Narayan, D., \& Petesch, P. (2002). An empowering approach to poverty reduction. In D. Narayan \& P. Petesch (Eds.), Voices of the poor: From many lands (pp. 461). Washington, D.C.: The World Bank.

Palmer, R. (2006). Beyond the basics: Balancing education and training systems in developing countries. Journal of Education for International Development, 2(1).

Power, M. (2002). Enlightenment and the era of modernity. In V. Desai \& R. B. Potter (Eds.), The companion to development studies (pp. 65). London: Hodder Arnold.

Rist, G. (1997). The History of Development: From Western Originis to Global Faith (P. Camiller, Trans.). London: Zed Books.

Sachs, J. D. (2005). The end of poverty: Economic possibilities of our times. New York: The Penguin Press.

SCUK Indonesia. (2006). Supporting social and economic development in Indonesia by increasing children's access to quality education: Save the Children UK.

Sen, A. (1999). Development as freedom. New York: Oxford University Press. 
Sindhunata. (2000). Pendahuluan. In Sindhunata (Ed.), Menggagas paradigma baru pendidikan: Demokratisasi, otonomi, civil society, globalisasi (pp. 9-14). Yogyakarta: Kanisius.

Sujanto, B. (2007). Guru Indonesia dan perubahan kurikulum: Mengorek kegelisahan guru. Jakarta: Sagung Seto.

Suryahadi, A., \& Sumarto, S. (2003). Poverty and vulnerability in Indonesia before and after the economic crisis. Asian Economic Journal, 17(1).

Thirwall, A. P. (2002). Development as economic growth. In V. Desai \& R. B. Potter (Eds.), The companion to development studies (pp. 41). London: Hodder Arnold.

Tucker, V. (1999). The myths of development: A critique of a Eurocentric discourse. In R. Munck \& D. O'Hearn (Eds.), Critical development theory: Contributions to a new paradigm. New York: Zed Books Ltd.

ul Haq, M. (2008). The human development concept. Human Development Reports Retrieved 1 November 2008, 2008, from http://hdr.undp.org/en/humandev/

UN, \& National Development Planning Agency. (2007). Report on the Achievement of Millennium Development Goals - Indonesia 2007. Jakarta: The United Nations and Indonesia National Development Planning Agency.

UN Millennium Project. (2008, 15 July 2008). MDGs: What they are. from http://www.unmillenniumproject.org/goals/index.htm

UNDP. (2008). Human Development Reports. The Human Development Index - going beyond income: Indonesia Retrieved 20 October 2008, 2008, from http://hdrstats.undp.org/countries/country_fact_sheets/cty_fs_IDN.html

UNESCO. (2000). World Education Report 2000. The right to education: towards education for all throughout life.

UNESCO. (2008a). Education for all. Retrieved 17 July, 2008, from http://www.unesco.org/education/efa/ed_for_all/

UNESCO. (2008b). Forty-six million children out-of-school in South and East Asia. Retrieved 17 July 2008, from http://portal.unesco.org/education/en/ev.phpURL_ID=28585\&URL_DO=DO_PRINTPAGE\&URL_SECTION=201.html

UNESCO - UIS. (2008). UIS Statistics in Brief - Education in Indonesia (Publication. Retrieved 19 January 2009, from UNESCO - UIS: http://stats.uis.unesco.org/unesco/TableViewer/document.aspx?ReportId=289\&I $\underline{F}$ LLanguage $=$ eng \&BR_Country $=3600 \& B R \_$Region $=40515$

UNICEF. (1999). The state of the world's children 1999: Education: United Nations Children's Funds.

UNICEF Indonesia. (2007). Basic Education for All. Retrieved 20 October 2008, 2008, from http://www.unicef.org/indonesia/education_2864.html

UNICEF Indonesia. (2008). At a glance: Statistics. Retrieved 17 August 2008, 2008, from http://www.unicef.org/infobycountry/indonesia_statistics.html

United Nations Millennium Development Goals. (2008). Millennium Development Goals 2015. Retrieved 12 October 2008, 2008, from http://www.un.org/millenniumgoals/bkgd.shtml

World Bank. (2008a). The Millennium Development Goals. Retrieved 15 July, 2008, from http://ddp-

ext.worldbank.org/ext/GMIS/gdmis.do?siteId=2\&goalId=5\&menuId=LNAV01 GOAL1

World Bank. (2008b). Poverty Analysis. Retrieved 19 June 2008, 2008, from http://go.worldbank.org/K7LWQUT9L0

World Education Forum. (2000). Education for All: Meeting our collective commitment. Dakar. 


\section{Appendix 1. Indonesia: Key Indicators}

Derived from UNICEF Indonesia's Statistics at

http://www.unicef.org/infobycountry/indonesia_statistics.html

\begin{tabular}{|c|c|}
\hline \multicolumn{2}{|l|}{ Basic Indicators } \\
\hline Under-5 mortality rank & 83 \\
\hline Under-5 mortality rate, 1990 per 000 & 91 \\
\hline Under-5 mortality rate, 2006 per 000 & 34 \\
\hline Infant mortality rate (under 1 ), 1990 per 000 & 60 \\
\hline Infant mortality rate (under 1 ), 2006 per 000 & 26 \\
\hline Neonatal mortality rate, 2000 per 000 & 18 \\
\hline Total population (thousands), 2006 & 228864 \\
\hline Annual no. of births (thousands), 2006 & 4427 \\
\hline Annual no. of under-5 deaths (thousands), 2006 & 151 \\
\hline GNI per capita (US\$), 2006 & 1420 \\
\hline Life expectancy at birth (years), 2006 & 70 \\
\hline Total adult literacy rate, $2000-2005^{*}$ & 90 \\
\hline $\begin{array}{l}\text { Primary school net enrolment/ attendance (\%), } \\
2000-2006^{*}\end{array}$ & 96 \\
\hline $\begin{array}{l}\% \text { share of household income } 1995-2004 * \text {, lowest } \\
40 \%\end{array}$ & 20 \\
\hline $\begin{array}{l}\text { \% share of household income } 1995-2004 * \text {, highest } \\
20 \%\end{array}$ & 43 \\
\hline
\end{tabular}




\section{Appendix 2. Status of MDGs on Education by Provinces, 1993-2006**}

Derived from the Report on the Achievement of MDGs of Indonesia 2007 (UN \& National Development Planning Agency, 2007, p. Annex 2/2)

\begin{tabular}{|c|c|c|c|c|c|c|c|}
\hline \multirow[t]{2}{*}{ CODE } & \multirow[t]{2}{*}{ PROVINCE } & \multicolumn{3}{|c|}{$\begin{array}{c}\text { NER PS/MT (7-12 YEARS) } \\
(\%)\end{array}$} & \multicolumn{3}{|c|}{$\begin{array}{l}\text { NER JHS/MTS (13-15 YEARS) } \\
\text { (\%) }\end{array}$} \\
\hline & & 1992 & 2000 & 2006 & 1992 & 2000 & 2006 \\
\hline 11 & Aceh & 89,0 & & 95,5 & 43,8 & & 78,4 \\
\hline 12 & North Sumatra & 89,9 & 94,2 & 94,0 & 56,4 & 67,2 & 73,1 \\
\hline 13 & West Sumatra & 90,2 & 92,7 & 94,2 & 53,2 & 63,0 & 67,8 \\
\hline 14 & Riau & 91,5 & 93,9 & 94,7 & 36,6 & 62,7 & 72,9 \\
\hline 15 & Jambi & 85,9 & 92,8 & 94,4 & 34,6 & 56,5 & 65,3 \\
\hline 16 & South Sumatra & 87,0 & 92,3 & 93,0 & 40,2 & 59,6 & 68,0 \\
\hline 17 & Bengkulu & 88,1 & 91,5 & 93,9 & 43,8 & 57,3 & 66,7 \\
\hline 18 & Lampung & 84,9 & 93,2 & 93,9 & 34,0 & 59,3 & 66,7 \\
\hline 19 & Bangka Belitung & & & 91,5 & & & 55,3 \\
\hline 20 & Riau Islands & & & 93,7 & & & 72,0 \\
\hline 31 & Jakarta & 94,2 & 91,4 & 90,8 & 69,2 & 77,0 & 71,4 \\
\hline 32 & West Java & 87,9 & 92,7 & 94,2 & 35,3 & 57,7 & 62,1 \\
\hline 33 & Central Java & 92,8 & 93,9 & 94,1 & 38,2 & 62,6 & 67,7 \\
\hline 34 & Yogyakarta & 95,2 & 94,3 & 94,4 & 62,9 & 75,4 & 72,3 \\
\hline 35 & East Java & 91,7 & 92,3 & 94,2 & 44,7 & 63,3 & 70,3 \\
\hline 36 & Banten & & & 94,8 & & & 66,6 \\
\hline 51 & Bali & 91,1 & 93,4 & 93,3 & 59,5 & 70,6 & 70,2 \\
\hline 52 & West Nusa Tenggara & 80,0 & 89,9 & 94,5 & 38,9 & 58,2 & 69,6 \\
\hline 53 & East Nusa Tenggara & 82,3 & 88,9 & 91,6 & 20,9 & 34,2 & 47,2 \\
\hline 61 & West Kalimantan & 71,6 & 89,5 & 93,8 & 22,1 & 47,0 & 60,9 \\
\hline 62 & Central Kalimantan & 93,3 & 94,3 & 96,0 & 39,7 & 60,7 & 67,7 \\
\hline 63 & South Kalimantan & 90,4 & 92,4 & 93,3 & 33,3 & 51,8 & 62,1 \\
\hline 64 & East Kalimantan & 90,2 & 91,4 & 92,9 & 51,6 & 60,4 & 64,0 \\
\hline 71 & North Sulawesi & 89,0 & 90,4 & 90,4 & 46,8 & 63,1 & 66,0 \\
\hline 72 & Central Sulawesi & 89,8 & 91,1 & 92,9 & 47,2 & 48,5 & 63,0 \\
\hline 73 & South Sulawesi & 80,8 & 88,6 & 91,1 & 39,8 & 52,4 & 60,3 \\
\hline 74 & South-East Sulawesi & 84,2 & 89,5 & 92,3 & 40,5 & 60,6 & 72,4 \\
\hline 75 & Gorontalo & & & 90,5 & & & 52,3 \\
\hline 76 & West Sulawesi & & & 91,7 & & & 55,2 \\
\hline 81 & Maluku & 85,7 & & 92,2 & 41,4 & & 76,9 \\
\hline 82 & North Maluku & & & 93,1 & & & 65,3 \\
\hline 94 & Papua & 71,6 & 81,8 & 78,1 & 42,7 & 35,1 & 47,4 \\
\hline 95 & West Irian Jaya & & & 88,2 & & & 53,9 \\
\hline & Indonesia & 88,7 & 92,3 & 94,7 & 41,9 & 60,3 & 66,5 \\
\hline
\end{tabular}

* NER PS/MT is Net Enrolment Ratio of Primary School (PS)/Madrasah Tsanawiyah (MT-Islamic Religious School) and refers to the number of children enrolled in primary school who belong to the age group that officially corresponds to primary schooling, divided by the total population of the same age group (UNICEF Indonesia, 2008).

* NER JHS/MTs is Net Enrolment Ratio of Junior High School (JHS)/Madrasah Tsanawiyah (MTs) and refers to the number of children enrolled in junior high school level who belong to the age group that officially corresponds to junior high school schooling, divided by the total population of the same age group (UNICEF Indonesia, 2008). 
Appendix 3. Distribution of Primary and Junior High School Net Enrolment Ratio by Province for 2006

Derived from the Report on the Achievement of MDGs of Indonesia 2007 (UN \& National Development Planning Agency, 2007, p. 27)
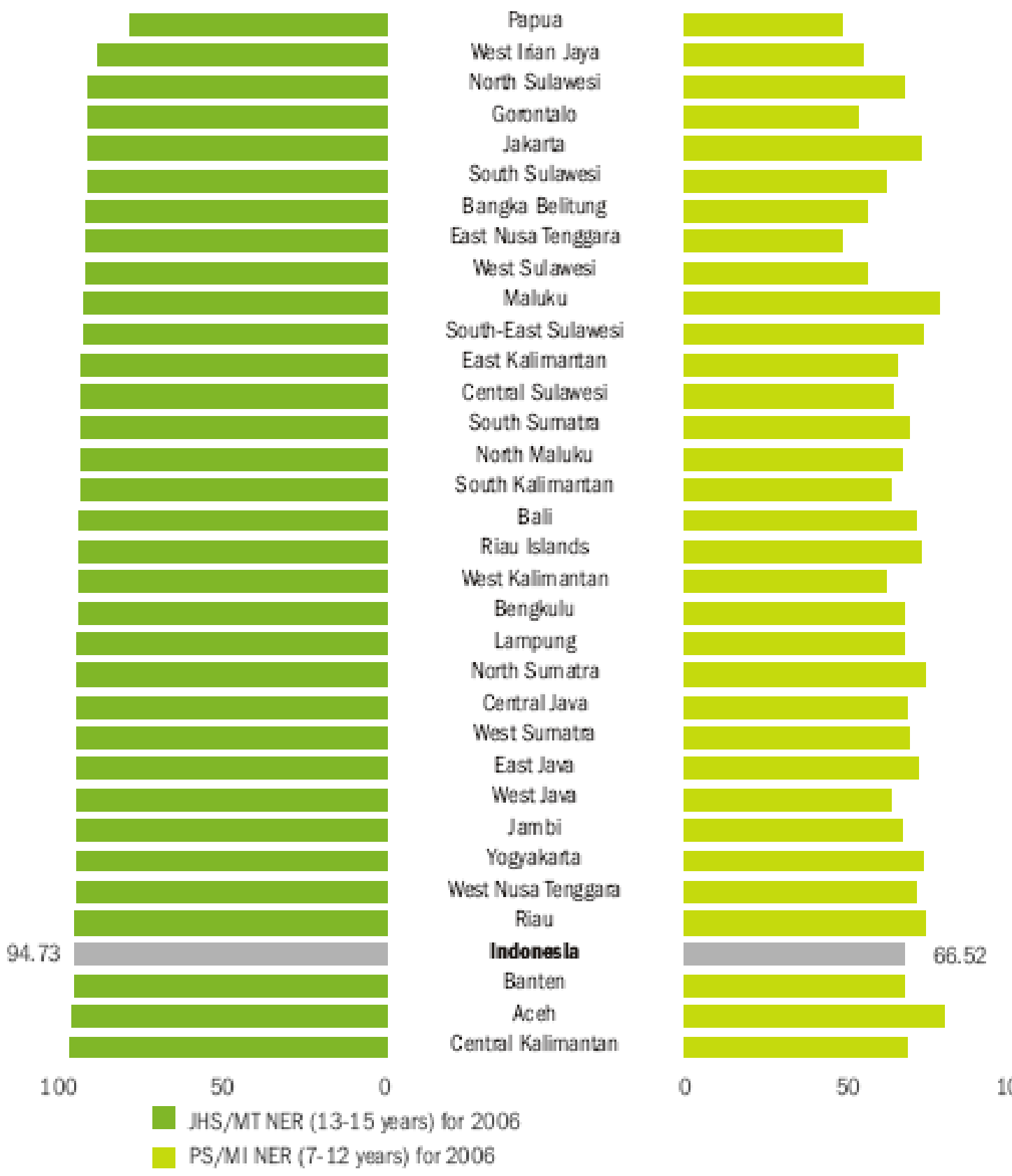

Source: National Socio-Economic Survey (BPS, 2006) 
Appendix 4. Drop out causes for population aged 7-15 years (2006)

Derived from Derived from the Report on the Achievement of MDGs of Indonesia 2007 (UN \& National Development Planning Agency, 2007, p. 34)

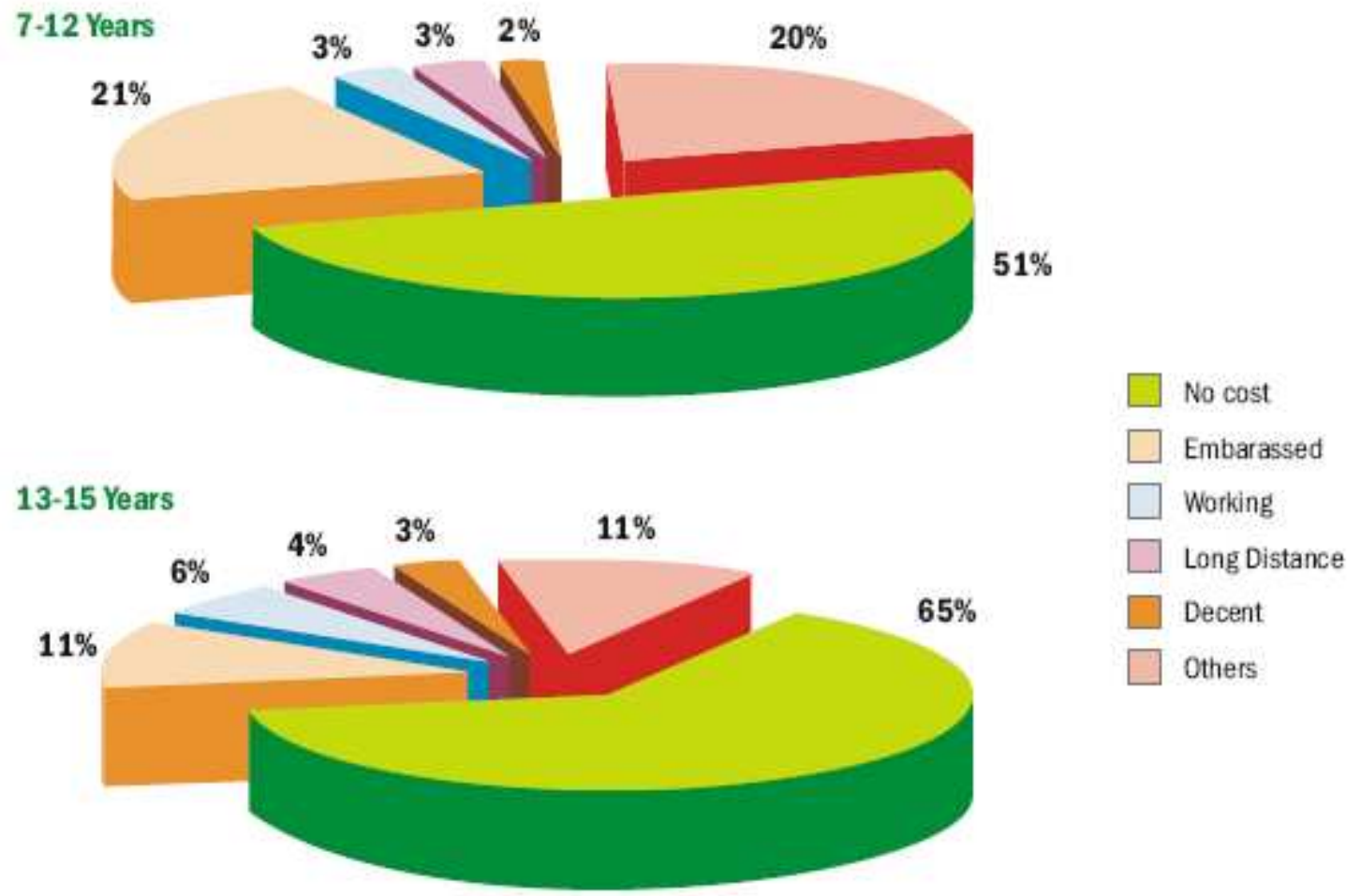

Source: National Socio-Economic Survey (BPS, 2006) 
Appendix 5. General Data of Case Study Participants from Batu Lapisi and Kampung Baru Communities ${ }^{11}$

\begin{tabular}{|c|c|c|c|c|c|c|c|c|c|c|c|c|c|}
\hline \multirow{2}{*}{ No. } & \multirow{2}{*}{ Village } & \multirow{2}{*}{ Parents } & \multirow{2}{*}{ Age } & \multirow{2}{*}{ Education } & \multirow{2}{*}{ Occupation } & \multirow{2}{*}{$\begin{array}{l}\text { Income/year } \\
\text { (in US\$) }\end{array}$} & \multicolumn{3}{|c|}{ Children } & \multicolumn{2}{|c|}{$\begin{array}{l}\text { Children's } \\
\text { Education }\end{array}$} & \multirow{2}{*}{$\begin{array}{c}\text { Child } \\
\text { Interviewed }\end{array}$} & \multirow{2}{*}{ Education } \\
\hline & & & & & & & Male & Female & Total & $\begin{array}{c}\text { In } \\
\text { school }\end{array}$ & $\begin{array}{l}\text { Out of } \\
\text { school }\end{array}$ & & \\
\hline 1 & $\begin{array}{l}\text { Batu } \\
\text { Lapisi }\end{array}$ & Mother & $30-40$ & 3 rd grade & Farmer & $\begin{array}{c}500,000= \\
\$ 53\end{array}$ & - & 1 & 1 & 1 & - & Daughter & 6 th grade \\
\hline 2 & $\begin{array}{l}\text { Batu } \\
\text { Lapisi }\end{array}$ & Mother & $30 \mathrm{~s}$ & $\begin{array}{l}\text { 2nd grade } \\
\text { Junior High }\end{array}$ & Farmer & $\begin{array}{c}1,750,000= \\
\$ 185\end{array}$ & 1 & 1 & 2 & 1 & 1 & None & $\begin{array}{c}\text { Child } \\
\text { Discontinue } \\
\text { Schooling }\end{array}$ \\
\hline 3 & $\begin{array}{l}\text { Batu } \\
\text { Lapisi }\end{array}$ & Mother & 36 & $\begin{array}{c}\text { D2-Diploma } \\
\text { (teaching) }\end{array}$ & $\begin{array}{c}\text { Primary } \\
\text { school } \\
\text { teacher }\end{array}$ & $\begin{array}{c}24,000,000= \\
\$ 2525\end{array}$ & - & 3 & 3 & 3 & - & Daughter & 4 th grade \\
\hline 4 & $\begin{array}{l}\text { Batu } \\
\text { Lapisi }\end{array}$ & Mother & $30 \mathrm{~s}$ & $\begin{array}{l}\text { Senior High } \\
\text { graduate }\end{array}$ & Farmer & $\begin{array}{c}500,000= \\
\$ 53\end{array}$ & 2 & 1 & 3 & 1 & - & Son & 4 th grade \\
\hline 5 & $\begin{array}{l}\text { Batu } \\
\text { Lapisi }\end{array}$ & Father & 55 & 3 rd grade & $\begin{array}{l}\text { Farm } \\
\text { labourer }\end{array}$ & unsure & 3 & 1 & 4 & - & 4 & None & $\mathrm{n} / \mathrm{a}$ \\
\hline 6 & $\begin{array}{l}\text { Batu } \\
\text { Lapisi }\end{array}$ & Father & $40 \mathrm{~s}$ & $\begin{array}{l}\text { Unschooled } \\
\text { (literate) }\end{array}$ & $\begin{array}{c}\text { Farm } \\
\text { labourer }\end{array}$ & unsure & 4 & 1 & 5 & 1 & 2 & Son & 4 th grade \\
\hline 7 & $\begin{array}{l}\text { Batu } \\
\text { Lapisi }\end{array}$ & Father & 49 & $\begin{array}{c}\text { 3rd grade } \\
\text { (semi- } \\
\text { literate) }\end{array}$ & $\begin{array}{c}\text { Farm } \\
\text { labourer }\end{array}$ & unsure & 2 & - & 2 & 2 & - & Son & 6 th grade \\
\hline
\end{tabular}

\footnotetext{
${ }^{11}$ Note: In Children education section, In school children are school age children who are currently enrolled in school while Out of school children are school age children but who are not enrolled in school. Please note that a child who is not yet of a school age is not considered out of school, but merely excluded from the section.
} 


\begin{tabular}{|c|c|c|c|c|c|c|c|c|c|c|c|c|c|}
\hline \multirow{2}{*}{ No. } & \multirow{2}{*}{ Village } & \multirow{2}{*}{ Parents } & \multirow{2}{*}{ Age } & \multirow{2}{*}{ Education } & \multirow{2}{*}{ Occupation } & \multirow{2}{*}{$\begin{array}{l}\text { Income/year } \\
\text { (in US\$) }\end{array}$} & \multicolumn{3}{|c|}{ Children } & \multicolumn{2}{|c|}{$\begin{array}{l}\text { Children's } \\
\text { Education }\end{array}$} & \multirow{2}{*}{$\begin{array}{c}\text { Child } \\
\text { Interviewed }\end{array}$} & \multirow{2}{*}{ Education } \\
\hline & & & & & & & Male & Female & Total & $\underset{\text { school }}{\ln }$ & $\begin{array}{l}\text { Out of } \\
\text { school }\end{array}$ & & \\
\hline 8 & $\begin{array}{l}\text { Batu } \\
\text { Lapisi }\end{array}$ & Father & 35 & $\begin{array}{l}\text { Primary } \\
\text { graduate }\end{array}$ & $\begin{array}{c}\text { Farm } \\
\text { labourer }\end{array}$ & $\begin{array}{c}1,050,000= \\
\$ 110\end{array}$ & 1 & 2 & 3 & 2 & 1 & Daughter & 5 th grade \\
\hline 9 & $\begin{array}{l}\text { Batu } \\
\text { Lapisi }\end{array}$ & Father & 32 & 6 th grade & Farmer & $\begin{array}{c}500,000= \\
\$ 53\end{array}$ & 1 & 1 & 2 & 1 & - & Son & 1st grade \\
\hline 10 & $\begin{array}{l}\text { Batu } \\
\text { Lapisi }\end{array}$ & Mother & 45 & $\begin{array}{l}\text { Primary } \\
\text { graduate }\end{array}$ & Farmer & unsure & 1 & 3 & 4 & 1 & 2 & Daughter & 2 nd grade \\
\hline 11 & $\begin{array}{l}\text { Batu } \\
\text { Lapisi }\end{array}$ & Mother & 39 & $\begin{array}{c}\text { Unschooled } \\
\text { (literate) }\end{array}$ & Farmer & $\begin{array}{c}1,000,000= \\
\$ 105\end{array}$ & 3 & 3 & 6 & 2 & 4 & None & $\mathrm{n} / \mathrm{a}$ \\
\hline 12 & $\begin{array}{l}\text { Batu } \\
\text { Lapisi }\end{array}$ & Mother & 25 & 5 th grade & $\begin{array}{l}\text { Farmer }+ \\
\text { motor taxi }\end{array}$ & $\begin{array}{c}8,400,000= \\
\$ 885\end{array}$ & 1 & 1 & 2 & 1 & - & Son & 3rd grade \\
\hline 13 & $\begin{array}{l}\text { Batu } \\
\text { Lapisi }\end{array}$ & Mother & 38 & $\begin{array}{l}\text { Primary } \\
\text { graduate }\end{array}$ & Farmer & $\begin{array}{c}1,750,000= \\
\$ 185\end{array}$ & 2 & 1 & 3 & 2 & 1 & Son & 6 th grade \\
\hline 14 & $\begin{array}{l}\text { Batu } \\
\text { Lapisi }\end{array}$ & Father & 45 & 3 rd grade & Farmer & $\begin{array}{c}1,000,000= \\
\$ 105\end{array}$ & 1 & 1 & 2 & 1 & 1 & Daughter & 6 th grade \\
\hline 15 & $\begin{array}{l}\text { Batu } \\
\text { Lapisi }\end{array}$ & Mother & $40 \mathrm{~s}$ & $\begin{array}{l}\text { Unschooled } \\
\text { (illiterate) }\end{array}$ & Farmer & $\begin{array}{c}1,000,000= \\
\$ 105\end{array}$ & 5 & - & 5 & 1 & 4 & Son & 2nd grade \\
\hline 16 & $\begin{array}{c}\text { Kampung } \\
\text { Baru }\end{array}$ & Mother & 28 & 5 th grade & Farmer & $\begin{array}{c}1,000,000= \\
\$ 105\end{array}$ & 2 & 2 & 4 & 1 & 3 & Daughter & $\begin{array}{c}\text { Primary } \\
\text { Graduate } \\
\text { (Discontinue) }\end{array}$ \\
\hline
\end{tabular}




\begin{tabular}{|c|c|c|c|c|c|c|c|c|c|c|c|c|c|}
\hline \multirow{2}{*}{ No. } & \multirow{2}{*}{ Village } & \multirow{2}{*}{ Parents } & \multirow{2}{*}{ Age } & \multirow{2}{*}{ Education } & \multirow{2}{*}{ Occupation } & \multirow{2}{*}{$\begin{array}{l}\text { Income/year } \\
\text { (in US\$) }\end{array}$} & \multicolumn{3}{|c|}{ Children } & \multicolumn{2}{|c|}{$\begin{array}{l}\text { Children's } \\
\text { Education }\end{array}$} & \multirow{2}{*}{$\begin{array}{c}\text { Child } \\
\text { Interviewed }\end{array}$} & \multirow{2}{*}{ Education } \\
\hline & & & & & & & Male & Female & Total & $\begin{array}{c}\text { In } \\
\text { school }\end{array}$ & $\begin{array}{l}\text { Out of } \\
\text { school }\end{array}$ & & \\
\hline 17 & $\begin{array}{c}\text { Kampung } \\
\text { Baru }\end{array}$ & Mother & $40 \mathrm{~s}$ & 4 th grade & Farmer & $\begin{array}{c}1,400,000= \\
\$ 147\end{array}$ & 3 & 1 & 4 & 1 & 3 & Son & $\begin{array}{c}\text { Primary } \\
\text { Graduate } \\
\text { (Discontinue) }\end{array}$ \\
\hline 18 & $\begin{array}{c}\text { Kampung } \\
\text { Baru }\end{array}$ & Mother & 28 & Unschooled & Farmer & $\begin{array}{c}500,000= \\
\$ 53\end{array}$ & 2 & 2 & 4 & 2 & 1 & Daughter & 3rd grade \\
\hline 19 & $\begin{array}{c}\text { Kampung } \\
\text { Baru }\end{array}$ & Mother & $40 \mathrm{~s}$ & Unschooled & Farmer & $\begin{array}{c}1,000,000= \\
\$ 105\end{array}$ & 1 & 4 & 5 & 1 & 4 & Daughter & 4 th grade \\
\hline 20 & $\begin{array}{c}\text { Kampung } \\
\text { Baru }\end{array}$ & Mother & 40 & $\begin{array}{l}\text { 2nd grade } \\
\text { (illiterate) }\end{array}$ & Farmer & $\begin{array}{c}700,000= \\
\$ 74\end{array}$ & 6 & 3 & 9 & 3 & 6 & Daughter & 3rd grade \\
\hline 21 & $\begin{array}{c}\text { Kampung } \\
\text { Baru }\end{array}$ & Mother & 38 & Unschooled & Farmer & $\begin{array}{c}350,000= \\
\$ 38\end{array}$ & 2 & 1 & 3 & 2 & 1 & Son & 4th grade \\
\hline 22 & $\begin{array}{c}\text { Kampung } \\
\text { Baru }\end{array}$ & Mother & 25 & Unschooled & Farmer & $\begin{array}{c}700,000= \\
\$ 74\end{array}$ & 1 & 3 & 4 & 2 & 2 & Son & 3rd grade \\
\hline 23 & $\begin{array}{c}\text { Kampung } \\
\text { Baru }\end{array}$ & Mother & 25 & Unschooled & Farmer & $\begin{array}{c}525,000= \\
\$ 55\end{array}$ & 2 & 1 & 3 & 2 & 1 & Daughter & 3rd grade \\
\hline 24 & $\begin{array}{c}\text { Kampung } \\
\text { Baru }\end{array}$ & Mother & 30 & $\begin{array}{c}\text { 3rd grade } \\
\text { (literate) }\end{array}$ & Farmer & $\begin{array}{c}350,000= \\
\$ 38\end{array}$ & 3 & - & 3 & 2 & 1 & Son & 3rd grade \\
\hline 25 & $\begin{array}{c}\text { Kampung } \\
\text { Baru }\end{array}$ & Mother & $40 \mathrm{~s}$ & Unschooled & Farmer & $\begin{array}{c}350,000= \\
\$ 38\end{array}$ & 5 & - & 5 & 1 & 4 & Son & 5 th grade \\
\hline
\end{tabular}




\begin{tabular}{|c|c|c|c|c|c|c|c|c|c|c|c|c|c|}
\hline \multirow{2}{*}{ No. } & \multirow{2}{*}{ Village } & \multirow{2}{*}{ Parents } & \multirow{2}{*}{ Age } & \multirow{2}{*}{ Education } & \multirow{2}{*}{ Occupation } & \multirow{2}{*}{$\begin{array}{l}\text { Income/year } \\
\text { (in US\$) }\end{array}$} & \multicolumn{3}{|c|}{ Children } & \multicolumn{2}{|c|}{$\begin{array}{l}\text { Children's } \\
\text { Education }\end{array}$} & \multirow{2}{*}{$\begin{array}{c}\text { Child } \\
\text { Interviewed }\end{array}$} & \multirow{2}{*}{ Education } \\
\hline & & & & & & & Male & Female & Total & $\begin{array}{c}\text { In } \\
\text { school }\end{array}$ & $\begin{array}{l}\text { Out of } \\
\text { school }\end{array}$ & & \\
\hline 26 & $\begin{array}{c}\text { Kampung } \\
\text { Baru }\end{array}$ & Father & 35 & $\begin{array}{l}\text { Primary } \\
\text { graduate }\end{array}$ & Farmer & $\begin{array}{c}3,500,000= \\
\$ 368\end{array}$ & 3 & 1 & 4 & 3 & - & Daughter & 5 th grade \\
\hline 27 & $\begin{array}{c}\text { Kampung } \\
\text { Baru }\end{array}$ & Mother & 39 & Unschooled & Farmer & $\begin{array}{c}2,800,000= \\
\$ 295\end{array}$ & 5 & 1 & 6 & 2 & 4 & Daughter & 5 th grade \\
\hline 28 & $\begin{array}{c}\text { Kampung } \\
\text { Baru }\end{array}$ & Mother & 40 & Unschooled & Farmer & $\begin{array}{c}3,500,000= \\
\$ 368\end{array}$ & 5 & 6 & 11 & 4 & 7 & Daughter & 6 th grade \\
\hline 29 & $\begin{array}{c}\text { Kampung } \\
\text { Baru }\end{array}$ & Mother & 35 & Unschooled & Farmer & $\begin{array}{c}350,000= \\
\$ 38\end{array}$ & 4 & 2 & 6 & 2 & 3 & Daughter & 4th grade \\
\hline 30 & $\begin{array}{c}\text { Kampung } \\
\text { Baru }\end{array}$ & Father & 45 & 3rd grade & Farmer & $\begin{array}{c}3,500,000= \\
\$ 368\end{array}$ & 2 & 2 & 4 & 4 & - & Daughter & 6 th grade \\
\hline
\end{tabular}


Appendix 6. Data on Perceptions of Participants from Batu Lapisi and Kampung Baru Communities' Perspectives ${ }^{12}$

\begin{tabular}{|c|c|c|c|c|c|c|c|c|c|c|c|c|}
\hline \multirow{2}{*}{ No. } & \multirow{2}{*}{ Village } & \multirow{2}{*}{ Parents } & \multirow{2}{*}{ Education } & \multirow{2}{*}{$\begin{array}{l}\text { No. of } \\
\text { Children }\end{array}$} & \multicolumn{2}{|c|}{$\begin{array}{l}\text { Children's } \\
\text { Education }\end{array}$} & \multirow{2}{*}{$\begin{array}{l}\text { Highest } \\
\text { Education } \\
\text { Aspired }\end{array}$} & \multirow{2}{*}{$\begin{array}{c}\text { Preferred } \\
\text { Assistance }\end{array}$} & \multirow{2}{*}{$\begin{array}{l}\text { Village or } \\
\text { City (Live } \\
\text { or Work) }\end{array}$} & \multirow{2}{*}{$\begin{array}{c}\text { Child } \\
\text { Interviewed }\end{array}$} & \multirow{2}{*}{$\begin{array}{l}\text { Highest } \\
\text { Education } \\
\text { Aspired }\end{array}$} & \multirow{2}{*}{$\begin{array}{l}\text { Village or } \\
\text { City (Live } \\
\text { or Work) }\end{array}$} \\
\hline & & & & & $\begin{array}{c}\text { In } \\
\text { school }\end{array}$ & $\begin{array}{l}\text { Out of } \\
\text { school }\end{array}$ & & & & & & \\
\hline 3 & $\begin{array}{l}\text { Batu } \\
\text { Lapisi }\end{array}$ & Mother & $\begin{array}{c}\text { D2-Diploma } \\
\text { (teaching) }\end{array}$ & 3 & 3 & - & $\begin{array}{c}\text { Unlimited, } \\
\text { highest } \\
\text { possible }\end{array}$ & $X$ & City & Daughter & $\begin{array}{l}\text { Teaching } \\
\text { college }\end{array}$ & City \\
\hline 4 & $\begin{array}{l}\text { Batu } \\
\text { Lapisi }\end{array}$ & Mother & $\begin{array}{l}\text { Junior High } \\
\text { graduate }\end{array}$ & 3 & 1 & - & $\begin{array}{l}\text { Depend on } \\
\text { child's } \\
\text { ability }\end{array}$ & Nothing & City & Son & No answer & No answer \\
\hline 6 & $\begin{array}{l}\text { Batu } \\
\text { Lapisi }\end{array}$ & Father & $\begin{array}{l}\text { Unschooled } \\
\text { (literate) }\end{array}$ & 5 & 1 & 2 & $\begin{array}{l}\text { To be } \\
\text { soldier }\end{array}$ & Unsure & $X$ & Son & $\begin{array}{l}\text { High school } \\
\text { (to be soldier) }\end{array}$ & Village \\
\hline 7 & $\begin{array}{l}\text { Batu } \\
\text { Lapisi }\end{array}$ & Father & $\begin{array}{c}\text { 3rd grade } \\
\text { (semi- } \\
\text { literate) }\end{array}$ & 2 & 2 & - & $\begin{array}{c}\text { To be } \\
\text { soldier or } \\
\text { doctor }\end{array}$ & Finance & Both & Son & $\begin{array}{l}\text { Junior High } \\
\text { School }\end{array}$ & City \\
\hline
\end{tabular}

\footnotetext{
${ }^{12}$ The order of participants in this appendix follows the order in Appendix 5. Thus, for general data of participants, please refer to Appendix 5.
} 


\begin{tabular}{|c|c|c|c|c|c|c|c|c|c|c|c|c|}
\hline \multirow{2}{*}{ No. } & \multirow{2}{*}{ Village } & \multirow{2}{*}{ Parents } & \multirow{2}{*}{ Education } & \multirow{2}{*}{$\begin{array}{l}\text { No. of } \\
\text { Children }\end{array}$} & \multicolumn{2}{|c|}{$\begin{array}{l}\text { Children's } \\
\text { Education }\end{array}$} & \multirow{2}{*}{$\begin{array}{l}\text { Highest } \\
\text { Education } \\
\text { Aspired }\end{array}$} & \multirow{2}{*}{$\begin{array}{l}\text { Preferred } \\
\text { Assistance }\end{array}$} & \multirow{2}{*}{$\begin{array}{l}\text { Village or } \\
\text { City (Live or } \\
\text { Work) }\end{array}$} & \multirow{2}{*}{$\begin{array}{c}\text { Child } \\
\text { Interviewed }\end{array}$} & \multirow{2}{*}{$\begin{array}{l}\text { Highest } \\
\text { Education } \\
\text { Aspired }\end{array}$} & \multirow{2}{*}{$\begin{array}{l}\text { Village or } \\
\text { City (Live or } \\
\text { Work) }\end{array}$} \\
\hline & & & & & $\begin{array}{c}\text { In } \\
\text { school }\end{array}$ & $\begin{array}{c}\text { In } \\
\text { school }\end{array}$ & & & & & & \\
\hline 8 & $\begin{array}{l}\text { Batu } \\
\text { Lapisi }\end{array}$ & Father & $\begin{array}{l}\text { Primary } \\
\text { graduate }\end{array}$ & 3 & 2 & 1 & Unsure & $\begin{array}{c}\text { Free } \\
\text { education } \\
\text { and School } \\
\text { items }\end{array}$ & Village & Daughter & $\begin{array}{l}\text { Junior High } \\
\text { School }\end{array}$ & Village \\
\hline 10 & $\begin{array}{l}\text { Batu } \\
\text { Lapisi }\end{array}$ & Mother & $\begin{array}{l}\text { Primary } \\
\text { graduate }\end{array}$ & 4 & 1 & 2 & $\begin{array}{l}\text { Primary } \\
\text { School }\end{array}$ & $\begin{array}{c}\text { Free } \\
\text { education }\end{array}$ & City & Daughter & $\begin{array}{c}\text { Continue } \\
\text { Junior High to } \\
\text { be teacher }\end{array}$ & City \\
\hline 11 & $\begin{array}{l}\text { Batu } \\
\text { Lapisi }\end{array}$ & Mother & $\begin{array}{c}\text { Unschooled } \\
\text { (literate) }\end{array}$ & 6 & 2 & 4 & $\begin{array}{l}\text { Senior } \\
\text { High } \\
\text { School }\end{array}$ & Unsure & City & None & $\mathrm{n} / \mathrm{a}$ & $\mathrm{n} / \mathrm{a}$ \\
\hline 13 & $\begin{array}{l}\text { Batu } \\
\text { Lapisi }\end{array}$ & Mother & $\begin{array}{l}\text { Primary } \\
\text { graduate }\end{array}$ & 3 & 2 & 1 & $\begin{array}{l}\text { Junior High } \\
\text { School }\end{array}$ & Money & Village & Son & $\begin{array}{l}\text { Junior High } \\
\text { School }\end{array}$ & City \\
\hline 14 & $\begin{array}{l}\text { Batu } \\
\text { Lapisi }\end{array}$ & Father & 3rd grade & 2 & 1 & 1 & Unsure & $\begin{array}{l}\text { Uniform, } \\
\text { Shoes }\end{array}$ & City & Daughter & $\begin{array}{l}\text { Junior High } \\
\text { School }\end{array}$ & City \\
\hline 15 & $\begin{array}{l}\text { Batu } \\
\text { Lapisi }\end{array}$ & Mother & $\begin{array}{l}\text { Unschooled } \\
\text { (illiterate) }\end{array}$ & 5 & 1 & 4 & Unsure & $\begin{array}{l}\text { Money (to } \\
\text { buy uniform } \\
\text { and shoes) }\end{array}$ & City & Son & $\begin{array}{l}\text { Junior High } \\
\text { School }\end{array}$ & City \\
\hline
\end{tabular}




\begin{tabular}{|c|c|c|c|c|c|c|c|c|c|c|c|c|}
\hline \multirow{2}{*}{ No. } & \multirow{2}{*}{ Village } & \multirow{2}{*}{ Parents } & \multirow{2}{*}{ Education } & \multirow{2}{*}{$\begin{array}{l}\text { No. of } \\
\text { Children }\end{array}$} & \multicolumn{2}{|c|}{$\begin{array}{l}\text { Children's } \\
\text { Education }\end{array}$} & \multirow{2}{*}{$\begin{array}{l}\text { Highest } \\
\text { Education } \\
\text { Aspired }\end{array}$} & \multirow{2}{*}{$\begin{array}{l}\text { Preferred } \\
\text { Assistance }\end{array}$} & \multirow{2}{*}{$\begin{array}{l}\text { Village or } \\
\text { City (Live or } \\
\text { Work) }\end{array}$} & \multirow{2}{*}{$\begin{array}{c}\text { Child } \\
\text { Interviewed }\end{array}$} & \multirow{2}{*}{$\begin{array}{l}\text { Highest } \\
\text { Education } \\
\text { Aspired }\end{array}$} & \multirow{2}{*}{$\begin{array}{l}\text { Village or } \\
\text { City (Live or } \\
\text { Work) }\end{array}$} \\
\hline & & & & & $\begin{array}{c}\text { In } \\
\text { school }\end{array}$ & $\begin{array}{c}\text { In } \\
\text { school }\end{array}$ & & & & & & \\
\hline 16 & $\begin{array}{c}\text { Kampung } \\
\text { Baru }\end{array}$ & Mother & 5 th grade & 4 & 1 & 3 & $\begin{array}{l}\text { Primary } \\
\text { School }\end{array}$ & $\begin{array}{c}\text { Money } \\
\text { (Tuition Fee) }\end{array}$ & Village & Daughter & $\begin{array}{l}\text { Primary } \\
\text { School }\end{array}$ & City \\
\hline 18 & $\begin{array}{c}\text { Kampung } \\
\text { Baru }\end{array}$ & Mother & Unschooled & 4 & 2 & 1 & $\begin{array}{l}\text { Primary } \\
\text { School }\end{array}$ & Items & Village & Daughter & Unsure & Village \\
\hline 19 & $\begin{array}{c}\text { Kampung } \\
\text { Baru }\end{array}$ & Mother & Unschooled & 5 & 1 & 4 & $\begin{array}{l}\text { Primary } \\
\text { School }\end{array}$ & $\begin{array}{l}\text { Money (self } \\
\text { arranged) }\end{array}$ & Village & Daughter & $\begin{array}{l}\text { Primary } \\
\text { School }\end{array}$ & Village \\
\hline 22 & $\begin{array}{c}\text { Kampung } \\
\text { Baru }\end{array}$ & Mother & Unschooled & 4 & 2 & 2 & $\begin{array}{l}\text { Primary } \\
\text { School }\end{array}$ & $\begin{array}{l}\text { Money (self } \\
\text { arranged) }\end{array}$ & Village & Son & Unsure & Village \\
\hline 23 & $\begin{array}{c}\text { Kampung } \\
\text { Baru }\end{array}$ & Mother & Unschooled & 3 & 2 & 1 & $\begin{array}{l}\text { Junior High } \\
\text { School }\end{array}$ & $\begin{array}{l}\text { Money (self } \\
\text { arranged) }\end{array}$ & Village & Daughter & $\begin{array}{l}\text { Junior High } \\
\text { School }\end{array}$ & Village \\
\hline
\end{tabular}




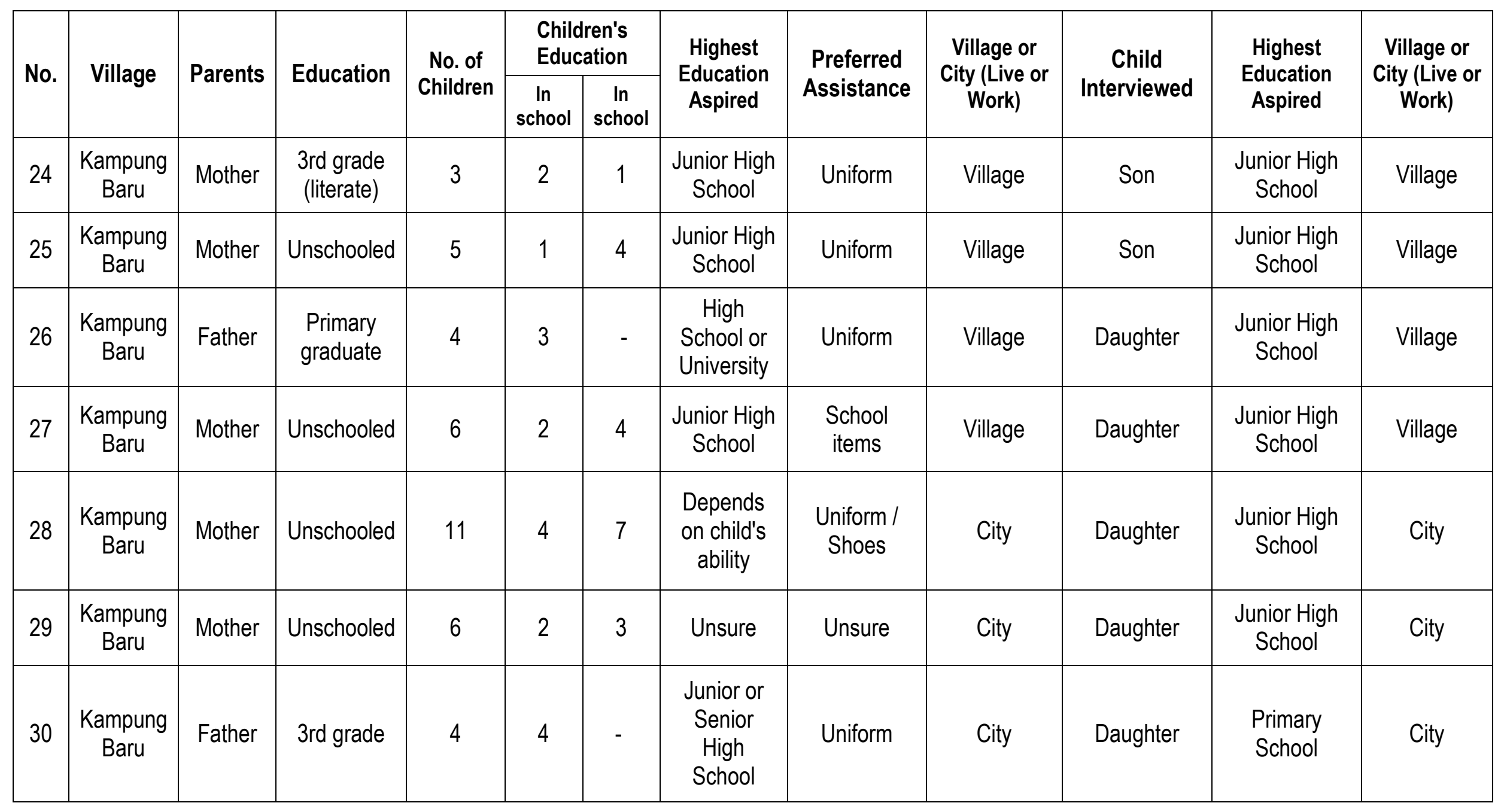


